\title{
CONSIDERATIONS FOR THE MEASUREMENT OF DEEP-BODY, SKIN AND MEAN BODY TEMPERATURES
}

Nigel A.S. Taylor ${ }^{1}$, Michael J. Tipton ${ }^{2}$ and Glen P. Kenny ${ }^{3}$

\author{
Affiliations: \\ ${ }^{1}$ Centre for Human and Applied Physiology, School of Medicine, \\ University of Wollongong, Wollongong, Australia. \\ ${ }^{2}$ Extreme Environments Laboratory, Department of Sport \& Exercise Science, \\ University of Portsmouth, Portsmouth, United Kingdom. \\ ${ }^{3}$ Human and Environmental Physiology Research Unit, School of Human Kinetics, \\ University of Ottawa, Ottawa, Ontario, Canada.
}

\section{Corresponding Author:}

Nigel A.S. Taylor, Ph.D.

Centre for Human and Applied Physiology,

School of Medicine, University of Wollongong,

Wollongong, NSW 2522, Australia.

Telephone: 61-2-4221-3463

Facsimile: 61-2-4221-3151

Electronic mail: nigel_taylor@uow.edu.au

RUNNING HEAD: Body temperature measurement 


\section{CONSIDERATIONS FOR THE MEASUREMENT OF DEEP-BODY, SKIN AND} MEAN BODY TEMPERATURES

\section{Abstract}

Despite previous reviews and commentaries, significant misconceptions remain concerning deep-body (core) and skin temperature measurement in humans. Therefore, the authors

8 have assembled the pertinent Laws of Thermodynamics and other first principles that

9 govern physical and physiological heat exchanges. The resulting review is aimed at

10 providing theoretical and empirical justifications for collecting and interpreting these data.

11 The primary emphasis is upon deep-body temperatures, with discussions of intramuscular,

12 subcutaneous, transcutaneous and skin temperatures included. These are all turnover indices

13 resulting from variations in local metabolism, tissue conduction and blood flow.

14 Consequently, inter-site differences and similarities may have no mechanistic relationship 15 unless those sites have similar metabolic rates, are in close proximity and are perfused by

16 the same blood vessels. Therefore, it is proposed that a gold standard deep-body

17 temperature does not exist. Instead, the validity of each measurement must be evaluated

18 relative to one's research objectives, whilst satisfying equilibration and positioning

19 requirements. When using thermometric computations of heat storage, the establishment of

20 steady-state conditions is essential, but for clinically relevant states, targeted temperature

21 monitoring becomes paramount. However, when investigating temperature regulation, the

22 response characteristics of each temperature measurement must match the forcing function

23 applied during experimentation. Thus, during dynamic phases, deep-body temperatures

24 must be measured from sites that track temperature changes in the central blood volume.

Keywords: calorimetry, core temperature, mean body temperature, muscle temperature, skin temperature, thermoregulation 
Direct and indirect calorimetry Page 11

Partitional calorimetry, thermometry and mean body temperature . Page 12

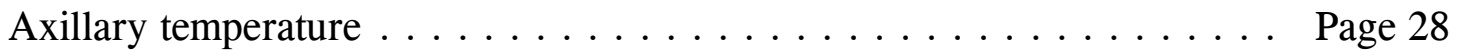

Rectal temperature . . . . . . . . . . . . . . . . . . . . Page 29

Oesophageal temperature . . . . . . . . . . . . . . Page 35

Auditory-canal temperature . . . . . . . . . . . . . . . Page 37

Tympanic-membrane temperature . . . . . . . . . . . . . Page 39

Gastrointestinal temperature . . . . . . . . . . . . . . . . Page 41

Intramuscular temperatures $\ldots \ldots \ldots \ldots$. . . . . . . . . Page 44

Transcutaneous temperature . . . . . . . . . . . . . . . Page 46

SUPERFICIAL-TISSUE TEMPERATURE MEASUREMENTS . . . . . . . . . . Page 49

Subcutaneous temperatures . . . . . . . . . . . . Page 50

Sources of thermal variability within and among skin sites . . . . . . Page 51

Skin temperatures . . . . . . . . . . . . . . . . . Page 53 


\section{INTRODUCTION}

2 Given existing reviews on body-temperature measurement (Woodhead and Varrier-Jones, 1916; Selle, 1952; Vale, 1981; Togawa, 1985; Brengelmann, 1987; Sawka and Wenger, 1988; Fulbrook, 1993; Ogawa, 1997; Moran and Mendal, 2002; Ring, 2006; Byrne and Lim, 2007; Pušnika and Miklaveca, 2009; Wartzek et al., 2011; Langer and Fietz, 2014; Werner, 2014), another contribution might seem unwarranted. However, following a presentation designed for students (Taylor, 2011), and arising from a debate on the cooling of hyperthermic individuals (Casa et al., 2010), it became apparent the assumed common knowledge on temperature measurement was not quite so common, nor could its existence

\section{First principles in thermodynamics}

Homeothermic species employ sophisticated autonomic and behavioural temperature regulatory mechanisms to maintain body temperature within a somewhat narrow range. A vast circulatory network, with counter-current heat exchange capabilities (Bernard, 1876; Forster et al., 1946; DuBois, 1951; Scholander and Schevill, 1955; He at al., 2003), transports and distributes metabolically derived and exogenous heat among the body tissues. These are enclosed within a membrane that permits energy and particle exchanges with the environment. As a consequence, homeotherms are open thermodynamic systems, yet they adhere to the same physical principles governing non-biological energy exchanges, and these first principles moderate physiological processes.

"A great deal of misconception could have been cleared by an application of the simple laws of heat flow." (DuBois, 1951; P 476).

The Laws of Thermodynamics define energetic relationships within thermodynamically closed (no material exchange) and isolated structures (no material or energy exchange). Whilst humans are rarely (if ever) in those states, these laws still apply, and provide the scientific foundation for understanding temperature measurement. Moreover, they define the principles of heat transfer. Therefore, several salient concepts, and their physiological implications, are highlighted below; readers are also directed to other treatments (Quinn, 1983; Narasimhan, 1999). 
1 The energy possessed and exchanged by animals is made up from dynamic (kinetic) and

2 static forms (potential: mass-, chemical-, nuclear- and force-related energies). This energy

3 cannot be created, nor can it be destroyed. Instead, it may be converted into another form

4 (First Law of Thermodynamics), and within a thermodynamic system, it can be used to

5 perform work on another system (external work), transferring energy to that system (Joule,

6 1850). The total amount of energy possessed by an object is known as its enthalpy, which is

7 minimal (but not absent) at temperatures approaching absolute zero (Third Law of

8 Thermodynamics). It varies with the pressure and volume (mass) of each system, and its

9 kinetic component causes sub-atomic and cellular movement and collisions, releasing

10 thermal energy. Thus, heat content is a function of this collision frequency (Worthing,

11 1941), and it is quantified using temperature measurements and calorimetry.

13 Consider a closed (inanimate) system with an outer membrane (diathermal wall) permissive 14 to energetic, but not to material exchange. If that system was placed within a stable 15 environment, the collision frequency of its particles would eventually stabilise, and a state 16 of thermal equilibrium (steady state) would exist. The temperature of that object would now 17 be constant, whilst particle motion continued. If another system with a lower enthalpy

18 comes into physical contact with the former, energy will be exchanged across their 19 contacting walls towards the latter. That is, thermal energy moves down energy gradients

20 (Second Law of Thermodynamics), either through a change of state (solid, liquid, gas) or

21 via conductive (molecule to molecule), convective (mass flow) or radiative transfers. This

22 establishes thermal gradients within and between these systems, with both systems

23 eventually attaining a common thermal equilibrium. For homeothermic species in a steady 24 state, thermal equilibration among tissues and organs is imperfect. This is because of the 25 continuous and widely variable metabolic heat production and mass (convective) transport 26 of heat that occur throughout the body.

\section{First principles in a physiological context}

29 To illustrate the implications of these principles for physiological measurements, a 30 thermodynamically closed system is used (a steel sphere). Its enthalpy was changed from one steady state to another on three occasions. Each trial commenced from a different thermal steady state (stirred water baths: $15^{\circ}, 25^{\circ}$ and $35^{\circ} \mathrm{C}$ ). Following equilibration, the 
was a temperature sensor, with Figure 1A showing output from that sensor. On each occasion, energy was conducted down a thermal gradient within the sphere, which gained kinetic energy. Eventually, a higher thermal steady state was achieved.

During the initial and final thermal steady states only, the sensor was in thermal equilibrium with both the water and the sphere. Since all three systems had equilibrated thermally, then the sensor provided a valid, instantaneous temperature measurement for both the sphere and the water, as long as the latter was precisely clamped. This is the principle of the Zeroth Law of Thermodynamics that forms the basis of thermometry: when three or more systems are in thermal equilibrium, they have the same temperature. In these circumstances, one can assume all parts of the sphere were at this temperature, although this is the only time this assumption is valid for either inanimate objects or living organisms. Furthermore, because the sensor was at the centre of the sphere, it was not immediately influenced by external energy transfers. These concepts are essential to understanding deep-body temperature measurement. Nevertheless, due to their relatively high resting metabolic heat production, thermal equilibration for mammals pertains only to the internal structures and not to the ambient environment.

During the dynamic phase of each trial, where the sphere asymptotically approached a new thermal equilibrium (Figure 1A: 80-450 s), the sensor furnished no meaningful information regarding either the initial or the final steady state. Instead, it only provided data about its own temperature, and that of the molecules in direct contact with the sensor. From 80-150 s, the coolest sphere gained heat most rapidly (Figure 1A), in accordance with Newton's Cooling Law (heat-transfer law [Newton, 1700]; heat conduction equation [Fourier, 1807]). That is, temperature change rates are proportional to the size of existing thermal gradients, as illustrated in Figure 1B where these curves are superimposed. This concept is also represented in Figure 1C, where the average rate of temperature change during these dynamic phases (right grouped bars) matches the corresponding thermal gradient (left grouped bars). These rates are also determined by the characteristics of the object (shape, 
dimensions, specific mass [density], thermal conductivity, specific heat capacity). These principles help one to interpret temperature measurements during dynamic phases.

Another consequence of Newton's heat-transfer law (Newton, 1700) and the heat conduction equation (Fourier, 1807), was that the final steady-state temperature $\left(38.5^{\circ} \mathrm{C}\right)$ was achieved at the same time (Figure 1A). This must always be so, regardless of the initial temperature (Figure 1B). Thus, pre-cooling (or pre-heating) has no influence on either the final temperature or the time at which it was obtained. In humans, a reduction in the preexposure, deep-body temperature, induced either through heat adaptation (Taylor, 2014) or pre-exercise cooling (Booth et al., 2004), does not provide a protective advantage by prolonging the time to reach some terminal tissue temperature, as some have indicated (Houmard et al., 1990; Buono et al., 1998; Marino, 2002; Reilly and Waterhouse, 2009; McLellan et al., 2013). This was demonstrated by Booth et al. (2004) using pre-cooling, pre-heating and thermoneutral treatments prior to exercise in the heat. These treatments elicited pre-exposure muscle (vastus lateralis) temperature differences of $7.5^{\circ} \mathrm{C}$, along with deep-body (oesophageal) temperature changes of $1^{\circ} \mathrm{C}$ either side of the thermoneutral state. Nonetheless, during subsequent exercise in the heat, muscle temperatures converged on a common point, with pre-cooled tissues gaining heat six times faster than pre-heated muscle $\left(0.23^{\circ} \mathrm{C} \cdot \mathrm{min}^{-1}\right.$ versus $\left.0.04^{\circ} \mathrm{C} \cdot \mathrm{min}^{-1}\right)$. This was also reflected in the oesophageal temperature increases (0-20 min: $0.09^{\circ} \mathrm{C} \cdot \mathrm{min}^{-1}$ [pre-cooled] versus $\left.0.03^{\circ} \mathrm{C} \cdot \mathrm{min}^{-1}\right)$. Thus, pre-cooling and pre-heating modified only the rate of heat transfer. These facts become self-evident as one's appreciation of first principles grows.

In some circumstances, skeletal muscle temperature will approximate that of the heart, as in the example above. This is a characteristic of tissues with high perfusion capacities. During cold exposures, however, tissue temperatures will differ markedly due to local heat losses exceeding heat production and delivery. These extremes highlight changes that occur whenever the enthalpy of an organism is moved away from a state of thermal equilibrium, and the further tissues are away from the centre of that organism, the less likely they are to possess the same thermal energy content; so their temperatures must be different. To model these situations, let us consider dynamic phases when temperature sensors are located at different depths within the same sphere. 
From the preceding description, one may reason that the centrally located sensor (Figure 1) provided little meaningful information about the temperature of locations closer to the surface of the sphere during non-steady-state conditions. Accordingly, sensors were implanted at $33 \%$ (shallow) and at $66 \%$ (deep) of the distance between the sphere's surface and centre, and thermal equilibration was again established $\left(38.5^{\circ} \mathrm{C}\right)$. Two dynamic phases were now induced in succession: transient cooling followed by protracted re-warming (Figure 2). The sphere was first immersed in cool water $\left(15^{\circ} \mathrm{C}\right.$ stirred) until the temperature of the central sensor first started to decrease (position A). At that time, the sphere was reimmersed in the warm water, where it remained until all sensors reached $35^{\circ} \mathrm{C}$.

INSERT FIGURE 2 ABOUT HERE

Not surprisingly, the shallowest sensor cooled earlier and more rapidly to its lowest point (position B: mean cooling rates: $0.13^{\circ} \mathrm{C}^{-1} \mathrm{~s}^{-1}$ [shallow] versus $0.07^{\circ} \mathrm{C} . \mathrm{s}^{-1}$ for both the deep and central sensors). This point was $2.7^{\circ} \mathrm{C}$ cooler than the thermal trough observed for the deep sensor (position $\mathrm{C}$ ) and $1.9^{\circ} \mathrm{C}$ cooler than the central sensor (position $\mathrm{D}$ ), and the times at which these minimal values were realised were dictated by the depth of each sensor. Moreover, once cooling was initiated, it continued for some time after the sphere was returned to the warm water. This is the classical afterdrop phenomenon (Currie, 1797; Alexander, 1945; Golden, 1979), for which, in living creatures, there are both conductive and convective (mass transport) elements (Golden and Hervey, 1981; Webb, 1986; Mittleman and Mekjavic, 1988), although the convective component is minimal at rest in some tissues during hypothermia (Caldwell et al., 2014). It follows, therefore, that an afterrise phenomenon must also exist when hyperthermic individuals are cooled.

Heat loss, once initiated, continued until the thermal gradient no longer existed, or was reversed. For this to occur, the outermost layer of molecules must gain energy from the water, forming a warmer layer (shell). Thus, one can imagine a series of infinitesimally small concentric shells (lamina) being formed that inexorably moved, as thermal fronts, towards the cooler centre until thermal equilibration occurred, with the temperature of each lamina being determined by the energy content of both the upstream and downstream 
1 lamina. Points B, C and D coincided with the arrival of a warm front at each sensor,

2 changing heat losses to heat gains, and successively terminating each afterdrop.

Two additional and instructive characteristics can be observed in Figure 2. Firstly, the between-sensor phase delays from the time of cold-water immersion to the first evidence of sensor cooling (shallow $15 \mathrm{~s}$, deep $25 \mathrm{~s}$, centre $35 \mathrm{~s}$ ), and from point of warm-water immersion to the end of the local afterdrop (shallow $40 \mathrm{~s}$, deep $70 \mathrm{~s}$, centre $85 \mathrm{~s}$ ), were a function of the length of the conductive path to the surface of the sphere. These delays are intuitive, and were perhaps first described by Golden and Hervey (1981) using mathematical and physical models. Webb (1986) reproduced these outcomes using gelatin and beef models, with both projects increasing our understanding of the impact of physiological insulation in dynamic thermal environments. Moreover, these outcomes have important interpretative consequences for the measurement of deep-body temperatures when the thermal energy content of the measurement site is primarily dependent upon thermal conduction, as is the case at the rectum. This dependency can be extended to include tissues in which perfusion becomes impaired or arrested, and this was elegantly demonstrated by Golden (1979). Using cold-immersed pigs that were euthanased 20 min following immersion, Golden (1979) observed that the rapid pre-mortem cooling of central venous blood and the oesophagus ended with circulatory arrest. Conversely, rectal tissue cooling, and to a lesser extent gastric cooling, continued at the same rate post-mortem. These observations provide an interesting and surprising insight into the role of the circulation in heat loss in the presence of cutaneous vasoconstriction.

Secondly, points D, E and F indicate times when the temperature traces of two sensors crossed. At these points, the thermal energy content of one sensor changed from being greater to less than that of the second sensor. At position E, the most slowly responding central sensor became cooler than the deep sensor, whilst at position D its temperature fell below the shallow sensor. Similarly, at position F, the deep and shallow sensors crossed. This conductive phenomenon occurs because of the thermal phase delays observed at different depths within the sphere. This same pattern will re-appear later when temperature traces from different deep-body tissues are plotted during sequential cooling and heating treatments (Figure 9), and its significance for temperature measurement will be explored. 


\section{WHY MEASURE TISSUE TEMPERATURES?}

2 Perhaps as an extension of the Zeroth Law, there arose the concept of compartmentalising

3 body tissues into thermally stable deep-body (core) and more variable superficial (shell)

$4 \quad$ structures (Benedict and Slack, 1911; Burton, 1935; Aschoff and Wever, 1958). In this

5 application, thermal equilibration applies only to the deep tissues, and whilst this

6 simplification lacks precision (Burton and Edholm, 1955; Snellen, 1966; Jay et al., 2007a;

$7 \quad$ Kenny and Jay, 2013), it does provide a point from which to introduce this topic.

Under truly basal conditions, the body core tissues are assumed to possess similar amounts of kinetic energy and to be in a state of thermal equilibrium, but not necessarily in equilibrium with the ambient environment. Accordingly, such sites should all be at similar, but perhaps not equal temperatures (Benedict and Slack, 1911; Du Bois, 1941; Bazett et al., 1948; Eichna et al., 1951). This state can also exist within a narrow range of thermal environments when thermal equilibration is achieved above and below the thermoneutral boundaries. Because deeper structures are insulated from the ambient medium by less thermally stable tissues that readily exchange heat with that environment, temperature gradients must exist within and among the deep and superficial tissues (Benedict and Slack, 1911; Bazett and McGlone, 1927; Burton and Bazett, 1936; Barcroft and Edholm, 1946; Pennes, 1948; Eichna et al., 1951; Grayson, 1951). These gradients are parabolic in nature (Benedict and Slack, 1911; Bazett and McGlone, 1927) and dictate heat transfer (Figure 1). Indeed, some regions (e.g. hands and feet) have unique characteristics that enable them to behave as physiological radiators (Taylor et al., 2014). Furthermore, thermal gradients are essential, since heat-producing organisms will eventually overheat and perish if insulated from the environment to the extent that all heat loss is prevented.

Beyond basal conditions, variations in the distribution of blood flow mean that the volume of the thermally less-stable body tissues changes. In the classical view, this was considered analogous to changing the dimensions of the body core, which could be created by postural shifts (Rowell, 1986), post-prandial hyperaemia (Granger and Kvietys, 1981), water immersion (Arborelius et al., 1972; Johansen et al., 1997), changes in metabolic rate (e.g. exercise: Rowell et al., 1967; Rowell, 1977), ambient temperature manipulations (Rowell et al., 1969, 1970; Caldwell et al., 2014) and anaesthesia (Ingram and Smith, 1970; Deakin, 1998). Thus, neither the temperature nor the dimensions of the core compartment 
1 remain fixed, and these changes influence temperature measurement validity. Furthermore,

2 uncertainty arises when endeavouring to assign a physiological meaning to any one deep-

3 body temperature or when validating surrogate indices. Thus, there is no gold standard

4 deep-body temperature, although if one existed, it must surely be in the form of a central

5 blood temperature:

"variations in temperature exist even within the body core and this precludes the temperature of a single organ as a measure of average deep tissue temperature" (Eichna et al., 1951: P 358).

Instead, the validity of each deep-body temperature measurement must be evaluated relative to one's research objectives, and not to its relationship with another deep-body index or to limitations imposed by unsophisticated ethics committees. In truth, it is more unethical to undertake research using methods unlikely to provide a valid test of one's working hypothesis, either in the laboratory or the field, regardless of measurement simplicity, convenience or subjective preferences. Thus, if one's interest lies with the temperature of a specific body tissue, then measure temperature from that site, or a valid surrogate, whilst ensuring that equilibration and positioning requirements are satisfied. If one has another purpose, then the strengths and limitations of each measurement must be evaluated against that purpose. In the sections that follow, the logic of these propositions is developed in the context of quantifying heat storage, studying clinical states, evaluating central and peripheral thermoafferent feedback and investigating body-temperature regulation. It will be shown that no single index can satisfy every research objective, although some measures are even less likely to achieve that outcome. Before entering that discussion, it must be recognised that changes in heat storage occur more slowly and are governed by the Laws of Thermodynamics, whilst thermal (neural) feedback is provided through a three-dimensional array of receptors that instantaneously respond to stimuli that often act only at discrete locations. Furthermore, the subsequent control of thermoeffector function is often of a whole-body nature, but with site-specific variations in intensity. Therefore, one must expect mean-body temperature measurements to necessarily differ in type and relative importance (weighting) across these research objectives (Simon, 1974; Werner, 2010).

\section{Measuring heat storage}

All metabolic processes ultimately result in heat production which occurs via cellular 
metabolism (bioenergetics) and cell work, with organisms constantly exchanging thermal energy with the environment. Much of our understanding of the exchange processes within an organism, and between it and its thermal environment, is based on data derived from classical calorimetric studies (Atwater and Rosa, 1899; Burton and Bazett, 1936; Kenny and Jay, 2013). When heat loss matches production, there is no nett heat storage, but when this balance is imperfect or disturbed, storage is altered. Thus, one reason for measuring tissue temperatures is to estimate variations in heat storage (partitional calorimetry), so before discussing specific tissue measurements, it is important to elaborate on some principles of calorimetry, measurement interactions with the Zeroth Law and estimations of heat storage.

\section{Direct and indirect calorimetry}

13 Calorimetry is the measurement of heat, which can occur directly using insulated devices (calorimeters: small rooms, boxes, baths, suits) or it can be approximated from changes in respiratory gas exchange (indirect calorimetry [respirometry]). The focus here is upon direct calorimetry. With this technique, the total amount of heat dissipated by the body is measured, including that yielded through aerobic and anaerobic pathways, although the latter is very hard to quantify. The resulting measurements represent the rate that thermal

These measurements were introduced in the late eighteenth century by Lavoisier and Laplace (1780), who developed an animal calorimeter (an adiabatic device) from which they derived metabolic heat production from the melting of ice and a knowledge of its latent heat. However, only direct calorimeters measure heat exchange, and in the case of human calorimeters, this represents whole-body heat loss. In their simplest form, calorimeters only measure non-evaporative heat loss (sensible heat loss), and modifications are required for quantifying evaporative (insensible) losses. These devices come in several forms, such as

28 flow, gradient, storage and compensating calorimeters (see: Webb, 1985; Kenny and Jay, 29 2013). Since our focus will soon turn towards partitional calorimetry, some background 30 information becomes essential. to balance heat exchanges with heat production and, in so doing, regulate mean body 
1 temperature (Pembrey, 1898; Cannon, 1929). When homeostatic mechanisms are

2 challenged, regulatory processes that modify heat production and exchange are activated to

3 restore the thermal status of the milieu intérieur (Bernard, 1876), or at least to regulate it

4 within physiologically acceptable boundaries (Werner et al., 2008). However, even in basal

5 states, there are continual exchanges of matter and energy across cellular and vascular

6 membranes. From an energetic perspective, this dynamic equilibrium is governed by the

7 First Law of Thermodynamics, as expressed in the heat balance equation (Gagge and

8 Gonzalez, 1996).

10 It is at this point that the unique contributions of calorimetry become apparent, with

11 whole-body calorimeters providing concurrent measurements of the rates of total heat

12 generation and exchange. These are illustrated in Figure 3A. Lags in the activation of heat

13 loss mechanisms relative to heat gains result in transient thermal imbalances. One such lag

14 is illustrated by the grey zone between the curves, with their difference determining the

15 change in stored thermal energy or heat content (Figure 3B). This change modifies the

16 enthalpy of the body which determines mean body temperature. Indeed, when heat storage

17 is both positive and constant, there will be a continuous increase in mean body temperature.

18 Thus, thermal equilibria require zero heat storage and temperature stability, and it is the

19 peripheral temperatures that stabilise more slowly.

INSERT FIGURE 3 ABOUT HERE

Partitional calorimetry, thermometry and mean body temperature

26 Due to the limited availability of direct calorimeters, other methods are often used to

27 estimate body heat storage and exchange. These involve partitional calorimetry and

28 thermometry (Gagge, 1936; Winslow et al., 1936; Hertzman et al., 1952; Stolwijk and

29 Hardy, 1966; Gagge and Hardy, 1967; Snellen, 1969; Vallerand et al., 1992b). The former

30 relies upon the partitioned estimation of dry and evaporative heat exchange avenues, with

31 estimations of the dry exchanges incorporating skin temperature measurements (Winslow et

32 al., 1936; Gagge and Nishi, 1977), which can be obtained by subtraction. When used with

33 indirect calorimetry to estimate heat production, heat storage can be quantified. However, it 
can also be estimated using thermometric methods. These rely on the derivation of a mean body temperature, which is most frequently calculated as a weighted summation of deepbody and the average skin temperatures; the two-compartment thermometry model. The weighting (mixing) coefficients for each compartment were originally developed as a function of the parabolic thermal gradient found within the cutaneous tissues, and the assumption of more uniform temperatures within the core tissues (Burton, 1935).

This thermal surrogate of heat storage is typically computed as the product of the change in mean body temperature, total body mass and the average specific heat capacity of the body tissues (Gagge and Gonzalez, 1996). The validity of this approximation is determined by the integrity of the multiplicands. However, imprecision with mass measurements translate into proportional errors, although even when only the initial mass is used, the error remains small when experimental mass changes are moderate. Therefore, the two primary error

Since several temperatures are used to calculate mean body temperature, then the first possible error source relates to obtaining, or at least approximating, a thermal equilibrium at the sites of temperature measurement (Zeroth Law). Consider Figure 1A, which illustrates a deep-body (deep-sphere) temperature measured from one site only. There are two steady-state zones (0-40 s and beyond $450 \mathrm{~s})$, and valid measurements for deriving mean sphere temperature can be taken in either of those zones. Now consider Figure 2, which has three temperature measures, each from a different location within the sphere. Imagine those sensors provided independent measures of deep-body temperature. Beyond $15 \mathrm{~s}$, steady states did not exist, so which trace provided the most valid measurement? From $75 \mathrm{~s}$ to $110 \mathrm{~s}$, the temperature of the shallowest sensor was rising whilst the others were falling. Which is the most valid measurement now? Beyond $150 \mathrm{~s}$, all temperatures were increasing at similar rates. Are these now valid? In reality, correctly calibrated sensors provide valid local measurements, even though neither local nor whole-sphere thermal steady states existed beyond $15 \mathrm{~s}$. However, validity must also be considered with respect to how the information will be used. If the objective was to derive a surrogate for body heat storage, then none of those measurements was valid. For this application, it is 
essential to establish an internal thermal steady state for all deep-body measurement sites (Snellen, 1966), and this steady-state requirement also applies to the thermal and moisture characteristics of clothing worn at the time of measurement (Lotens and Havenith, 1995).

Unlike a rapidly responding direct calorimeter, in which dynamic phases are less problematic, the thermometric derivation of heat storage is frequently invalidated under non-steady-state conditions, especially when thermal fronts are moving in different directions. This is illustrated in Figure 2 between points A and D. Prior to point B, it appears as though thermal fronts were only travelling towards the surface of the sphere. Conversely, as soon as the sphere was immersed in warm water (35 s), a warmer front started to move inwards, whilst less-warm fronts continued travelling outwards; positioning sensors closer to the surface would have revealed that outcome. Point B was created by the arrival of the warmer front at the depth of that sensor. Beyond $75 \mathrm{~s}$, that sensor was storing heat. Yet the deep and central sensors were still losing heat. Therefore, both position and time determined whether or not each sensor was gaining or losing heat.

Clearly, the validity of thermometric computations of heat storage are dependent upon establishing steady-state conditions. How long does this take in humans? In sections that follow, it will be shown that thermal equilibration for healthy individuals of normal body mass resting under thermoneutral conditions varies from 30-70 min. During constant-load exercise within thermally compensable conditions, this may take 30-45 min (Kenny and 22 Jay, 2013).

A second error source accompanies the assumption the body can be sub-divided into two thermal compartments when determining mean body temperature; a stable core and a lessstable shell. It is well accepted that using only a deep-body temperature to compute heat storage is erroneous (Burton, 1935), so most investigators use temperatures obtained from two compartments. Yet despite its wide use, several groups have suggested this approach can result in significant underestimations of heat storage (Vallerand et al., 1992b; Snellen, 2000; Jay et al., 2007a, 2007b; Sawka and Castellani, 2007). Comparisons using direct calorimetry showed those errors increased when moderate intensity exercise ( $\sim 40 \%$ maximal aerobic power) was performed in warmer conditions (i.e. $15.5 \%$ at $24^{\circ} \mathrm{C}$ versus $35.5 \%$ at $30^{\circ} \mathrm{C}$ ). Adding more deep-body measurements improved the estimation (rectum, 
oesophagus, auditory canal), as did changing the compartmental weighting coefficients (Jay et al., 2007b, 2010). Nevertheless, those modifications still only accounted for $\sim 56 \%$ of the variance in heat storage observed using direct calorimetry. Including skeletal muscle temperatures may prove helpful, since muscle constitutes a large fraction of the total mass (36-45\%; female-male [healthy, active individuals]) and it has a high specific heat capacity

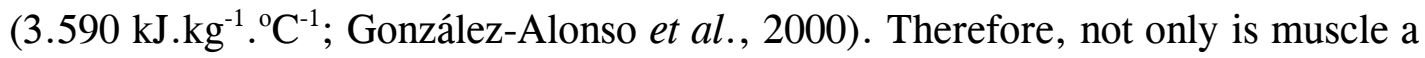
significant heat source during exercise, but it represents an important heat sink. For instance, the combined relative mass of bone and adipose tissue (30-40\%; male-female) would have an average specific heat capacity approximately half that of muscle (1.802 $\mathrm{kJ} . \mathrm{kg}^{-1} \cdot{ }^{\circ} \mathrm{C}^{-1}$; Karmani, 2006; Foundation for Research on Information Technologies in Society, 2013). Thus, muscles can store almost twice as much heat. Collectively, the studies above show that the current thermometric models for estimating changes in body heat content and rates of heat storage are inaccurate, even when used under steady-state conditions.

These inaccuracies are likely to be accentuated when comparing subjects with diverse body compositions and morphological configurations (Livingstone et al., 1987; Chudecka et al., 2014), and even during different thermal environments (Burton and Edholm, 1955; Vallerand et al., 1992a), where the weighting coefficients for the deep-body and shell compartments are necessarily modified. Attention here is directed only at variations in body composition, and it is accepted that the average specific heat capacity of humans is 3.47-

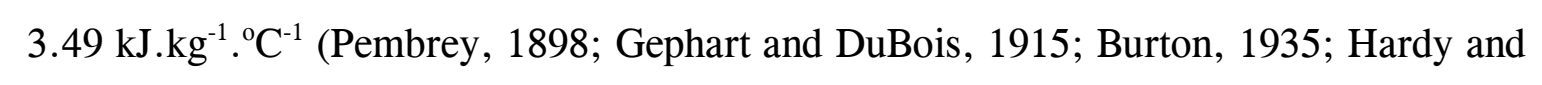
DuBois, 1938; Lipkin and Hardy; 1954). This varies among tissues, so errors must occur 4 when individuals deviate from that standard, as is the case for contemporary populations. 5 For example, for each $1^{\circ} \mathrm{C}$ change in mean body temperature, changes in body composition 26 among individuals of the same mass result in proportional changes in both the whole-body 27 specific heat and heat storage. Thus, exchanging muscle for adipose tissue reduces the 28 whole-body specific heat capacity and heat storage equally. The reverse also pertains, with 29 these potential errors adding to those already described. Not surprisingly, considerable 30 caution is required when deriving and interpreting body heat storage from mean body 31 temperature measurements.

\section{Studying clinically relevant states}


Arnold (1840) was perhaps the first to investigate the relationship between body temperatures and illness, collecting data over 25 years from healthy and infirmed individuals. It is now appreciated that significant variations in both deep-body (Hunt, 1844; Wunderlich, 1869; Wunderlich and Seguin, 1871; Woodhead and Varrier-Jones, 1916; DuBois, 1941; Eichna et al., 1951; Taylor et al., 1994; Blatteis, 2007) and superficial tissue temperatures (Korpelainen et al., 1995; Lavery et al., 2004; Arora et al., 2008; Eglin et al., 2013) are associated with pathological states, and this is another reason why tissue temperatures are measured. Indeed, the extent of these thermal changes often reflects the severity of the condition and its prognosis.

Accordingly, relevant and accurate temperature measurement during the acute phase of some conditions is important. Unfortunately, when significant thermal gradients exist, deepbody measurement is challenging, and it can become very difficult for some of the most clinically relevant sites. Furthermore, depending upon the site chosen, its temperature can reflect whole-body heat storage or simply the temperature of blood irrigating those tissues and their local metabolic rate. Finally, temperature measurement may be compromised in emergency situations to facilitate treatment, resulting in the use of more remote measures (Barnason et al., 2012).

Some clinical conditions are both instructive and relevant to this communication, and one such example relates to near-drowning in very-cold water. In this situation, aspirating cold water $\left(<6^{\circ} \mathrm{C}\right)$ into the lungs rapidly cools the heart, carotid artery blood and the brain. Using a live animal model, Conn et al. (1995) demonstrated that drowning in cold water $\left(4^{\circ} \mathrm{C}\right)$ produced a $7.5-8.5^{\circ} \mathrm{C}$ reduction in carotid blood, and therefore brain, temperature in as little as $2 \mathrm{~min}$, whereas immersion without drowning resulted in a fall of $<1^{\circ} \mathrm{C}$ over the same period. However, in both conditions, rectal temperature remained relatively stable. This very rapid reduction in brain temperature provides hypothermia-induced protection against hypoxia that can sometimes permit prolonged submersion ( $>30 \mathrm{~min}$ ) with full recovery. In these situations, it is brain temperature, and certainly not that of the rectum, that is the clinically relevant and critical deep-body index, as it determines the likelihood of survival and the rationale for continued resuscitation (Tipton and Golden, 2011). The principle highlighted by this example applies to many scenarios including localised infections (Dellinger et al., 2013), as well as to therapeutic, whole-body and regional 
cooling (Bernard et al., 2002) or heating (Alphandéry, 2014). In such circumstances, targeted temperature monitoring is essential (Werner, 2014).

\section{Quantifying thermoafferent feedback}

Tissue-temperature measurements are also used to estimate thermoafferent flow (feedback) from the deep and superficial thermoreceptors (Magoun et al., 1938; Zotterman, 1959; Hardy et al., 1964; Boulant, 1996; Pierau, 1996). Receptor feedback is integrated within the hypothalamus, with that arising from the deeper tissues generally exerting greater influence over organs participating in body-temperature regulation (Stolwijk and Hardy, 1966; Proppe et al., 1976; Jessen, 1996; Werner et al., 2008). However, feedback from the skin is important during thermal adaptation (Regan et al., 1996; Tipton et al., 2013; Taylor, 2014) and when its temperature changes very rapidly (Brown and Brengelmann, 1970; Nadel et al., 1971; Libert et al., 1978; Tipton, 1989). Nevertheless, direct measurement of afferent flow is challenging, so it is not unreasonable to assume that if one could measure the static and dynamic thermal characteristics of the tissues in which these receptors are positioned, then one may obtain a meaningful surrogate of thermoafferent feedback (Nadel et al., 1973; Libert et al., 1984; Cotter and Taylor, 2005).

There are several qualifications that must be addressed before this assumption can be accepted. Firstly, temperature sensors must be embedded within tissues that remain in equilibrium with the thermoreceptors. Those receptors must not be damaged nor can localised responses (e.g. hyperaemia) be initiated that will change local tissue temperatures (reactive error: modifying variables through the act of taking measurements). Secondly, each sensor must be equilibrated with the local tissue temperature. Thirdly, the sensors must not be influenced by conditions beyond those that elicit an equivalent modification to the energy content of the target tissues. Fourthly, sensors must be small enough and sensitive enough that response times do not lag far behind those of the thermoreceptors. Whilst sensors must be in thermal equilibrium with the surrounding tissues, the thermal status of the whole body will not necessarily be in the same thermal state, although this is not a requirement for research of this nature. Fifthly, chemicals (neurotransmitter analogues) exist that can stimulate thermoreceptors without a change in temperature (e.g. menthol [a monocyclic terpene alcohol]), and this interaction disassociates temperature from thermoreceptor feedback (Gillis et al., 2010). Finally, the sensor distribution must be 
sufficiently extensive to faithfully represent the thermoreceptive field(s) of interest. From these considerations, it is evident some temperature measurements no longer rely upon a strict application of the Zeroth Law. Instead, dynamic phases become the primary focus.

These are very demanding qualifications. Whilst they are not unreasonable, in practice, they are rarely satisfied. For physicists, adherence is often paramount. For physiologists working with open thermodynamic systems with heat-producing elements and extensive, three-dimensional arrays of deep-body (Simon et al., 1986; Villanova et al., 1997; Boulant, 1996) and superficial thermoreceptors (Ivanov et al., 1986; Pierau, 1996), the task would seem impossibly difficult, even in animal models. Nevertheless, all who take such measures should appreciate the significance of these qualifications, and their susceptibility to violation, if indices of thermoreceptor feedback are sought.

\section{Investigating body-temperature regulation}

The final topic of this section relates to investigating homeostasis. Since all tissues providing thermal sensory feedback are themselves parts of the regulated body mass (Simon, 1974; Jessen, 1996), then changes in those tissue temperatures provide essential information to those with an interest in body-temperature regulation. While the deep-body tissues dominate this feedback (Stolwijk and Hardy, 1966; Proppe et al., 1976; Jessen, 1996; Werner et al., 2008), it would be wrong to suggest that shell tissues are excluded from that regulated mass, as they too are components of the thermal feedback loops. Accordingly, one might also expect to see thermoeffector function tracking variations in shell temperatures. Thus, a weighted combination of simultaneously measured, rapidly responding deep-body and shell temperatures might provide insight into temperature regulation (Stolwijk and Hardy, 1966); the regulated mean body temperature. However, the weighting coefficients for its deep-body and shell constituents may differ from those used to describe body heat storage (Werner, 2014).

An example of the deeper-tissue relationships with effector function is illustrated in Figure 4, with sudomotor responses during a sinusoidal (24-min cycling) forcing function overlayed onto three deep-body temperatures and one active intramuscular temperature (vastus lateralis; Todd et al., 2014). The sweat rate trace is the average of five local measurements (sweat capsules), and the merits of each temperature measurement will be 
1 discussed later, but several features are noted here. Firstly, four variables tracked the

2 sinusoidal function, although not all with equivalent precision. Secondly, the sweating

3 response appeared to be tracking temperature changes reflected by both the oesophageal and

4 intramuscular indices, whilst preceding those observed via the auditory canal. Thirdly, the

5 intramuscular and oesophageal temperature peaks preceded those for sweating, with

6 respective average phase delays of $26 \mathrm{~s}$ and $47 \mathrm{~s}$ (Todd et al., 2014). Fourthly, two deepbody locations transiently stored and lost heat, returning to approximately equivalent peaks

8 and troughs, while rectal temperature increased progressively over the trial $\left(>0.2^{\circ} \mathrm{C}\right)$. It is

9 not unreasonable, therefore, to conclude that index provides less meaningful information

10 concerning thermoeffector control during some dynamic phases, as reported by others

11 (Benzinger and Taylor, 1963; Piironen, 1970; Brengelmann, 1987).

INSERT FIGURE 4 ABOUT HERE

Within another, non-steady-state experiment (Cotter et al., 1995), four different deep-body temperatures appeared to provide similar, but not equivalent information (Figure 5), although the forcing function was not designed for teasing out differences among these variables. In this case, subjects were cycling at a constant work rate in the heat $\left(36.5^{\circ} \mathrm{C}\right)$, so neither the temperatures, which rose monotonically, nor the sweating responses, which increased asymptotically, were stable over the first 10-20 min. Indeed, local sweat rates began to plateau as each site approached its maximal flow. Thus, once those temperatures were uncoupled from the sudomotor responses, they ceased providing useful information concerning the neural control of sweating. Instead, they now reflected heat storage.

INSERT FIGURE 5 ABOUT HERE

Under steady-state conditions, another set of relationships exists, and an internal thermal equilibrium is approximated. This occurs within thermoneutral conditions, but it is also 
stable. In these circumstances, most deep-body temperatures provide the same information, even though local temperatures may vary. Thus, whilst rectal temperature is inadequate in certain dynamic phases (Figure 4), it is perfectly acceptable during steady states.

One may therefore conclude that, when investigating body-temperature regulation, the choice of a temperature index must be made after considering the forcing function used to provoke the homeostatic disturbance. During some manipulations, it is absolutely critical to measure temperature from a site that rapidly tracks changes in central nervous system and cardiac temperatures (Cooper et al., 1964; Hayward et al., 1984). In other, more slowly changing states, this requirement becomes less important.

\section{INDICES OF DEEP-BODY TEMPERATURE}

The preceding overview provides a scientific rationale against which one may evaluate the methods for measuring deep-body temperature. Such measurements are taken by positioning sensors within, or in contact with, deep-body structures. Whilst some specialised organs have high metabolic rates (e.g. brain, liver, heart, kidneys) and are the primary heat sources, less-active tissues behave as short-term heat sinks (e.g. bone, adipose, skin), particularly during states of altered heat storage. Moreover, even under steady-state conditions, there is a non-stop flow and redistribution of thermal energy throughout the body via convective and conductive mechanisms, before its excess is dissipated to the environment. Consequently, the idea that the entire body can achieve a state of thermal equilibration is an over-simplification. During exercise, skeletal muscle metabolism can be dramatically elevated, altering heat production and the distribution of both blood flow (Saltin et al., 1998; Tschakovsky and Pyke, 2008) and thermal energy.

Not surprisingly, many body regions have different steady-state temperatures (Bernard, 1876 [animals]; Horvath et al., 1950b [dogs]; DuBois, 1951 [humans]; Eichna et al., 1951 [humans]; Minard and Copman, 1963 [humans]; Houdas and Ring, 1982 [humans]). Some temperatures will be equivalent due to similarities in heat production and removal, whilst others may be equivalent even though they produce vastly different amounts of thermal energy. Thus, these tissue temperatures are turnover indices resulting from changes in three variables (tissue conduction, local metabolism, local blood flow), each of which can be 
1 independently modified. Accordingly, unless any two sites are in close proximity, are

2 perfused by the same blood vessels and have the same metabolic rate, then it is highly

3 unlikely that the temperature of one will bear any mechanistic relationship with that of the

4 other, regardless of their numerical value. Nevertheless, each temperature may provide a

5 valid reflection of local heat storage. In this section, intra-regional differences in how these

6 qualifications apply to various deep-body temperature indices will be explored.

\section{Comparisons among measurement sites}

9 Body temperature measurement can be traced back to the eighteenth century. While the 10 relationship between energy, heat and work (Joule, 1850) had not yet been recognised, 11 others were exploring the temperature of the body, and its local and situational variations 12 (Martine, 1740; Currie, 1797; Currie and Percival, 1792; Becquerel and Breschet, 1835;

13 Beaumont, 1838). During the nineteenth century, the classical works of Wunderlich (1869) 14 and Bernard (1876) led to the view that the resting body core temperature was typically $37^{\circ} \mathrm{C}\left(98.6^{\circ} \mathrm{F}\right)$, which it is not, while Liebermeister (1875) and Pembrey and Nicol (1898) advocated measuring deep-body temperature via the rectum due to its thermal stability.

From this legacy arose detailed descriptions of the variability in deep-body temperatures in resting, normothermic individuals. The most extensive contribution was that of Eichna et al. (1951), added to by Minard and Copman (1963) and Houdas and Ring (1982). In Figure 6 , these temperature distributions are further embellished, although the message remains

The classical view was that the rectum is the hottest site (Bernard, 1876; Pembrey and Nicol, 1898; Haldane, 1905; Horvath et al., 1950a; Eichna et al., 1951), although most commentators only considered tissues positioned to the left of rectal temperature in Figure 6. From that perspective, the classical view is upheld, but when further sites were explored, a slightly different picture emerged. Notwithstanding the restrictions of comparing data collected from different population samples (Figure 6), with limited numbers for some sites 
and with most studies contributing data for three or fewer sites, it is now recognised that the rectum is not the hottest site. Instead, brain tissues are the hottest (Hayward et al., 1966; Shiraki et al., 1988; Mellergård, 1994), with thermal gradients (Fusco, 1963; Mellergård, 1994) permitting conductive heat loss from the deeper to the cortical tissues. The critical point is that heat loss is essential to life. This heat transfer relies upon thermal gradients, and these dictate the existence of temperature variations throughout the body. Therefore, it is important that each deep-body temperature is described using site- and depth-specific identifiers.

\section{Sources of variability among deep-body temperature measurements}

"My hardest task during these last six months has been to find the average normal body temperature and the average diurnal range. All the best workers who have written on this subject have carefully avoided giving these figures." (DuBois, 1941; P 25).

Whilst homeothermic species evolved with a capacity for body-temperature regulation (Grigg et al., 2004), there is no fixed temperature (set-point) that regulatory systems are striving to achieve (Brown and Brengelmann, 1970; Mekjavic and Eiken, 2006; Werner et $a l .$, 2008). Indeed, there is no anatomical location in which resides some reference thermal state against which all instantaneous temperatures are compared. Instead, every stable mean body temperature is merely the result of a balance between heat transfer and the autonomic regulatory processes that defend mean body temperature (Werner et al., 2008). Consequently, across population samples, one finds a wide distribution of basal, deep-body temperatures measured at the same site (Figure 7: DuBois, 1941; Ivy, 1944; Eriksson et al., 1985; Sund-Levander et al., 2002), the average of which can give the false impression of a common target. However, such apparent normality is a "statistical abstraction" (Minard and Copman, 1963; P 527), with dispersal about the mean reflecting instantaneous differences in feedback and effector activation, in combination with variations in body dimensions, specific mass, thermal conductivity, specific heat capacity and diurnal fluctuations in heat production and exchange. Thus, chronic neural disturbances can modify the normal temperature distribution among and within the deep tissues. For example, in resting (supine), spinal-cord injured individuals ( $N=9$; C4-L5), the inter-site temperature variations normally observed in able-bodied people are reduced: oesophagus $36.7^{\circ}$, auditory 
canal $36.6^{\circ}$ and rectum $36.6^{\circ} \mathrm{C}(P>0.05$; Wilsmore, 2008). Gass et al. (1988) reported similar changes in the oesophageal and rectal temperatures of paraplegics during wheelchair propulsion, and these outcomes presumably resulted from an altered balance between heat production and exchange (Pembrey, 1898; Sawka et al., 1989).

INSERT FIGURE 7 ABOUT HERE

Depending upon the temperature index used, its distribution among individuals can vary in width and skewness (Figure 7), and the variation within a site can be as much as $1.5-2.4^{\circ} \mathrm{C}$ (DuBois, 1941; Ivy, 1944; Eriksson et al., 1985). A narrow distribution might be considered advantageous, even though it can also be a characteristic of sites that are less responsive to thermal transients. In some circumstances, this too may be desirable. The second feature of these distributions (skewness) has implications for the assumptions of some statistical procedures. Indeed, it may even lead one to question the merits of

Apart from this inter-individual variation, most deep-body temperatures undergo significant changes throughout daily and, in women, monthly menstrual cycles. Before pursuing these cyclical changes, it is necessary to return briefly to first principles. Within deep-body tissues, radiative and phase change heat transfers do not occur. Instead, each local temperature is the result of local heat production, and convective and conductive exchanges. For inanimate objects, the metabolic and convective elements do not exist. For poorly perfused tissues, convective heat flow may also be negligible. In this circumstance, the balance between local metabolism and tissue conduction determines local tissue temperatures. For instance, during protracted cold exposure, hand and foot blood flows can fall below those necessary to support metabolism (Abramson, 1965; Caldwell et al., 2014).

29 Thus, deep-hand or -foot temperatures bear little resemblance to intrathoracic temperatures.

30 This physiological amputation highlights the need to consider tissue blood flow for every 31 site from which one endeavours to measure deep-body temperature. Indeed, that blood flow 32 is dictated by each organ's physiological role and metabolic rate. Therefore, the consequences of low perfusion in conduit structures used for measuring deep-body 
temperatures (e.g. gastrointestinal tract, auditory canal) must be considered, and this qualification is relevant to most sites in Figure 6, with half of those representing wellinsulated tissues with local blood flows that vary inversely with exercise intensity and changes in deep-body temperature (Rowell et al., 1967, 1969, 1970). Consequently, it is theoretically possible for the temperature of such sites to increase in parallel with, but not due to, a rise in central blood temperature. This can be explained simply on the basis of reducing heat removal from a well-insulated, heat-producing organ (Molnar and Read,

8 1974), and this point arises again in a subsequent section.

Our first source of temperature variation relates to the time taken for thermal equilibration. For those investigating whole-body metabolism, the requirements for attaining a true basal state are rigorous (e.g. 10-h fast, overnight sleep, extended supine rest in thermoneutral conditions), as variations due to extraneous influences need to be minimised. Similarly, although much less demanding, thermal equilibration to each new steady state requires time. For instance, in thermoneutral conditions, the whole-body equilibration time for resting (seated) individuals varies from 30-70 min (Cranston et al., 1954; Vallerand et al., 1992b), during which deep-body temperatures approach stability. This is generally observed as a temperature reduction, and it dictates sufficiently long preparatory times before data collection. For laboratory research, this is easily satisfied. In the field, it is more frequently infringed than it is observed. Moreover, when exercising at a fixed work rate, and therefore at a constant rate of heat production, equilibration time will vary with both exercise intensity and the rate of dry heat exchange. These also have experimental implications, and when heat storage is the focus, equilibration is critical.

Within individuals, the nychthemeral (circadian) variations in brain temperature (parahippocampal gyrus) can be in excess of $0.5^{\circ} \mathrm{C}$ (Landolt et al., 1995). Cyclical patterns in deep-body temperature have also been described, peaking around 17:00 $\mathrm{h}$ with a trough observed close to 04:00 h (Pembrey and Nicol, 1898; Richet and Langlois, 1898; DuBois, 1941; Smith, 1969; Reilly and Waterhouse, 2009). This pattern is evident across species and is linked to nocturnal behaviours (Simpson and Galbraith, 1905). The thermal trough occurs during sleep, with deep-body temperature falling while skin blood flow rises before sleep commences (Campbell and Broughton, 1994; Baker et al., 2001). Variations of a similar magnitude are associated with the menstrual cycle (Rubenstein, 1937; Buxton and 
Atkinson, 1948), with a lower temperature observed prior to ovulation (follicular phase), rising at ovulation and remaining elevated during the luteal phase (Coyne et al., 2000; Baker et al., 2001). These cyclical variations in naturally cycling, pre-menopausal women (20-45 y) have a significant and time-dependent impact on all deep-body temperatures.

Lower basal, deep-body temperatures are also observed in endurance-trained (Holmgren et al., 1960; Shvartz et al., 1974; Baum et al., 1976) and heat-adapted individuals (Dreosti, 1935; Ladell, 1951; Buono et al., 1998; Patterson et al., 2004). Those variations are slightly smaller $\left(0.3-0.4^{\circ} \mathrm{C}\right)$, and are hypothesised to be due to reduced body heat storage. Since this varies inversely with heat loss, then an elevated resting cutaneous blood flow will lower the basal mean body temperature (Werner, 1994). During exercise, a lower mean body-temperature threshold for sweating, as well as an elevated sudomotor sensitivity and peak sweat flows, combine to lower body temperature at the same fixed work rate

\section{Blood temperatures}

"Not only is the tissue temperature variable even in homoiotherms, but important variations in arterial blood temperature are common" (Bazett et al., 1948; P 18).

Much to the chagrin of cardiovascular physiologists, thermal physiologists often consider the heart as a thermal mixing chamber. Indeed, the heart accepts and mixes venous blood from all regions before delivering it to the lungs, where its temperature change is negligible due to counter-current heat transfers (Eichna et al., 1951; Mather et al., 1953; Bligh, 1957b; Walker et al., 1961; Jaeger et al., 1980), although not all hold this view (Kiyatkin, 2007). It then distributes this thermally homogenised fluid to all parts of the body. 
1 Therefore, the temperature of the blood leaving the left ventricle is close to that

2 encountered by the downstream deep-body tissues, though it loses heat en route, and the

3 time constant for dynamic thermal changes at those sites is a function of local blood flow

4 (Piironen, 1970).

Notable exceptions to this generalisation occur within metabolically active organs, in which blood behaves as a physiological coolant, increasing in temperature as it removes heat, or in tissues where perfusion is transiently impaired or arrested, with heat exchanges now becoming conduction dependent (Golden, 1979). Examples of such vascular and tissue heat exchanges are presented in Figure 8, with carotid arterial blood being $0.3-0.4^{\circ} \mathrm{C}$ cooler than that within the jugular veins. This gradient across the brain obtains during rest and exercise (Baker et al., 1972; Nybo et al., 2002), although this relationship can differ in species displaying selective-brain cooling (e.g. sheep: Maloney et al., 2001). Similarly hot venous blood from the liver is observed (Figure 8), with high local blood flow preventing hepatic overheating. In fact, it was suggested that the liver is cooler than the rectum simply due to local differences in heat balance (Graf, 1959). Foetal temperatures are also $0.3-0.4^{\circ} \mathrm{C}$ warmer than the uterus (Houdas and Ring, 1982). This must be so since the foetal and maternal circulatory systems are not connected, and conductive heat heat loss must occur down the thermal gradient and across the membranes separating the placenta and the uterus. Conversely, the limbs, and particularly the hands and feet (Taylor et al., 2014), facilitate heat dissipation in resting individuals, as illustrated by the $0.3^{\circ} \mathrm{C}$ reduction in blood temperature between the femoral artery and vein (see Davy [1814] and Pembrey [1898]).

It has been suggested that the intra-cardiac temperature (Eichna et al., 1951) and pulmonary arterial blood (Bligh, 1957b, 1973; Brengelmann, 1987) provide a good indication of the average temperature of the body core. Since minimal heat exchange occurs across human lungs, then so too would aortic blood, along with that in its immediate branches: the carotid arteries. Most accept these propositions, and this is certainly the view of the current authors, although few have the capability to undertake these temperature measurements, 
forcing reliance upon surrogate indices. These indices will now be discussed with respect to both first principles and hypothesis testing.

\section{Sublingual (oral) temperature}

Sublingual temperature has historical precedence. Arnold (1840) undertook extensive research $(25 \mathrm{y})$, noting "there are generally one or two degrees of heat $\left[{ }^{\circ} \mathrm{F}\right]$ between experiments under the tongue and in the axilla, which was always found the lowest" (Arnold, 1840; P 76). From his afebrile subjects, Arnold (1840) observed a mean sublingual temperature of $36.8^{\circ} \mathrm{C}(N=107)$, whilst Whiting (1915) subsequently recorded an average of $36.9^{\circ} \mathrm{C}(N=601)$. Both values seem high relative to Figure 6 , but not Figure 7, and although the latter procedure appeared valid ("under tongue with closed mouth for three minutes" P 2), neither basal conditions nor thermal equilibration could be assured.

The primary limitation of the sublingual index is the evaporative cooling of the buccal cavity accompanying breathing (Pembrey, 1898; Haldane, 1905), the after-effect of drinking (Woodman et al., 1967) and heat exchange through the cheeks (Sloan and Keatinge, 1975). Heat exposures seem not to be a problem (Mairiaux et al., 1983; Amano et al., 2013), and nasal breathing of sufficient duration allows the sublingual mucosa to equilibrate with deep-body temperatures.

The tongue receives an abundant blood supply (Hellekant, 1976) via the bilateral lingual arteries which branch from the external carotids, giving rise to the suprahyoid, dorsal lingual, deep lingual and sublingual arteries (Standring, 2008; Hansen and Netter, 2010). This ensures the sublingual space is potentially supplied with blood at the same temperature as that delivered to the brain. But since the lingual veins (dorsal lingual, deep lingual, sublingual) are in intimate contact with those arteries (Standring, 2008; Hansen and Netter, 2010), then arterial blood may be cooled (counter-current exchange). Nasal breathing minimises this effect, but the bias introduced by cold exposure (Sloan and Keatinge, 1975) is harder to counteract. Moreover, ensuring nasal-only breathing during longer-duration exercise can create difficulties. body temperature. Indeed, Cranston et al. (1954) reported this index to be more responsive 
to dynamic phases than rectal temperature, as did Piironen (1970) and Daanen (2006).

Edwards et al. (1978), Mairiaux et al. (1983) and Brengelmann (1987) suggested it was on par with oesophageal and tympanic-membrane temperatures, although Mairiaux et al. (1983) did report a slightly sluggish response. Accordingly, it is important to know how long nasal breathing must continue to achieve sublingual thermal equilibration among the mucosa, deeper tissues and thermometer (Zeroth Law).

This question was perhaps first investigated by Benedict and Slack (1911), finding that 7 min was necessary for equilibration. In a more extensive experiment, Nichols and Kucha $(1972 ; N=390)$ reported the time to achieve the highest sublingual temperature in $90 \%$ of subjects was $11 \mathrm{~min}$. Whilst others have used longer equilibration times ( $>20 \mathrm{~min}$ : Cranston et al., 1954; Sloan and Keatinge, 1975), some sampling periods are far too short (3 min: Strydom et al., 1965; Togawa, 1985). Surprisingly, some investigators undertaking validation experiments have neglected reporting equilibration times (Edwards et al., 1978; Mairiaux et al., 1983; Mackowiak et al., 1992; Ganio et al., 2009), rendering the validity of those observations uncertain.

\section{Axillary temperature}

19 Historical precedence also applies to axillary temperature (Arnold, 1840). However, the

20 further one moves away from the deep-body tissues, the more variable is the tissue

21 temperature (Benedict and Slack, 1911; Burton, 1935), and the less likely it is to track the

22 thermal status of the core. As a consequence, axillary temperature is often the lowest index

23 (Arnold, 1840 [equilibration time not reported]; Machino, 1959; Ilsley et al., 1983

24 [equilibration time not reported]; Erickson and Woo, 1994; Figure 6). When seeking

25 surrogate indices, it is best to avoid values at either end of a data range, for, according to

26 error theory (Beers, 1953), such data are least likely to be correct. Whilst the strict

27 application of this theory is inappropriate here, one must ask whether or not it is wise to

28 choose a representative temperature index that differs markedly from most deep-body sites.

30 Most accept this criticism. Nevertheless, the axilla has features that support its use. For 31 instance, the axillary arteries are continuations of the left subclavian and right 32 brachiocephalic arteries that arise from the aortic arch (Standring, 2008; Hansen and 33 Netter, 2010). These vessels carry blood from the deep tissues, and since they are well 
1 insulated, this blood will initially have similar thermal characteristics, but will be modified

2 by counter-current exchanges. Of greater concern, however, is the possibility that lower

3 axillary temperatures may result from inadequate equilibration. Machino (1959) showed

4 equilibration time was $\sim 20 \mathrm{~min}$, at which point axillary temperature was $0.2^{\circ} \mathrm{C}$ higher than

5 measured at $10 \mathrm{~min}$. Clearly, data collected within this 20-min interval are invalid as they

6 do not conform with the requirements of thermometry. To the current authors' knowledge,

7 systematic research has not been undertaken using this index when all sources of variability

8 were minimised.

\section{Rectal temperature}

11 It is perhaps appropriate to commence this section with opposing views, separated by about 50 years, since 50 years further on, some still passionately defend the former opinion.

“... rectal temperature, which under ordinary conditions gives the highest readings, undoubtedly gives the truest indications of the internal body temperature ..." (Haldane, 1905; P 495).

“... it seems no longer justified to substitute a temperature in the lower pelvis or intestine for the central temperature actually sought" (Benzinger and Taylor, 1963; P 111). its high metabolic rate, whilst the rectum is hot due its thermal inertia, which results from a low perfusion and heat removal; it is not due to bacterial activity (Rubin et al., 1951; Durotoye and Grayson, 1971). Indeed, the dissociation between these temperatures was illustrated by Tanabe and Takaori (1964: rabbits), who modified carotid blood temperature, showing brain and tympanum temperatures to be similarly influenced, whilst rectal temperature changes were negligible. Thus, any similarity between brain and rectal temperatures is not mechanistically linked. Therefore, unless a mechanistic connection exists, then it is very misleading to suggest that thermal equivalence, or the lack thereof, between any two indices validates, or invalidates, either measurement (Roth et al., 1996; Gass and Gass, 1998; Craig et al., 2000, 2002; Hissink Muller et al., 2008; Ganio et al., 2009; Childs and Lunn, 2013), particularly when equilibration requirements may have been violated. 
1 Whilst blood arriving at the rectum comes from the abdominal aorta via the inferior

2 mesenteric (superior rectal), internal iliac (middle rectal) and internal pudendal arteries

3 (inferior rectal: Standring, 2008; Hansen and Netter, 2010), this flow serves only its

4 metabolic requirements. Of those vessels, it is the superior rectal (haemorroidal) artery that

5 supplies tissues from which rectal temperatures are typically measured $(12-15 \mathrm{~cm}$ beyond

6 the anal sphincter), and these vessels are small relative to the mass of the rectum, so heat is

7 not easily exchanged. The haemorroidal veins have similar dimensions (inferior, middle,

8 superior: Standring, 2008; Hansen and Netter, 2010), so venous heat removal is also quite

9 slow. Therefore, the rectum possesses the thermal characteristics of an under-perfused site.

10 The bladder is similarly perfused, and it too is hot (Figure 6), as is the vagina (Benedict

11 and Slack, 1911), although its blood flow is higher and more variable (Emmanuel et al.,

12 2000). In fact, the lower abdominal cavity is so well insulated that many mammals evolved

13 with the male genitals below the pelvic floor to optimise heat exchange and testicular

14 function (Waites and Moule, 1961). Against this background, mechanisms affecting heat

15 exchanges in the rectal tissues will be explored.

Firstly, the rectal canal contains a thermal gradient, diminishing towards the anus, and

18 permitting heat flow to the ambient medium (Benedict and Slack, 1911; Mead and

19 Bonmarito, 1949; Nielsen and Nielsen, 1962; Lee et al., 2010). Indeed, longitudinal

20 gradients exist throughout the gastrointestinal tract (Cranston et al., 1954; Rawson and

21 Quick, 1972; Caputa, 1980; Jaeger et al., 1980). In perhaps the most detailed project

22 involving the rectum, depths from 4-19 $\mathrm{cm}$ beyond the anal sphincter were studied in

23 resting and exercising individuals $(N=19$; Lee et al., 2010). From $8-13 \mathrm{~cm}$, rectal tissue

24 had a consistent temperature, varying $<0.1^{\circ} \mathrm{C}$. This was also apparent at $19 \mathrm{~cm}$, but at 16

$25 \mathrm{~cm}$ (ampulla), there was an inexplicable rise of about $0.5^{\circ} \mathrm{C}$. Most recently, Buono et al.

26 (2014) demonstrated this gradient to be modified by ambient conditions; increasing in the

27 cold and narrowing in the heat. Consequently, standardisation of measurement depth is

28 important if absolute temperature is of interest, yet some have not recognised this

29 (Darowski et al., 1991; Mariak et al., 1993, 1994; Mellergård, 1994). Furthermore,

30 movement of faecal matter within the bowel is challenging, as this lengthens the conductive

31 path when a sensor becomes lodged within the stool. Various practices can minimise this

32 possibility (e.g. timing of meals relative to experimentation, pre-experimental bowel

33 evacuation). 
1 Secondly, heat exchanged with neighbouring tissues is modulated by variations in heat

2 production and perfusion. Several factors modify blood flow to, and the temperature of, the

3 lower abdomen, and three have relevance to this discussion. In women, changes in uterine

4 and vaginal blood flows accompanying menstrual cycling will modify heat flux (Emmanuel

5 et al., 2000). During upright immersion, there is an hydrostatically driven, yet

6 temperature-dependent (Pendergast, 1988), displacement of venous blood into the upper

7 thorax. This involves all dependent tissues (Arborelius et al., 1972), but primarily the

8 abdominal structures (Johansen et al., 1997), and it elevates the role of conduction in

9 organs so affected. Lower-body exercise elevates leg heat production, some of which is

10 transported centrally (femoral veins), with the balance dissipated peripherally (Gisolfi and

11 Robinson, 1970; González-Alonso, 2012). The femoral veins are not, however, in contact

12 with the rectum (Standring, 2008; Hansen and Netter, 2010), although it has long been held

13 that this blood flow was an important influence on rectal temperature (Asmussen and

14 Nielsen, 1947). Instead, Mittleman and Mekjavic (1988) demonstrated, following an

15 extended arterial occlusion of all limbs during cold-water immersion $\left(15^{\circ} \mathrm{C}\right)$, that re-

16 establishing limb blood flow produced an 8.8-fold reduction in oesophageal, but only a 1.8-

17 fold change in rectal temperature. This reinforces the interpretative difficulty of

18 temperatures recorded from sites that are more heavily dependent upon conductive

19 transfers, as those tissues have a considerable thermal inertia. Most recently, Todd et al.

20 (2014) highlighted this dissociation during sinusoidal cycling (Figure 4), and each of these

21 outcomes is more consistent with a conductive heat-flow dominance at the rectum.

In addition, rectal temperature exceeds most intravascular temperatures in humans (Bazett et al., 1948; Pennes, 1948; Eichna, 1949; Eichna et al., 1951; Ilsley et al., 1983; Mariak et al., 1993) and animals (Horvath et al., 1950b; Bligh, 1957a). Aulick et al. (1981) demonstrated this for femoral venous blood across metabolic rates from 173-401 W.m ${ }^{-2}$ $(N=3)$. This state resists heat influx until the thermal gradient is reversed, although the blood need not be hotter than the rectal tissues to elevate rectal temperature, it just needs to reduce heat removal. In this regard, vessels serving the gluteal muscles (inferior gluteal arteries and veins, internal iliac vein; Standring, 2008) may be sufficiently close to alter nearby tissue temperatures, although Aulick et al. (1981) suggested another reason for the rise in rectal temperature during endurance exercise; altered rectal-tissue perfusion. 
Although rarely investigated, rectal (mucosal) blood flow varies with daily activities, and with hormonal and skin temperature fluctuations. For example, blood flow rises after eating, but decreases during the follicular phase of the menstrual cycle, and during head-up tilting (Emmanuel et al., 2000) and smoking (Emmanuel and Kamm, 1999). It appears to be higher in men than women, and lowest in postmenopausal women (Emmanuel and Kamm, 1999). During physical exercise, visceral blood flow, and presumably that of the rectum, is reduced as the intensity rises (Rowell et al., 1967; Otte et al., 2001). Abdominal venous volume also decreases during upright immersion (Johansen et al., 1997). Furthermore, when skin temperature is manipulated, both intestinal and rectal blood flows seem to change in the opposite direction (Grayson, 1950, 1951).

This paints a complex picture. In a well-insulated region with a stable metabolic rate, convective heat removal primarily modifies tissue temperature. Thus, systematically high rectal temperatures are probably associated with its relatively low basal blood flow (Graf, 1959). This may also occur if its arterial supply is hotter, yet it is hard to conceive how this may eventuate without hyperthermia, as the rectum is one of the hottest deep-body sites during normothermia. Nonetheless, femoral arterial temperature is amongst the warmest (Figure 8), even though it may be cooled by companion veins. Thus, whilst rectal and mesenteric arterial temperatures are unknown, one assumes they are warmer, since those vessels arise from the abdominal aorta before passing through, and being warmed by, hotter visceral structures. Indeed, in four studies in which both rectal and gastrointestinal tract temperatures were simultaneously measured (Figure 6), two showed the latter to be higher (Lee et al., 2000; McKenzie and Osgood, 2004), one recorded equal values (Easton et al., 2007) while the fourth found higher rectal temperatures $(N=4$; Taylor, 2012: unpublished observations [Figure 9]). Furthermore, animal data have revealed the stomach, duodenum, ileum and large intestine are $\sim 0.5^{\circ} \mathrm{C}$ hotter than the aorta (Durotoye and Grayson, 1971). Thus, it is not unreasonable to suggest that variations in either the flow or temperature of If this is accepted, one must then consider what happens when rectal blood flow changes, as convective heat removal is flow- and temperature-dependent (He et al., 2003). One outcome is a temperature change in the opposite direction if this blood removes locally 
1 produced heat, as it does at the liver and brain. However, high hepatic and cerebral flows

2 are dictated by the functions those tissues fulfil, but this does not apply to the rectum

3 (Durotoye and Grayson, 1971). In fact, Grayson (1951) reported that as rectal blood flow

4 increased, its temperature $(16.5 \mathrm{~cm}$ deep) rose in synchrony, although that interpretation is

5 not universally accepted (Wissler, personal communication). This response persisted

6 regardless of whether the flow change was induced by a cutaneous thermal stimulus or an

7 adrenaline infusion, and it was possibly an homeostatic reflex involving blood pressure

8 regulation. The only scenario that could account for a synchronous rise in blood flow and

9 temperature was a greater flow of warmer blood that reduced heat removal, although it was

10 not necessary for this blood to have been hotter than the rectal tissues. Femoral artery

11 occlusion during skin cooling failed to eliminate this change (Grayson, 1951), indicating the

12 blood was of intra-abdominal origin. These paradoxical skin and deep-body temperature

13 changes are observed at many sites, including the central arteries (Leslie, 1778; Burton and

14 Bazett, 1936; Bazett et al., 1948; DuBois, 1951; Ladell, 1951; Cranston et al., 1954;

15 Hardy, 1954; McCaffrey et al., 1975; Edwards et al., 1978). At the commencement of

16 external cooling, for instance, cutaneous vasoconstriction transiently and instantaneously

17 alters heat balance by modifying skin blood flow. As a result, deep-body heat storage

18 occurs until conductive heat loss lowers peripheral tissue temperatures enough to re-

19 establish the thermal gradient and heat loss from the body core. This same mechanism may

20 explain simultaneous increments in rectal blood flow and temperature.

22 Whilst some rectal temperature variations may be tracking whole-body changes, in other

23 circumstances (Figure 4), a temperature elevation may be explained by a different

24 mechanism. For example, combined exercise and heat stresses may induce a powerful

25 reduction in visceral blood flow, and in this circumstance, heat transfer becomes more

26 heavily dependent upon conduction. The conductive model in Figure 2 is relevant here; the

27 lower the flow, the greater is the conductive contribution and the longer is the phase delay

28 (thermal inertia) for changes in thermal states. In Figure 4, intramuscular and oesophageal

29 temperatures tracked sinusoidally varying heat production while rectal temperature climbed

30 continuously, even after the other temperatures returned to pre-treatment baselines. This is

31 consistent with a flow-dependence at those sites and thermal inertia within the rectum.

33 This phase delay of the rectal temperature response is frequently observed, varying between 
6-60 min (Burton and Bazett, 1936; Bazett et al., 1948; Eichna, 1949; Cooper and Kenyon, 1957; Gollan, 1959; Äikäs et al., 1962; Benzinger and Taylor, 1963; Guidry and McDowell, 1966; Piironen, 1970; Saltin et al., 1970; Molnar and Read, 1974; Edwards et al., 1978; Hayward et al., 1984; Savard et al., 1985; Vallerand et al., 1992b; Lee et al., 2000; Lee et al., 2010; Nagano et al., 2010; Teunissen et al., 2012). One consequence is that the offset between rectal and oesophageal temperatures can change from $<0.5^{\circ} \mathrm{C}$ to $>10^{\circ} \mathrm{C}$ during extreme states (Gollan, 1959), another is that thermoeffector activation may 8 precede rectal temperature changes (Benzinger and Taylor, 1963; Snellen, 1969; Todd et 9 al., 2014), and a third is that steady-state rectal temperatures during exercise may take 50 10 min to be obtained (Greenleaf and Castle, 1972), depending upon the compensability of the conditions. Thus, "rectal temperature appears to be a lagging and unsatisfactory index" (Eichna et al., 1951; P 353).

A further illustration of this delay is seen in Figure 9 (one participant), where deep-body cooling (cold-water immersion: $12.5^{\circ} \mathrm{C}$ ) to an oesophageal temperature of $35^{\circ} \mathrm{C}$ was immediately followed by exercise in the heat $\left(40^{\circ} \mathrm{C}\right)$ until it reached $39^{\circ} \mathrm{C}$. The time for each site to fall $0.1^{\circ} \mathrm{C}$ below its pre-immersion baseline was: $50 \mathrm{~s}$ (oesophagus), $285 \mathrm{~s}$ (auditory canal), $305 \mathrm{~s}$ (rectum) and $360 \mathrm{~s}$ (gastrointestinal tract). These variations reflect the contributions of convective and conductive losses, and were shorter when the former dominated. When conduction prevailed, trace cross-overs occurred following a change in the external temperature (also see Figure 2). These were also present at points A, B, C and D (Figure 9). Beyond point B, rectal temperature fell below oesophageal temperature, and remained so thereafter, as eventually did gastrointestinal (point $\mathrm{C}$ ) and auditory-canal temperatures (point D). This cross-over phenomenon is also widely reported (Eichna, 1949; Bligh, 1957a; Cooper and Kenyon, 1957; Severinghaus, 1959; Benzinger and Taylor, 1963; Minard and Copman, 1963; Piironen, 1970; Keatinge and Sloan, 1975; Gibson et al., 1981; Golden and Hervey, 1981; Hayward et al., 1984; Savard et al., 1985; Webb, 1986; Ash et al., 1992; Teunissen et al., 2012). Indeed, the current authors were unable to find exceptions, yet its implications have rarely been discussed. 
1 In many experiments, cross-over artefacts are irrelevant. In others, they may lead to

2 misinterpretation. For instance, some normothermic, steady-state temperature offsets

3 (Figure 6) are reversed during dynamic phases when heating follows cooling (Figure 9), or

4 when cooling follows heating (Gibson et al., 1981). Unawareness of this can have adverse

5 clinical and scientific consequences when warming hypothermic, or cooling hyperthermic

6 individuals (Severinghaus, 1959; Molnar and Read, 1974; Hayward et al., 1984; Ash et

7 al., 1992; Taylor et al., 2008; Weingart et al., 2009; Casa et al., 2010; Pearson et al.,

8 2012). In such instances, one cannot substitute a conduction-dependent surrogate index for

9 the temperature of a critical and temperature-sensitive tissue, unless the former has been

10 shown to faithfully track the dynamic response of the latter.

\section{Oesophageal temperature}

"A temperature-measuring device located in the oesophagus at the level of the heart would, by reason of its close proximity, seem to provide a more useful index of heart temperature than would a similar device introduced into the opposite end of the alimentary canal" (Cooper and Kenyon, 1957; $\mathrm{P}$ 619).

Depending upon the distance above the cardiac sphincter, the oesophagus is sandwiched between the spinal column, trachea and the left main bronchus, as well as the heart and several major blood vessels (thoracic aorta, left common carotid, right pulmonary arteries, superior vena cava; Standring, 2008; Hansen and Netter, 2010). Whilst the oesophagus is merely another conduit, its intimate contact with these structures, in combination with its relatively low heat capacity, means that its temperature is readily influenced by convective heat exchanges. There is also a longitudinal temperature gradient within the oesophagus (Cranston et al., 1954; Severinghaus, 1959; Whitby and Dunkin, 1968, 1969, 1971; Caputa, 1980; Jaeger et al., 1980), but this is not merely a conductive gradient down to the mouth, but a gradient dictated by its contiguous structures. pronounced, so a sensor positioned here will not just have a lower absolute temperature, it will track ventilatory cycling (Nielsen and Nielsen, 1962; Whitby and Dunkin, 1969; Jaeger et al., 1980). At the level of the carina, local tissue temperatures can be $>1{ }^{\circ} \mathrm{C}$ 
cooler than within the lower third of the oesophagus (Severinghaus, 1959), particularly when breathing cold air (Jaeger et al., 1980). In its lower-third (fifth-tenth thoracic vertebrae), vascular exchanges dominate (Cooper and Kenyon, 1957; Severinghaus, 1959; Whitby and Dunkin, 1968, 1971; Brengelmann et al., 1979; Mekjavic and Rempel, 1990), and oesophageal temperature is stable and independent of the inspired-air temperature ($40^{\circ} \mathrm{C}$ : Jaeger et al., 1980). To ensure the correct positioning of the sensor within this vascular zone, it is necessary to standardise insertion depth, both absolutely and relative to stature (Brengelmann et al., 1979; Mekjavic and Rempel, 1990). Nevertheless, in all positions, it is modified by swallowing saliva and drinking.

These powerful vascular influences were most clearly illustrated by Gollan (1959) during extracorporeal cooling (dogs). Right atrial blood was cooled before being returned via the descending aorta, partially bypassing the cardiopulmonary circulation. Therefore, cooled blood perfused the lower systemic vessels before those above the heart. Hence, the abdomen should have cooled earlier, and perhaps also deeper, than the mediastinum. Whilst intra-abdominal temperatures were not reported, myocardial temperature was reduced to $<5^{\circ} \mathrm{C}$. This was tracked by oesophageal temperature $\left(<10^{\circ} \mathrm{C}\right)$, yet rectal temperature remained above $20^{\circ} \mathrm{C}$ (Gollan, 1959). Cooper and Kenyon (1957) reported similar outcomes in patients rendered hypothermic prior to aortic surgery. When aortic clamps were released at the completion of each procedure, blood flow to the legs returned, resulting in the cephalad displacement of cold blood. Just $15 \mathrm{~s}$ after release, oesophageal temperature dropped $0.7^{\circ} \mathrm{C}$, while the corresponding change at the rectum was $0.1^{\circ} \mathrm{C}$. Indeed, the authors found oesophageal temperature was never $>0.15^{\circ} \mathrm{C}$ away from paraaortic temperature, yet rectal temperature deviated $>2^{\circ} \mathrm{C}$. This close oesophageal tracking of central blood temperatures has been reported by others (Lees et al., 1980; Hayward et al., 1984; Shiraki et al., 1986; Nybo et al., 2002).

This thermal responsiveness of the oesophagus relative to central blood temperature (80-s time delay: Shiraki et al., 1986) demonstrates that it has not simultaneously equilibrated with poorly perfused deep-body tissues or tissues more distant from major blood vessels. Therefore, this index is unable to provide information concerning the temperature (or the heat storage) of those tissues, and by the same logic, the reverse state must also exist. 
deep-body locations or surrogates (Edwards et al., 1975; Gibson et al., 1981).

\section{Auditory-canal temperature}

Auditory-canal (aural) temperature measurement was perhaps initiated by Williams and Thompson (1948), who reported a close association with sublingual temperature. From Figure 4, it is clear that an insulated auditory-canal temperature can track variations in deep-body temperature, as reported by others (Cooper et al., 1964; Greenleaf and Castle, 1972; Edwards et al., 1978; Hayward et al., 1984), albeit with an offset (Figure 6) and a phase delay (Figure 4). This raises an important question: is it more important to determine actual temperatures or temperature changes? The answer to this question dictates one's acceptance of data derived from the various indices described herein, and the acceptability of normalising body temperatures when presenting these data.

The auditory canal is supplied with blood from both superficial and deep sources. At its entrance (pinna, lobe, external meatus), the anterior auricular artery provides blood from the superficial temporal artery (Standring, 2008). This is a relatively shallow vessel coming from the external carotids. The posterior auricular artery, also arising from the external carotid, feeds tissues deeper within the auditory canal as well as the skin behind the ear (Standring, 2008). Facial skin receives arterial blood from the internal carotids (supraorbital and supratrochlear arteries). This, in combination with its proximity to the brain, explains why forehead temperature is among the warmest skin sites (Sheard et al., 1941; Olesen and Fanger, 1973; Werner and Reents, 1980; Zaproudina et al., 2008), why it varies during pathological conditions (Weinstein et al., 1991; $\mathrm{Ng}$ and Chong, 2006) and why it is sometimes comparable to axillary and rectal temperatures (Ilsley et al., 1983). Unfortunately, surface temperatures are powerfully influenced by ambient conditions, thus explaining why the temporal artery surface temperature cannot reliably track deep-body temperatures (Low et al., 2007; Kistemaker et al., 2006; Ronneberg et al., 2008).

As a consequence of its vascular configuration, the auditory canal responds rapidly to changes in carotid artery (Cooper et al., 1964) and cardiac temperatures (Hayward et al., 1984). This was nicely demonstrated by Cooper et al. (1964), who infused the right internal carotid with warm saline $\left(44^{\circ} \mathrm{C}\right)$ and observed an immediate rise in auditory-canal temperature, but not that of the contralateral ear. Since the tympanum, but not the auditory 
canal, receives blood from this vessel, the authors suggested that retrograde flow at the bifurcation of the internal and external carotids might explain this observation. This is probable, as is the contribution from a direct influence on tympanic-membrane temperature.

Nevertheless, the auditory canal is influenced by variations in ambient temperature (Gibbons, 1967; Greenleaf and Castle, 1972; Morgans et al., 1981; Sharkey et al., 1987; Hansen et al., 1993; Coso et al., 2008; Nagano et al., 2010; Teunissen et al., 2011a) and wind (Teunissen et al., 2011a), producing a thermal gradient down the canal (Cooper et $a l .$, 1964). The cooler the air temperatures, the greater is the gradient, although it can be reversed. Thus, absolute temperatures are depth-dependent and lower than oesophageal Under ambient temperatures not too different from deep-body temperature, this offset has minimal impact on tracking deep-body temperature changes (Greenleaf and Castle, 1972; Cotter et al., 1995; Figure 4). Indeed, sites 0.3-1.7 cm within the canal track changes in oesophageal temperature with a faster response than sublingual temperature (Cooper et al., 1964). Auditory-canal temperature also responds to postural variations (Greenleaf and Castle, 1972), being higher when supine, as observed in other deep-body sites (Cranston et al., 1954; Graf, 1959; Ogawa et al., 1993). Nevertheless, those using this index may face criticism from others who believe the external-temperature influence always invalidates this measurement, even though the bias disappears in the heat and can be minimised through insulation. Strangely, conduction- and ambient temperature-dependent rectal bias often appear more palatable.

Given that some investigators and clinicians consider absolute temperature to be critical, Keatinge and Sloan (1975) developed a servo-controlled, zero-gradient device that first heated the outer ear to that of the auditory canal (also see Moore and Newbower, 1978). Once equilibrated, the temperature of the pinna tracked auditory-canal temperature, removing both the thermal gradient and the ambient bias. Under these conditions, auditorycanal temperature is typically higher than oesophageal temperature, as is tympanicmembrane temperature (Figures 5 and 6; Keatinge and Sloan, 1975; Cotter et al., 1995). Curiously, this device received little attention, yet its dynamic response characteristics 
exceeded those of rectal temperature (Keatinge and Sloan, 1975; Maw and Taylor, 1992).

\section{Tympanic-membrane temperature}

To the authors' knowledge, the first recordings of tympanic-membrane temperature were made Benzinger (1959). From that work arose contributions of Cabanac and Caputa (1979), and controversy surrounding deep-body temperature indices. This was not so much about the utility of various indices, but using tympanic temperature to support the case for selective-brain cooling in humans (Nybo and White, 2008), and it was driven by passionate protagonists (Benzinger, 1969; Brengelmann, 1993; Cabanac, 1993; Simon, 2007). Whilst that discussion is avoided here, its root centred on the arterial supply for the tympanic membrane, with controversy relating to the certainty of membrane contact by the sensor and whether or not its temperature suffered from an ambient bias.

Arterial blood travels to the brain via the internal carotid and vertebral arteries, both of which branch off the subclavian artery, rejoining to form the cerebral arterial circle (circle of Willis: Standring, 2008; Hansen and Netter, 2010). Posteriorly, the basilar artery leads from the vertebral arteries to the circle, and from it arise vessels supplying the inner ear: the labyrinthine (auditory) arteries (Standring, 2008; Hansen and Netter, 2010). The tympanic membrane receives blood from two sources: the glaserian (anterior tympanic) artery, which leaves the maxillary artery soon after branching from the external carotid, and the caroticotympanic artery that arises from the internal carotid (Standring, 2008). The deep auditory canal, close to the tympanum, receives external carotid blood via the posterior auricular artery (Standring, 2008).

This anatomical configuration raised the possibility the tympanic membrane might faithfully track carotid arterial temperature, and it was hypothesised this blood would modify both hypothalamic and tympanic temperatures (Benzinger and Taylor, 1963; Brinnel and Cabanac, 1989). This was challenged by Brengelmann (1987, 1993). Nybo et al. (2002) subsequently found that, during rest and exercise, carotid arterial temperature was consistently cooler than jugular venous blood. Therefore, whilst true tympanic-membrane temperature can track blood and oesophageal temperatures (Figure 5: Tanabe and Takaori, 1964; Piironen, 1970; Molnar and Read, 1974; Shiraki et al., 1986, 1988; Brinnel and Cabanac, 1989; Cotter et al., 1995; Sato et al., 1996), that blood was acting as a brain 
coolant (Hayward and Baker, 1968; Figure 8).

3 Brinnel and Cabanac (1989) suggested true tympanic-membrane temperature could only be measured via direct contact with its lower, anterior quadrant. The anatomical description above supports that proposition, although this requires otoscopic or possibly acoustic verification (Benzinger and Taylor, 1963; criticised by Brengelmann, 1987). Without verification, membrane measurements cannot be assumed. Nevertheless, while unverified measures are not tympanic, they are auditory-canal temperatures, which are similar but not equivalent (Figure 6). Indeed, due to the curvature of the auditory canal and the presence of cerumen (ear wax), infrared thermometers infrequently measure tympanic temperature (e.g. Shinozaki et al., 1988; Daanen, 2006; Easton et al., 2007; Lee et al., 2011).

As with the auditory canal, there is evidence that ambient and facial-skin temperatures can bias tympanic-membrane temperature (Nadel and Horvath, 1970). Using the method of Benzinger and Taylor (1963: subject-determined sensor positioning), that group reported no apparent bias in air temperatures from $10^{\circ}-28^{\circ} \mathrm{C}$ (Nadel and Horvath, 1969). This was subsequently verified, although from $22^{\circ}-44^{\circ} \mathrm{C}$, an elevation of $0.04^{\circ} \mathrm{C}$ for each $1^{\circ} \mathrm{C}$ rise in air temperature was described (Nadel and Horvath, 1970). Together, these studies showed two thermal plateaux, separated by a less-stable range $\left(22^{\circ}-34^{\circ} \mathrm{C}\right)$. The first was a possible negative bias in air from $10^{\circ}-22^{\circ} \mathrm{C}$ (tympanic temperature $36.4^{\circ} \mathrm{C}$ ) with the second appearing to be without bias $\left(34^{\circ}-44^{\circ} \mathrm{C}\right.$; tympanic temperature $\left.37.1^{\circ} \mathrm{C}\right)$.

McCaffrey et al. (1975) tested this evidence by simultaneously heating $\left(45^{\circ}-50^{\circ} \mathrm{C}\right.$ water) and cooling $\left(3^{\circ}-4^{\circ} \mathrm{C}\right.$ water $)$ the circum-orbital facial surfaces whilst recording tympanic temperature bilaterally. These very powerful treatments highlighted this skin temperature influence. Yet, whilst this study is often cited as proof this index is flawed, close examination reveals the maximal difference was just $0.4^{\circ} \mathrm{C}$, which occurred because both skin temperatures were driven in opposite directions by $\sim 45^{\circ} \mathrm{C}$. Thus, the unilateral effects obtained when heating $\left(45^{\circ}-50^{\circ} \mathrm{C}\right)$ and cooling $\left(3^{\circ}-4^{\circ} \mathrm{C}\right)$ were half that value. While still present, the extreme conditions under which those effects were induced means this bias will be less pronounced under typical laboratory conditions, although Nybo et al. (2002) reported bias during face fanning. 
1 One must also entertain the possibility that, in several of these investigations, the sensors

2 were not in intimate contact with the tympanum. This was tested by Sato et al. (1996) using

3 a bespoke tympanic sensor. Neither ice cooling nor skin cooling elicited by facial fanning

4 influenced membrane temperature. Although when membrane contact was lost, this bias

5 appeared, and herein lies the critical point; if membrane contact has not been verified, then

6 one is measuring auditory-canal temperature. Indeed, Sato et al. (1996) recommended that

7 contact can be verified by testing for the presence of facial skin cooling interference.

8 Moreover, Shibasaki et al. (1998) established this for infrared thermometry, when a

9 flexible, optical-fibre probe was used to approach the tympanum.

11 Gastrointestinal temperature

12 Gastrointestinal temperatures were first measured by Beaumont (1838), well in advance of 13 the experiments of Wunderlich (1869), with interest re-emerging and expanding following 14 the miniaturising of sensors and data loggers (Byrne and Lim, 2007), although this is not a 15 recent phenomenon either (Fox et al., 1961). Since intestinal thermoreceptors exist 16 (Rawson and Quick, 1972; Villanova et al., 1997), there are mechanistic interests in those 17 tissues.

The gastrointestinal tract is much more than a conduit structure. However, since radio pills used to measure temperature travel along the tract, their location is dependent upon gastrointestinal motility. This can be modified, along with thermal equilibration requirements, due to the nature of the experiment (Misiewicz et al., 1968; reactive error). Moreover, since convective and conductive heat exchanges vary among sites, the thermal inertia of the local tissues changes as sensors travel along the tract.

Not surprisingly, Pearson et al. (2012) reported gastrointestinal temperature to lag behind pulmonary artery temperature during passive, whole-body heating and cooling. Kolka et al . (1993) and Teunissen et al., (2012) observed a similar delay relative to oesophageal temperature, but not rectal temperature, which it generally exceeds (Figure 6). These delays

30 introduce bias during dynamic phases. However, gastrointestinal and arterial temperatures were equivalent when thermal equilibration was approached ( $\sim 45 \mathrm{~min}$; Pearson et al., 2012). One may therefore question comparisons among gastrointestinal and other deepbody surrogates during dynamic phases, and when sampling did not occur from the same 
1 intestinal location (technically very challenging).

3 To gain an appreciation for variations in gastrointestinal temperatures during transit, one 4 author consumed seven radio pills over a 37-h period (Figure 10A), including consecutive 5 nights (Figure 10B), whilst maintaining a normal routine (office work). The minimal transit 6 time was $9.2 \mathrm{~h}$, and all pills ingested before retiring were passed before breakfast. Times for Figures 10A, C and D are referenced to trial commencement (time zero), with Figure

8 10C emphasising an endurance run (commencing at 06:20 h [12.2 h after time zero], 9 duration $50 \mathrm{~min}$ ) and Figure 10D highlighting resistance exercise (commencing at 18:40 h $10 \quad$ [24.5 $\mathrm{h}$ after time zero], duration $40 \mathrm{~min}$ ).

INSERT FIGURE 10 ABOUT HERE

During running, pill temperatures rose linearly following an initial lag (Figure 10C), as expected in an unregulated thermal state in which heat storage was constant and positive. The overall temperature changes were $3.0^{\circ} \mathrm{C}$ (sensor 2 ) and $2.9^{\circ} \mathrm{C}$ (sensor 3 ), with peak values occurring $\sim 5 \mathrm{~min}$ after exercise ceased $\left(39.6^{\circ} \mathrm{C}\right.$ and $39.3^{\circ} \mathrm{C}$ respectively). This reflected a conductive heat transfer dominance. The maximal between-sensor difference was $1.1^{\circ} \mathrm{C}$, which occurred during recovery, and immediately prior to the passing of sensor 2. It was assumed that sensor was recording low colonic (stool) temperature, whilst the other measured gastric temperature, as it was consumed $60 \mathrm{~min}$ before exercising. It was also assumed that running increased gastric motility (Keeling and Martin, 1987). During resistance exercise, the highest temperature was $38.0^{\circ} \mathrm{C}$ (sensor 5). At the same time, the other temperatures were $37.5^{\circ} \mathrm{C}$ (sensor 3 ), $37.5^{\circ} \mathrm{C}$ (sensor 4 ) and $37.4^{\circ} \mathrm{C}$ (sensor 6), with a maximal between-sensor difference of $0.7^{\circ} \mathrm{C}$ (sensor 5 versus 6). Thus, for this individual, exercise was associated with significant temperature variations along the gastrointestinal tract.

When these exercise data were removed, the within sensor temperature ranges during transit averaged $1.0^{\circ} \mathrm{C}$ (Figure 10A: range $0.7-1.6^{\circ} \mathrm{C}$ ). Therefore, the variability during exercise was also evident during sedentary activities, reflecting local differences in tissue 
metabolism and heat exchanges. When sleep data were compared across consecutive nights using sensors ingested just before retiring (Figure 10B: sensors 2 and 7; time referenced to pill ingestion), the classical temperature decline appeared during the first hour (Campbell and Broughton, 1994; Baker et al., 2001), but the circadian trough at about 04:00 h was less apparent. This time is beyond the $6 \mathrm{~h}$ plotted, as the subject arose at 03:45 h. On the second evening (sensor 7), a trough was approached. Throughout sleep, peak temperatures of $36.9^{\circ} \mathrm{C}$ (sensor 2 ) and $36.8^{\circ} \mathrm{C}$ (sensor 7) were observed, with respective within-sensor transit ranges being $0.6^{\circ} \mathrm{C}$ and $0.7^{\circ} \mathrm{C}$. Every sensor was recording during sleep on one of the two nights, although sensors 1, 3, 4, 5 and 6 were ingested at varying times before

10
retiring. When these data were analysed, the average, within-sensor overnight temperature range was $0.5^{\circ} \mathrm{C}$, with neither the temperature peaks nor the troughs falling outside the data shown in Figure 10B. The significance of this outcome can be appreciated when one considers typical circadian (Landolt et al., 1995) and menstrual variations (Buxton and Atkinson, 1948) in deep-body temperature, as well as temperatures changes that elicit thermoeffector responses (Werner et al., 2008; shivering: Tipton et al., 2013; sweating: Machado-Moreira et al., 2014). These temperature changes are $0.3-0.5^{\circ} \mathrm{C}$, rendering the signal to noise ratio of gastrointestinal measurements unacceptable to many.

Recommendations for the delay between ingesting radio pills and data collection appear to be predicated on gastric emptying times (Goodman et al., 2009), and avoiding artefacts introduced by food and liquid consumption. Perhaps the most detailed investigation of radio-pill transit times was conducted by Roach et al. (2010). Subjects ingested a new sensor as each passed, with 65 transits recorded over $7 \mathrm{~d}(N=11)$. The mean transit time for single pills was $27.4 \mathrm{~h}$ (range: $4.6-82.8 \mathrm{~h}$ ), although the individual with the shortest single transit also had one passage exceeding $26 \mathrm{~h}$, while another person had a difference between the shortest and longest transit times of $55 \mathrm{~h}$. McKenzie and Osgood (2004) described a transit mean of $24 \mathrm{~h}$ (range: $12.5-134.4 \mathrm{~h}: N=10$ ), whilst O'Brien et al. (1997) reported the overnight passing of pills in three individuals. Clearly, since defaecation is entrained and infrequently modified by daily routine changes, then such data are exceedingly difficult to interpret. However, this research emphasises that some individuals pass pills very rapidly (6.2\% within $12 \mathrm{~h}$ : Roach et al., 2010), and that pill location within the tract is time- and person-specific (Livingstone et al., 1983; Kolka et al., 1993; Goodman et al., 2009). By implication, validation of gastrointestinal temperatures against 
other indices seems to lack justification, particularly if the reference index was less than ideal for the experiment.

To evaluate the influence of drinking on data collection, Wilkinson et al. (2008) tracked gastrointestinal temperatures during the hourly ingestion of cold drinks $\left(250 \mathrm{~mL}, 5-8^{\circ} \mathrm{C}\right.$, $N=10$ ). The thermal artefact accompanying drinking lasted $32 \mathrm{~min}$ (SD 10), decreasing over time and being absent in all individuals $11.5 \mathrm{~h}$ after ingestion. Under controlled conditions, these interferences can be prevented, firstly by ingesting pills with water at $37^{\circ} \mathrm{C}$ and then by preventing fluid consumption (Gibson et al., 1981; Kolka et al., 1997; Ducharme et al., 2001). However, under field conditions, the latter may be less feasible, with artefact prevention constituting an important design consideration.

From this discussion, one may conclude that rectal temperature, due to its inherent stability, is preferable to gastrointestinal measurements (consider radio-pill suppositories). Within thermal steady states, rectal temperatures faithfully quantify deep-body heat content, but with minimal measurement artefact. Whilst gastrointestinal temperature tracks changes in local heat storage, it is subject to the vagaries of localised fluctuations in heat production and exchange encountered en route, and these artefacts confound interpretation.

\section{Intramuscular temperatures}

21 The first investigations of muscle temperatures appear to have been performed by Becquerel and Breschet (1835). Researchers have now demonstrated muscle temperature to influence tissue oxygenation (Barcroft and King, 1909), with heating (Starkie et al., 1999; Ferguson et al., 2002), but not cooling (Booth et al., 2001), modifying substrate utilisation and energy turnover. In resting states, intramuscular temperatures are not homogeneous (Webb, 1992), but increase with sensor depth (parabolic profile) and vary with proximity to large arteries and bones (Kenny et al., 2003). Indeed, muscles reveal a radiating thermal gradient that supports conductive heat losses. In addition, distal muscle tissues, which are smaller and have less thermal insulation, are readily influenced by the environment (Bazett and McGlone, 1927; Barcroft and Edholm, 1946; Pennes, 1948; Booth et al., 2004). These characteristics render resting skeletal muscles ill-suited as deep-body surrogate sites.

\section{During exercise, and immediately thereafter, active skeletal muscles become significant}


heat sources (Figure 11: Pembrey, 1898; Buchthal et al., 1945; Kenny et al., 2003, 2006; Booth et al., 2004; Kenny and Jay, 2007; Todd et al., 2014). This becomes exaggerated in hotter conditions (Saltin et al., 1972) due to impaired heat conduction. At the start of exercise, rapid intramuscular temperature changes are observed (Figure 4), reflecting variations in heat storage, with temperatures becoming more uniform as exercise continues. Among muscles, however, the inter-site variability expands as metabolic variations from one segment to another increase (Figure 11: Kenny et al., 2003, 2006).

In the quadriceps, for instance, the rate of temperature rise is a function of force generation intensity (Edwards et al., 1975), and recent evidence has linked sudomotor responses to those thermal changes, possibly indicating the presence of thermosensitive elements within skeletal muscle (Todd et al., 2014). In many cases, the temperature of active muscles may exceed some deep-body temperatures (Figure 4), although this is not a pre-requisite for a core temperature elevation, as it is the balance (turnover) between heat production and removal that explains local thermal variations. Indeed, data from Todd et al. (2014) revealed the intramuscular temperatures of three participants exceeded oesophageal temperature on $>90 \%$ of their simultaneous measurement during exercise, with an average difference of $0.43^{\circ} \mathrm{C}$. For another five individuals, the reverse obtained; mean difference $0.46^{\circ} \mathrm{C}$. Nevertheless, there was a strong, positive correlation between oesophageal and intramuscular temperatures $(r=0.79)$ across subjects (Todd et al., 2014).

Taken together, this evidence highlights the dynamic nature of intramuscular temperature during exercise. Differences between active and inactive muscle temperatures, as well as variations in heat distribution between the muscles and deeper tissues, emphasise the thermal significance of blood. Not only does its specific heat capacity exceed that of

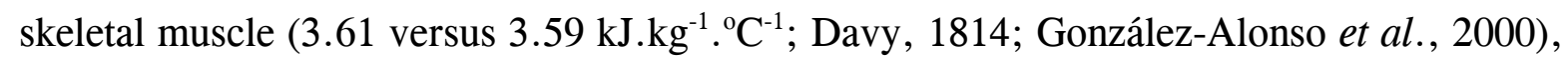
but the relative perfusion of the active and inactive limbs (Bevegård and Shepherd, 1966; Nishiyasu et al., 1992), the ratio of that flow to the muscle mass and the arteriovenous temperature differences (Aulick et al., 1981) have profound affects on muscle temperature, 
convective heat flow and deep-body heat storage during exercise.

3 During early recovery (15-20 min), and irrespective of exercise intensity, intramuscular

4 temperatures decrease by values comparable to oesophageal temperature (Kenny et al.,

52003 , 2006). Indeed, the thermal gradient from the deep muscle (vastus medialis) to the oesophagus remained constant for the final $45 \mathrm{~min}$ of recovery (Kenny et al., 2003). This is consistent with thermal equilibration and a uniform heat distribution. More recent studies

8 revealed this sustained tissue temperature elevation occurred in parallel with a marked and 9 sustained increase in body heat content (Kenny et al., 2010; Kenny et al., 2008). It appears 10 that, during an inactive and seated recovery, blood pooling in the dependent regions traps 11 heat and thereby contributes to a sustained elevation in muscle temperature.

\section{Transcutaneous temperature}

Due to continual heat exchanges between the skin and the ambient medium, a temperature gradient exists within the latter; the boundary layer (McGlone and Bazett, 1927). When clothing is worn, that layer becomes warm and humid, impeding heat loss and reducing environmental influences on skin temperature (Benedict et al., 1919). These changes reduce the transcutaneous thermal gradient, with skin temperatures becoming more uniform (Pandolf and Goldman, 1978; McLellan et al., 2013) as the skin blood vessels become engorged (Fogarty et al., 2004). This resembles an exteriorisation of the deep-body temperature, and when well-insulated clothing is worn, it may be possible to track deepbody temperature from changes in transcutaneous temperature.

Since the zero-gradient (heat-flux) technique for measuring auditory-canal temperature (Keatinge and Sloan, 1975) removes the thermal gradient within the auditory canal, negating external interference, Fox and Solman (1971), Fox et al. (1973a) and Togawa (1979) used this approach for the transcutaneous tracking of deep-body temperature. Clinical techniques of this form were evaluated by several groups (Ball et al., 1973; Kobayashi et al., 1975; Singer and Lipton, 1975; Togwa et al., 1976 [Togawa]; Carter and Perry, 1977; Lees et al., 1980; Smith et al., 1980; Yamakage et al., 2002; Yamakage and Namiki, 2003; Kitamura et al., 2010; Teunissen et al., 2011b), usually under resting, thermoneutral conditions with minimal or no clothing over the measurement site. An extension of this approach, albeit it of questionable validity, used plastic-strip thermometers 
positioned over blood vessels and hotter skin surfaces (Lewit et al., 1982).

Another variation, developed to find a technically less-demanding and more robust method for field use, used clothing insulation and insulated-skin temperature measurements (Dollberg et al., 1993; Bogh et al., 1994; Taylor et al., 1999; Edwards et al., 2002; Armstrong, 2006; Gunga et al., 2008). Those studies yielded inconsistent outcomes that appeared linked to the quality of the thermal insulation and ambient conditions.

For each of these approaches to be successful, two pre-requisites must be satisfied. Firstly, two thermal gradients must be simultaneously minimised; the core-to-shell and ambient-toskin gradients. It is not sufficient to achieve one without the other. Only when these heat fluxes have been removed, or at least dramatically reduced, can thermal equilibration among the skin, deeper tissues and temperature sensor be assured (Zeroth Law requirements). Zero-gradient instruments adequately satisfy this criterion, whilst insulatedskin temperature measurements approach it to varying degrees, and in proportion to the thickness and surface area of the insulating cover.

The second, often overlooked, consideration relates to positioning the sensor over a suitable skin surface. It is recognised that skin temperatures in normothermic individuals are quite variable, with some sites being consistently warmer (Benedict et al., 1919; Bedford, 1935; DuBois, 1941; Olesen and Fanger, 1973; Werner and Reents, 1980; Zaproudina et al., 2008). The forehead is one such site, but it is not the warmest, just the warmest among sites commonly evaluated. Instead, the inner canthus of the eye (junction of upper and lower eyelids) provides the closest, surface approximation of deep-body temperature among resting (Barnes, 1967; Ring, 2007), but not exercising individuals (Teunissen and Daanen, 2011). Other potential sites for this approximation include the navel (Barnes, 1967; Olesen and Fanger, 1973) and the lower occiput, neck and upper-thoracic vertebrae (Olesen and Fanger, 1973; Zaproudina et al., 2008; Marins et al., 2014), or regions where body segments are naturally apposed (axilla, groin: Barnes, 1967; Ilsley et al., 1983; Darowski et al., 1991; Childs et al., 1999).

Unless both of these requirements are satisfied, uncertainty must exist concerning the precision with which the surface index tracks deep-body temperature. For example, whilst 
the inner canthus may provide the closest resting approximation, it is not viable to modify thermal gradients at that site, so its use is restricted to non-exercising, steady-state conditions that vary only slightly from thermoneutrality. Moreover, the zero-gradient devices, which can readily satisfy both criteria, are often ill-suited for field use.

Accordingly, Taylor et al. (1998, 1999) and Armstrong (2006) evaluated the feasibility of insulated-skin temperatures (forehead, jugular, upper spine [T2-T4], ventral wrist) for predicting changes in deep-body (oesophageal) temperature in clothed and exercising individuals in warm-hot conditions. The earlier investigation, conducted at $33^{\circ}$ and $40^{\circ} \mathrm{C}$, revealed the insulation largely, but not completely, removed the ambient-to-skin thermal gradient, so an air-temperature bias was evident (Taylor et al., 1999), as confirmed by Gunga et al. (2008). The strength of the correlation between sensor and oesophageal temperatures was site dependent, with the forehead being superior to the spine, followed by the wrist and jugular sites. Prediction errors were primarily influenced by inter-individual insulated-skin temperature variability, so it appeared that calibration for each user might be required (Taylor et al., 1999; Eglin et al., 2004; Armstrong, 2006). Finally, when rectal predictions of oesophageal temperature were compared with those derived from two insulated sites combined (forehead plus spine [T2-T4]), <50\% of those comparisons yielded predictions superior to those obtained from the insulated-skin temperatures (Taylor

Armstrong then undertook a two-stage investigation. In the first, a retrospective analysis was performed using data from three experiments. These included 64 separate trials performed in temperate $\left(25^{\circ} \mathrm{C}\right.$ [Wilsmore, 1996: $N=12$ ], $27^{\circ} \mathrm{C}$ [Taylor et al., 1998: $N=7$ ] $)$ and hot conditions $\left(33^{\circ} \mathrm{C}\right.$ [Taylor et al., 1998: $N=7$; Armstrong and Fogarty, 1999: $N=5$, unpublished observations], 40 ${ }^{\circ} \mathrm{C}$ [Wilsmore, 1996: $N=17$; Taylor et al., 1998: $N=6$ ]). In every trial, oesophageal, rectal and insulated-skin temperatures (spine: T2-T4) were recorded. In all trials except those of Wilsmore (1996), participants wore military combat fatigues. Data were modelled (regression) to predict changes in deep-body temperature. datasets (47 trials), in which oesophageal, rectal and insulated-skin temperatures were again measured (Taylor et al., 2001 [N=8, 29.8 $8^{\circ}$, five thermal protective ensembles]; Fogarty 
et al., $2004\left[N=7,39.6^{\circ} \mathrm{C}\right.$, thermal protective clothing]). For the cooler conditions, predictive models failed to explain $48 \%$ of the observed variance; this was unacceptable. In the heat, the unexplained variance dropped to $<20 \%$, yet even with this improvement, every model over-predicted oesophageal temperature, with errors exceeding $1^{\circ} \mathrm{C}$ in each case. Thus, oesophageal temperature changes were tracked with acceptable accuracy, but actual temperature predictions were less reliable, possibly due to convective and conductive phase delays in the delivery of central heat to the periphery. For individuals wearing thermal protective clothing in the heat $\left(40^{\circ} \mathrm{C}\right)$, it was concluded that oesophageal temperature changes could be predicted using an insulated skin temperature measured over the upper spine. To achieve this, the following equation was recommended: oesophageal temperature $=5.4784 * 0.8569 *$ insulated skin temperature (Armstrong, 2006).

Recently, Xu et al. (2013) and Niedermann et al. (2014) predicted deep-body temperature from skin temperatures, transcutaneous heat fluxes and heart rate. Unfortunately, these models were validated against gastrointestinal and rectal temperatures, the thermal inertia of which limited their utility. Nevertheless, there is merit in the approach, which should be undertaken using a more dynamically responsive, deep-body temperature index.

\section{SUPERFICIAL-TISSUE TEMPERATURE MEASUREMENTS}

Under basal (normothermic) conditions, the superficial (shell) tissues are not in a state of thermal equilibrium with either the body core or the ambient environment. Instead, the kinetic energy possessed by, and therefore the temperature of, those structures forms part of the core-to-ambient temperature gradient. Thus, those tissues are transient retainers (relays) of thermal energy, and as such, the shell compartment does not satisfy the requirements of the Zeroth Law under thermoneutral conditions, even when local skin temperatures are stable. That is, heat flux is constant.

The body shell does, however, constitute a significant portion of the thermally regulated mass (Simon, 1974; Jessen, 1996), but with much more variable temperatures than the deep-body tissues. That variability is location dependent, both among (Benedict et al., 1919; DuBois, 1941; Olesen and Fanger, 1973; Werner and Reents, 1980; Webb, 1992; Niu et al., 2001; Zaproudina et al., 2008 [Figure 12]; Marins et al., 2014) and within sites (Pennes, 1948; Livingstone et al., 1987; Frim et al., 1990). It is also time and body- 

composition dependent (Hardy, 1934b; Frim et al., 1990; Chudecka et al., 2014), as the temperatures of the shell tissues are largely dictated by thermal exchanges between the body core and surrounding environment (Bedford and Warner, 1934; Snellen, 1966; Psikuta et $a l .$, 2014). Therefore, these temperatures only provide point-specific thermal information. But since about $50 \%$ of the body is within $2.5 \mathrm{~cm}$ of the skin surface (Burton, 1935), then the shell tissues represent a significant mass and potential heat sink. Thus, a knowledge of shell temperatures is essential, as is an appreciation of their usefulness and limitations.

INSERT FIGURE 12 ABOUT HERE

\section{Subcutaneous temperatures}

The parabolic form of the body core-skin thermal gradient is well established (Benedict and Slack, 1911; Bazett and McGlone, 1927). However, few have explored subcutaneous temperatures, which represent the penultimate location along that gradient. Exceptions include Bazett and McGlone (1927), Pennes (1948), Smith (1962), Webb (1992), Cotter et al. (1996), Cotter (1998) and Zeyl et al. (2004). The initial work of Bazett and McGlone (1927) described subcutaneous temperature gradients within the initial $6 \mathrm{~mm}$ of tissue $(N=2)$. When averaged across trials, these varied from $0.22-0.48^{\circ} \mathrm{C} \cdot \mathrm{mm}^{-1}$. Subsequently, Smith (1962), revealed intramuscular-to-subcutaneous temperature gradients of $2.6^{\circ} \mathrm{C}$ (gastrocnemius), $2.0^{\circ} \mathrm{C}$ (tibialis anterior) and $1.7^{\circ} \mathrm{C}$ (intercostals) in afebrile patients prior to anaesthesia, but the ambient conditions were below thermoneutrality $\left(20.7^{\circ} \mathrm{C}\right)$ with cutaneous vasoconstriction presumably accentuating each gradient.

The most extensive investigation was that of Webb (1992), who studied subcutaneous temperatures in normothermic, seated males $(N=6$; triceps, forearm, chest, back, calf, thigh). He reported an average temperature of $33.9^{\circ} \mathrm{C}$, with simultaneous oesophageal and mean skin temperatures of $36.9^{\circ}$ and $33.5^{\circ} \mathrm{C}$. Intramuscular temperatures were measured at each of two depths (20 and $40 \mathrm{~mm}$ ) from the back and thigh (unspecified locations). At the back, the muscle-to-skin gradient was $2.7^{\circ} \mathrm{C}$, while the gradient to the subcutaneous site was $0.9^{\circ} \mathrm{C}$. For the thigh, the respective gradients were $0.8^{\circ} \mathrm{C}$ and $-0.1^{\circ} \mathrm{C}$; the negative value was not explained, nor was there evidence to indicate that it might be incorrect. 


\section{Sources of thermal variability within and among skin sites}

2 When exposed to very cold conditions, generalised cutaneous vasoconstriction maximises

3 the core-to-shell temperature gradient and minimises the shell-to-ambient gradient. Since

4 skin blood flow can decrease below the local metabolic requirement during cooling (Abramson, 1965), the primary avenue for heat exchange becomes conductive. In that state, local tissue temperatures move closer to the ambient temperature (Pennes, 1948), particularly when one is surrounded by a medium with a high thermal conductivity.

$8 \quad$ Furthermore, skin temperatures become more heterogeneous (Benedict et al., 1919;

9 Bedford, 1935; Hardy and DuBois, 1938; Sheard et al., 1941; Werner and Reents, 1980;

10 Webb, 1992), particularly at the distal sites (physiological amputation). These protective

11 mechanisms buffer heat losses, with both an elevated subcutaneous adiposity and its more

12 even distribution (e.g. women) insulating the skin from its heat source; the body core.

At the other extreme, cutaneous vasodilatation (Rowell et al., 1969, 1970) makes skin temperatures more homogeneous (Bedford, 1935; Hardy and DuBois, 1938; Sheard et al., 1941; Werner and Reents, 1980; Webb, 1992). This reduces the core-to-shell and shell-toambient thermal gradients as blood circumnavigates the subcutaneous tissues to heat the skin. This too is protective, as it minimises heat gain while optimising the mass (convective) delivery of core heat. Heat dissipation must, however, now rely upon the evaporation of sweat. Thus, we have defined the thermally mediated, physiological outer limits for skin temperatures, with the regions between those extremes being most frequently investigated.

One of those states includes the transcutaneous temperature measurements described above, the focus of which was removing local thermal gradients. Those conditions provide an extreme situation that highlights an important fact, for it follows that, whenever anything covers the skin, the temperature immediately below that cover is altered due to modifications of the local heat exchanges (reactive error).

Even though the skin is rarely equilibrated with the body core, the Zeroth Law requires thermal equilibration with the sensor, and to achieve this, both intimate contact with the skin and insulation from ambient conditions are essential. Most often, these are both obtained (or approximated) using adhesive tape to cover and secure sensor contact, with 
commercial skin sensors typically having a small insulating mass mounted on the rear surface. These characteristics modify local temperatures (reactive error), and this occurs with all contact thermometers (Hardy, 1934a, 1934b; Stoll and Hardy, 1950; Tyler, 2011). In addition, the size (heat sink) and temperature of the sensor can modify the local skin temperature when first applied (Hardy, 1934b; Sasaki and Kamada, 1952), as can the contact pressure (Stoll and Hardy, 1950; Guadagni et al., 1972; Jirák et al., 1975; Mahanty and Roemer, 1979). One must therefore not be surprised at the observation that contact and covered skin temperatures differ from each other (Buono and Ulrich, 1998; James et al., 2014) and from the corresponding non-contact values (Buono et al., 2007; Psikuta et al., 2014), particularly if bias was introduced through atypical measurement practices (Buono and Ulrich, 1998). Moreover, comparing measurement devices using human skin Therefore, if skin temperatures without bias are required, one should consider non-contact techniques that measure radiation emitted from the skin surfaces (Figure 12: Aldrich, 1928; Hardy, 1934a; Pennes, 1948; Nakayama et al., 1977, 1981; Livingstone et al., 1987; Torii et al., 1992; Vallerand et al., 1992b; Choi et al., 1997; Zaproudina et al., 2008; Costello et al., 2012; Fournet et al., 2013; Marins et al., 2014). Unfortunately, this technique cannot be used to determine skin temperatures under clothing without significant modification. The method is based on the principle that all objects with a temperature above absolute zero emit electromagnetic radiation. Thermal-imaging cameras require information concerning the efficiency with which the target object emits thermal (infrared) radiation to calculate temperature. This defines the emissivity of that object, which is a ratio, and has a value between one (black body) and zero (white body). The emissivity of human skin is 0.97-0.98 (Hardy and Muschenheim, 1934; Mitchell et al., 1967; Watmough and Oliver, 1968; Togawa, 1989), but errors in determining that value will be transferred to all calculations (Bernard et al., 2013).

Hardy (1934c) determined that water vapour above the skin did not significantly influence skin radiation. However, recent research has shown that substances on the skin surface 
1 produce emissivity changes (Bernard et al., 2013). Of relevance here is the presence of

2 moisture. Since water has a lower emissivity than skin, it lowers the overall emissivity, and

3 in their investigation, where the emissivity was set at 0.98 , it resulted in temperature errors

$4>3.0^{\circ} \mathrm{C}$. This has significant implications for measurements in sweating individuals.

\section{Skin temperatures}

As the skin represents the interface between the body and the environment, the accurate

8 measurement of its temperature is important, yet several assumptions underlie the

9 measurement of local and mean skin temperatures. The validity of those assumptions

10 depends upon what is measured and why. For example, skin temperature is sometimes

11 measured to quantify thermal gradients, and therefore heat exchanges between the body

12 surface and the environment or the deep-body tissues. The pattern and dynamic nature of

13 skin temperature changes following some perturbations (e.g. local cooling) are used in the

14 diagnostic assessment of locomotor and vascular disorders and some malignancies. In this

15 context, post-cooling increases in skin temperature are assumed, sometimes erroneously, to

16 be an analogue of skin blood flow (Davey et al., 2013). However, the actual temperature

17 obtained for these differing functions depends on the location and number of sites

18 measured, the ambient medium and its temperature, the metabolic state of the body (rest,

19 exercise) and the stimulus applied to the thermoregulatory system (thermal, chemical).

Skin temperature has most often been measured using sensors attached to the skin surface, and as noted earlier, the method of attachment can change both the dynamic response and absolute temperature. For field use, wires can become limiting, and so other devices have been developed, including telemetry-based systems, iButtons ${ }^{\circledR}$, indwelling subcutaneous sensors and infrared thermographic devices. Whilst these are not without limitations and logistical challenges, they offer alternatives, and may be the best option in some circumstances (Clark and Edholm, 1985; van Marken Lichtenbelt et al., 2006; Dugay et $a l ., 2009)$. In very dynamic phases, such as sudden immersion into cold water, skin temperatures change very rapidly, driving the autonomically evoked cold-shock responses (Tipton, 1989). Even the psychophysical responses appear closely related to local skin temperature change rates (Guéritée, 2012). Clearly, it is critical that the dynamic response characteristics of the methods are fast enough to accurately track those rapid changes. 
difficult to quantify.

Accurate skin temperature measurement is critical to measuring transcutaneous heat flux, but a frequently observed error is the assumption that the two are always synonymous. They are not. Indeed, a range of heat fluxes is possible at the same skin temperature depending, again, on the environment, physical activity and tissue insulation. For example, an increase in temperature is often taken to indicate cutaneous vasodilatation, and the corresponding and reciprocal changes in heat flux and tissue insulation. Whilst this can be the case, the quantity of heat flowing down the thermal gradient must also be considered. During exercise, for example, cutaneous vasodilatation is driven by an elevated mean body temperature (Werner et al., 2008), yet the skin temperature may be prevented from rising by the similarly activated secretion and evaporation of sweat (Clark et al., 1977; Torii et al., 1992; Gagge and Gonzalez, 1996). Nevertheless, tissue insulation actually decreases, vasodilatation occurs and 2-3 times more heat is transferred down a similar thermal gradient. Therefore, skin temperatures (turnover indices) and heat fluxes both depend upon

At exercise onset, during its progression and also at its cessation, changes in skin temperature are complex, regionally variable and often transient in nature. As one commences exercise, feedforward emanating from the rostral brain simultaneously activates motor and sympathetic neurons, producing a transitory reduction in skin blood flow whilst sweating increases (Christensen and Nielsen, 1942; van Beaumont and Bullard, 1963).

23 Therefore, the delayed rise in skin temperature noted above can also be ascribed to a shortterm reduction in the convective delivery of central heat to the periphery.

As exercise continues, there are concomitant increases in intramuscular and deep-body temperatures (Pembrey, 1898; Kenny et al., 2003, 2006; Todd et al., 2014), with the former occurring very rapidly (Figure 4). Accordingly, skin temperature directly over the working musculature rises by several degrees (Clark and Edholm, 1985), and these temperatures must deviate with regional variations in intramuscular temperature observed during exercise and recovery (Figure 11). A further complication relates to the presence of forced convective and evaporative cooling during exercise, particularly that which is performed under field conditions (Clark et al., 1977; Saunders et al., 2005). 
Of course, individual skin temperatures are determined by local heat exchanges with the muscle and environment. Therefore, since muscles generate and loose heat at different rates, then some skin regions will experience faster temperature changes than others. Since blood pools and traps heat in the dependent zones during recovery (Kenny et al., 2010; Kenny et al., 2008), those skin sites will remain warmer for longer following the cessation of exercise. Finally, when exercise stops, the thermal influences of forced convection disappear and heat production returns more slowly towards resting levels. The implication of these interactions is that the reported independence of mean skin temperature from work rate can be meaningless when considered in terms of local skin temperature changes.

Instead, absolute and regional variations in resting skin temperature depend upon local heat production, the convective delivery of heat and local heat exchanges that are powerfully influenced by ambient temperature and, to a lesser extent, the method of measurement. During exercise, these variables are further modified, but not simply by its presence, but by the exercise mode and its duration, and whether or not vasodilatation and sweating have been evoked and to what level. Other factors that influence the absolute and dynamic profile of skin temperature may include: gender, age, ethnicity, subcutaneous adiposity and

18 its distribution, and the presence of clothing and tissue damage (e.g. burns) or various

19 chemicals applied to the skin (Colucci et al., 1982; Graham et al., 1989; Inoue et al., 20 1992; Taylor et al., 1995; Gillis et al., 2010). All of these factors interact. It therefore becomes apparent that, quite apart from what may appear to be a very simple measurement, skin temperatures have very complex interactions that can always complicate, and can often confuse or defy interpretation.

\section{Combining skin temperatures into a meaningful mean}

26 Individual skin temperatures are normally combined to provide a mean skin temperature for the purposes described above. Therefore, to know that temperature with absolute precision, one must take measurements from every possible site. Since this is impossible, then the classical estimations used weighted summations of many sites, with mixing coefficients representing site-specific fractional contributions to the total body surface area (e.g. DuBois and DuBois, 1915; ISO 9886:2004). Notwithstanding this practice, the greater the number of skin sites sampled, the smaller is the fractional representation of the total surface area of each site and the greater is the accuracy of the ensuing estimation. 
1 Perhaps the most demanding method remains that proposed by Winslow et al. (1936), with

215 measurement sites advocated. At the other end of the range, there are suggestions of

3 three (Burton, 1934) and four sites (Ramanathan, 1964; Mitchell and Wyndham, 1969). Yet

4 these too have their utility, providing the experimental conditions elicit thermal

5 homogeneity across the skin surface (Teichner, 1958; Olesen, 1984), and providing one

6 accepts reduced accuracy (Olesen, 1984; Choi et al., 1997). For example, Clark et al.

7 (1977) reported a disparity of up to $4^{\circ} \mathrm{C}$ in mean skin temperatures between infrared and

8 thermocouple measurements, with the size of the difference depending upon the number of

9 sites used in the latter method. When 11-13 sites were used, the difference was $<1.5^{\circ} \mathrm{C}$.

Olesen (1984) compared ten equations for estimating mean skin temperature with the temperatures obtained from 14 unweighted skin sites chosen to represent an equal area of the body surface. It was determined that the number of sites necessary to obtain an accurate estimation of mean skin temperature was related to the extent of the intra-site variability. Thus, in warm conditions, 2-4 sites could be sufficient. For thermoneutral conditions, 4-8 sites were necessary, and in cold conditions, 8-12 sites were recommended. Olesen (1984) concluded that if one required a mean skin temperature estimate that was $95 \%$ certain to be within $0.2^{\circ} \mathrm{C}$ of its actual value, then it was necessary to measure $10-14$ sites. However, an accuracy of $1^{\circ} \mathrm{C}$ could be achieved with just 2-6 sites. Finally, since large variations in skin temperatures are apparent for sites in close proximity, then precise sensor placement during repeated trials becomes essential, yet such precision is infrequently reported or missing.

One frequently finds mean skin temperature calculations developed for use in one environment being used in inappropriate and un-validated conditions; for example, the Ramanathan (1964) method is often used in cold conditions. Therefore, careful consideration should be given to the number of sites and locations sampled; these must vary with the nature of the environment, clothing worn and responses investigated. Whilst traditional surface area weighting methods are useful for determining heat exchange at the body surface, this approach assumes an homogenous and uniform distribution of cutaneous thermoreceptors; such distributions do not exist (Hardy and Oppel, 1938). If one is looking for a relationship between cutaneous thermoafferent feedback and a thermoeffector response, then weighing coefficients might be of greater utility if based on thermoreceptor density or regional variations in cutaneous thermosensitivity. For example, when examining 
1 thermal sensation and comfort in transient and non-uniform thermal environments, one

2 might expect an improved correlation between skin temperature and the psychophysical

3 responses if a greater weighting was given to the hands and feet; which dominate thermal

4 comfort in the cold (Zhang et al., 2004). In hotter conditions, sudomotor function and the

5 psychophysical responses display regional variations in thermosensitivity (Cotter and

6 Taylor, 2005). In these circumstances, the skin temperature model used should perhaps be

7 more related to the cortical homunculus than to a thermal manikin.

9 Perhaps unsurprisingly, many of the conclusions reached for the measurement of deep-body

10 temperature also apply to the measurement of skin temperature: measurement validity

11 should be evaluated relative to the research objectives, and the responsiveness of the

12 temperature index must match the forcing function used to disturb homeostasis. It follows

13 from the above that detailed consideration should also be given to the number and

14 distribution of skin temperature measurements, and the precision and reproducibility of

15 those measures with respect to the ambient medium, its temperature, the characteristics of

16 the population sample (gender, age, ethnicity, adiposity), the interaction of exercise and the

17 use of clothing. Compromise is inevitable, if only for logistical reasons, but measurement

18 limitations should be recognised and considered when analysing and interpreting data.

\section{CONCLUSION}

21 This review was aimed at providing comprehensive theoretical and empirical justifications

22 for the selection and use of valid body temperature measurements that would best match the

23 research objectives of, and the sensitivity of the forcing functions applied within, each

24 experiment. Not all readers will accept every interpretation. However, it is hoped that

25 sufficient material has been assembled to allow such decisions to be based upon objective

26 evaluations of the available evidence. A further purpose was a possible restoration of the

27 past common knowledge concerning temperature measurements, so that some contemporary

28 misconceptions might gradually disappear. Since tissue temperatures are turnover indices

29 modified by local metabolism, tissue conduction and blood flow, it has been posited that a

30 gold standard deep-body temperature does not exist. Moreover, temperature similarities or

31 differences among sites are proposed to lack a mechanistic relationship unless those sites

32 are in close proximity, are perfused by the same blood vessels and have equivalent

33 metabolic rates. It is therefore concluded that, for thermometric computations of whole- 
1 body heat storage, the establishment of steady-state conditions is absolutely essential, as is

2 the simultaneous measurement of several deep-body temperatures. For many clinical states,

3 targeted temperature monitoring is critical. When investigating temperature regulation

4 during dynamic phases, deep-body temperatures must either be measured from the central

5 (cardiac or pulmonary) blood volume or from sites that reliably track those temperatures.

\section{ACKNOWLEDGMENTS}

8 The authors wish to pay tribute to the research careers of several scientists, the counsel and

9 guidance of whom helped shape their views and approach to science in general, and to

10 thermal physiology in particular: Frank Golden, Bill Keatinge, Jan Snellen and Paul Webb.

11 The pivotal contributions of our students and colleagues are also acknowledged, as are the

12 editorial suggestions of Jürgen Werner and Eugene Wissler during manuscript preparation.

14 Research from the authors' laboratories summarised within this review was supported, in 15 part, by funding from the following organisations. Taylor: Australian Research Council and 16 the Defence Science and Technology Organisation (Australia); Tipton: U.K. Ministry of 17 Defence, Shell U.K., and the U.K. Home Office; Kenny: Natural Sciences and Engineering

18 Research Council of Canada, Canadian Institutes of Health Research, Workplace Safety and 19 Insurance Board (Ontario) and Canada Foundation for Innovation (Leader's Opportunity 20 Fund).

\section{CONFLICT OF INTEREST}

23 There are no conflicts of interest. 


\section{REFERENCES}

Abramson, D.I. (1965). Pathophysiology of arteriovenous shunts in the extremities. Journal of Cardiovascular Surgery. Sept 5-18(Supplement):217-230.

Äikäs, E., Karvonen, M.J., Piironen, P., and Ruosteenoja, R. (1962). Intramuscular, rectal and oesophageal temperature during exercise. Acta Physiologica Scandinavica. 54:36-70.

Aldrich, L.B. (1928). A study of body radiation. Smithsonian miscellaneous collections, Volume 81, number 6. Smithsonian Institution, Washington.

Alexander, L. (1945). The treatment of shock from prolonged exposure to cold, especially in water. Combined Intelligence Objectives Subcommittee, Item No. 24, File No. 26-37, Pp. 1-228.

Alphandéry, E. (2014). Perspectives of breast cancer thermotherapies. Journal of Cancer. 5:472-479.

Amano, T., Koga, S., Inoue, Y., Nishiyasu, T., and Kondo, N. (2013). Characteristics of sweating responses and peripheral sweat gland function during passive heating in sprinters. European Journal of Applied Physiology. 113:2067-2075.

Arborelius, M.J., Balldin, U.I., Lila, B., Lundgren, C.E.G. (1972). Regional lung function in man during immersion with the head above water. Aerospace Medicine. 43:701-707.

Armstrong, K.A. (2006). Theoretical bases for the development of a personal heat strain monitor. Master of Science, University of Wollongong.

Arnold, W. (1840). A practical treatise on the bilious remittent fever; its causes and effects. John Churchill, London.

Arora, N., Martins, D., Ruggerio, D., Tousimis, E., Swistel, A.J., Osborne, M.P., and Simmons, R.M. (2008). Effectiveness of a noninvasive digital infrared thermal imaging system in the detection of breast cancer. American Journal of Surgery. 196:523-526.

Aschoff, J., and Wever, R. (1958). Kern und Schale im wärmehaushalt des menschen. Naturwissenschaften. 20:477-487.

Ash, C.J. Cook, J.R., McMurry, T.A., and Auner, C.R. (1992). The use of rectal temperature to monitor heat stroke. Missouri Medicine. 89:283-288.

Asmussen, E., and Nielsen, M. (1947). The regulation of the body-temperature during work performed with the arms and with the legs. Acta Physiologica Scandinavica. 
$14: 373-382$.

Atwater, W.O., and Rosa, E.B. (1899). Description of a new respiration calorimeter and experiments on the conservation of energy in the human body. United States; Office of Experiment Stations. Government Printing Office, Washington.

Aulick, L.H., Robinson, S., and Tzankoff, S.P. (1981). Arm and leg intravascular temperatures of men during submaximal exercise. Journal of Applied Physiology. 51:1092-1097.

Baker, N.C., Cerone, S.B., Gaze, N., and Knapp, T.R. (1984). The effect of type of thermometer and length of time inserted on oral temperature measurements of afebrile subjects. Nursing Research. 33:109-111.

Baker, M.A., Stocking, R.A., and Meehan, J.P. (1972). Thermal relationship between tympanic membrane and hypothalamus in conscious cat and monkey. Journal of Applied Physiology. 32:739-742.

Baker, F.C., Waner, J.I., Vieira, E.F., Taylor, S.R., Driver, H.S., and Mitchell, D. (2001). Sleep and 24 hour body temperatures: a comparison in young men, naturally cycling women and women taking hormonal contraceptives. Journal of Physiology. 530:565-574.

Ball, S.G., Chalmers, D.M., Morgan, A.G., Solman, A.J., and Losowsky, M.S. (1973). A clinical apraisal of transcutaneous deep body temperature. Biomedicine. 18:190194.

Barnes, R.B. (1967). Determination of body temperature by infrared emission. Journal of Applied Physiology. 22:1143-1146.

Barcroft, H., and Edholm, O.G. (1946). Temperature and blood flow in the human forearm. Journal of Physiology. 104:366-376.

Barcroft, J., and King, W.O.R. (1909). The effect of temperature on the dissociation curve of blood. Journal of Physiology. 39:374-384.

Barnason, S., Williams, J., Proehl, J., Brim, C., Crowley, M., Leviner, S., Lindauer, C., Naccarato, M., and Storer, A. (2012). Emergency nursing resource: non-invasive temperature measurement in the emergency department. Journal of Emergency Nursing. 38:523-530.

Baum, E., Brück, K., and Schwennicke, H.P. (1976). Adaptive modifications in the thermoregulatory system of long-distance runners. Journal of Applied Physiology. 40:404-410. 
Bazett, H.C., Love, L., Newton, M., Eisenberg, L., Day, R., and Forster, R. (1948). Temperature changes in blood flowing in arteries and veins in man. American Journal of Physiology. 1:3-19.

Bazett, H.C., and McGlone, B. (1927). Temperature gradients in the tissues of man. American Journal of Physiology. 82:415-451.

Beaumont, W. (1838). Experiments and observations on the gastric juice, and the physiology of digestion. MacLachlan \& Stewart, Edinburgh.

Becquerel, A, and Breschet, G. (1835). Premier mémoire sur la chaleur animale. Annales de chimie et de physique. 16:113-136.

Bedford, T. (1935). Skin temperature in relation to warmth of the environment. Journal of Hygiene. 35:307-317.

Bedford, T., and Warner, C.G. (1934). On methods of measuring skin temperature. Journal of Hygiene. 34:81-98.

Beers, Y. (1953). Introduction to the theory of error. Addison-Wesley Publishing Company, Reading, Massachusetts.

Benedict, F.G., Miles, W.R., and Johnson, A. (1919). The temperature of the human skin. Proceedings of the National Academy of Science of the United States of America. 5:218-222.

Benedict, F.G., and Slack, E.P. (1911). A comparative study of temperature fluctuations in different parts of the human body. Carnegie Institution of Washington, Washington. Publication number 155.

Benzinger, T.H. (1959). On physical heat regulation and the sense of temperature in man. Proceedings of the National Academy of Sciences of the United States of America. 45:645-659.

Benzinger, T.H. (1969). Heat regulation: homeostasis of central temperature in man. Physiological Reviews. 49:671-759.

Benzinger, T.H., and Taylor, G.W. (1963). Cranial measurements of internal temperature in man. In: Hardy, J.D. (Editor). Temperature: Its measurement and control in science and industry. Volume 3, part 3. Reinhold Publishing Corporation, New York. Pp. 111-120.

Bernard, C. (1876). Leçons sur la chaleur animale, sur les effets de la chaleur et sur la fièvre. J.-B. Baillière et Fils, Paris.

Bernard, S.A., Gray, T.W., Buist, M.D., Jones, B.M., Silvester, W., Gutteridge, G., and 
Smith, K. (2002). Treatment of comatose survivors of out-of-hospital cardiac arrest with induced hypothermia. New England Journal of Medicine. 346:557-563.

Bernard, V., Staffa, E., Mornstein, V., and Bourek, A. (2013). Infrared camera assessment of skin surface temperature--effect of emissivity. Physica Medica. 29:583-591.

Bevegård, B.S., and Shepherd, J.T. (1966). Reaction in man of resistance and capacity vessels in forearm and hand to leg exercise. Journal of Applied Physiology. 21:123-132.

Blatteis, C.M. (2007). The onset of fever: new insights into its mechanism. Progress in Brain Research. 162:3-14.

Bligh, J. (1957a). The relationship between the temperature in the rectum and of the blood in the bicarotid trunk of the calf during exposure to heat stress. Journal of Physiology. 136:393-403.

Bligh, J. (1957b). A comparison of the temperature of the blood in the pulmonary artery and in the bicarotid trunk of the calf during thermal polyponea. Journal of Physiology. 136:404-412.

Bligh, J. (1973). Temperature regulation in mammals and other vertebrates. Frontiers of Biology, Volume 30. North-Holland, Amsterdam.

Bogh, M., Minors, D.S., and Waterhouse, J.M. (1994). Can insulated skin temperature act as a substitute for rectal temperature when studying circadian rhythms? Chronobiology International. 11:332-339.

Booth, J.D., Wilsmore, B.R., MacDonald, A.D., Zeyl, A., McGhee, S., Calvert, D., Marino, F.E., Storlien, L.H., and Taylor, N.A.S. (2001). Whole-body pre-cooling does not alter human muscle metabolism during sub-maximal exercise in the heat. European Journal of Applied Physiology. 84:587-590.

Booth, J.D., Wilsmore, B.R., MacDonald, A.D., Zeyl, A., Storlien, L.H., and Taylor, N.A.S. (2004). Intramuscular temperatures during exercise in the heat following pre-cooling and pre-heating. Journal of Thermal Biology. 29:709-715.

Boulant, J.A. (1996). Hypothalamic neurons regulating body temperature. Comprehensive Physiology 2011, Supplement 14: Handbook of Physiology, Environmental Physiology: 105-126. First published in print 1996.

Brengelmann, G.L. (1987). Dilemma of body temperature measurement. In: Shiraki, K., and Yousef, M.K. (Editors). Man in stressful environments: thermal and work 
physiology. Charles C. Thomas, Springfield. Pp. 5-22.

Brengelmann, G.L. (1993). Specialized brain cooling in humans? Federation of the American Societies for Experimental Biology Journal. 7:1148-1152.

Brengelmann, G.L., Johnson, J.M., and Hong, P.A. (1979). Electrocardiographic verification of esophageal temperature probe position. Journal of Applied Physiology. 47:638-642.

Brinnel, H., and Cabanac, M. (1989). Tympanic temperature is a core temperature in humans. Journal of Thermal Biology. 14:47-53.

Brown, A.C., and Brengelmann, G.L. (1970). The interaction of peripheral and central inputs in the temperature regulation system. In: Hardy, J.D., Gagge A.P., and Stolwijk, J.A.J. (Editors). Physiological and behavioral temperature regulation. Thomas, Springfield, Ill. Pp. 684-702.

Buchthal, F., Høncke, P., and Lindhard, J. (1945). Temperature measurement in human muscles in situ at rest and during muscular work. Acta Physiologica Scandinavica. $8: 230-258$.

Buono, M.J., Heaney, J.H., and Canine, K.M. (1998). Acclimation to humid heat lowers resting core temperature. American Journal of Physiology. 274:R1295-R1299.

Buono, M.J., Holloway, B., Levine, A., Rasmussen, C., and Kolkhorst, F.W. (2014). Effect of air temperature on the rectal temperature gradient at rest and during exercise. International Journal of Physiology, Pathophysiology and Pharmacology. 6:61-65.

Buono, M.J., Jechort, A., Marques, R., Smith, C., and Welch, J. (2007). Comparison of infrared versus contact thermometry for measuring skin temperature during exercise in the heat. Physiological Measurement. 28:855-859.

Buono, M.J., and Ulrich, R.L. (1998). Comparison of mean skin temperature using 'covered' versus 'uncovered' contact thermistors. Physiological Measurement. 19:297-300.

Burton, A,C. (1934). A new technic for the measurement of average skin temperature over surfaces of the body and the changes of skin temperature during exercise. Journal of Nutrition. 7:481-496.

Burton, A,C. (1935). Human calorimetry: II. The average temperature of the tissues of the body. Journal of Nutrition. 9:261-280.

Burton, A,C., and Bazett, H.C. (1936). A study of the average temperature of the tissues, 
of the exchanges of heat and vasomotor responses in man by means of a bath calorimeter. American Journal of Physiology. 117:36-54.

Burton, A.C., and Edholm, O.G. (1955). Man in a cold environment: physiological and pathological effects of exposure to low temperatures. Hafner Publishing Company, New York.

Buxton, C.L., and Atkinson, W.B. (1948). Hormonal factors involved in the regulation of basal body temperature during the menstrual cycle and pregnancy. Journal of Clinical Endocrinology and Metabolism. 8:544-549.

Byrne, C., and Lim, C.L. (2007). The ingestible telemetric body core temperature sensor: a review of validity and exercise applications. British Journal of Sports Medicine. 41:126-133.

Cabanac, M. (1993). Selective brain cooling in humans: "fancy" or fact? Federation of the American Societies for Experimental Biology Journal. 7:1143-1146.

Cabanac, M., and Caputa, M. (1979) Natural selective cooling of the human brain: evidence of its occurrence and magnitude. Journal of Physiology. 286:255-264.

Caldwell, J.N., Matsuda-Nakamura, M., and Taylor, N.A.S. (2014). Three-dimensional interactions of mean body and local skin temperatures in the control of hand and foot blood flows. European Journal of Applied Physiology. Epub ahead of print. DOI: $10.1007 / \mathrm{s} 00421-014-2894-\mathrm{X}$

Campbell, S.S., and Broughton, R.J. (1994). Rapid decline in body temperature before sleep: fluffing the physiological pillow? Chronobiology International. 11:126-131.

Cannon, W.B. (1929). Organisation for physiological homeostasis. Physiological Reviews. 9: 399-431.

Caputa, M. (1980). Thermal gradients in the oesophagus of man during exercise and passive warming. Journal of Thermal Biology. 5:249-251.

Carter, K.B., and Perry, A.M. (1977). An assessment of a non-invasive technique for measuring deep body temperature. Journal of Medical Engineering and Technology. $1: 29-32$.

Casa, D.J., Kenny, G.P., and Taylor, N.A.S. (2010). Immersion treatment for exertional hyperthermia: cold or temperate water? Medicine and Science in Sports and Exercise. 42:1246-1252.

Castle, S.C., Yeh, M., Toledo, S., Yoshinkawa, T.T., and Norman, D.C. (1993). Lowering the temperature criterion improves detection of infections in nursing home 
residents. Aging: Immunology and Infectious Disease. 4:67-76.

Chamberlain, J.M., Terndrup, T.E., Alexander, D.T., Silverstone, F.A., Wolf-Klein, G., O’Donnell, R., and Grandner, J. (1995). Determination of normal ear temperature with an infrared emission detection thermometer. Annals of Emergency Medicine. 25:15-20.

Childs, C., Harrison, R., and Hodkinson, C. (1999). Tympanic membrane temperature as a measure of core temperature. Archives of Disease in Childhood. 80:262-266.

Childs, C., and Lunn, K.W. (2013). Clinical review: Brain-body temperature differences in adults with severe traumatic brain injury. Critical Care. 17:222.

Choi, J.K., Miki, K., Sagawa, S., Shiraki, K. (1997). Evaluation of mean skin temperature formulas by infrared thermography. International Journal of Biometeorology. $41: 68-75$.

Christensen, E.H., and Nielsen, M. (1942). Investigations of the circulation in the skin at the beginning of muscular work. Acta Physiologica Scandinavica. 4:162-170.

Chudecka, M., Lubkowska, A., and Kempińska-Podhorodecka, A.( 2014). Body surface temperature distribution in relation to body composition in obese women. Journal of Thermal Biology. 43:1-6.

Clark, R.P., and Edholm, O.G. (1985). Man and his thermal environment. Edward Arnold Limited, London.

Clark, R.P., Mullan, B.J., and Pugh, L.G.C.E. (1977). Skin temperature during running a study using infra-red colour thermography. Journal of Physiology. 267:53-62.

Colucci, W.S., Gimbrone, M.A., McLaughlin, M.K., Halpern, W., and Alexander, R.W. (1982). Increased vascular catecholamine sensitivity and alpha-adrenergic receptor affinity in female and oestrogen-treated male rats. Circulation Research. 50:805-811.

Collins, K.J., Dore, C., Exton-Smith, A.N., Fox, R.H., MacDonald, I.C., and Woodward, P.M. (1977). Accidental hypothermia and impaired temperature homoeostasis in the elderly. British Medical Journal. 1(6057):353-356.

Conn, A.W., Miyasaka, K., Katayama, M., Fujita, M., Orima, H., Barker, G., and Bohn, D. (1995). A canine study of cold water drowning in fresh versus salt water. Critical Care Medicine. 23:2029-2037.

Consolazio, C.F., Johnson, R.E., and Pecora, L.J. (1963). Physiological variability in young men. In: Physiological measurements of metabolic functions in man. 
McGraw-Hill Book Company, New York. Pp. 453-480.

Cooper, K.E., Cranston, W.I., and Snell, E.S. (1964). Temperature in the external auditory meatus as an index of central temperature changes. Journal of Applied Physiology. 19:1032-1035.

Cooper, K.E., and Kenyon, J.R. (1957). A comparison of temperatures measured in the rectum, oesophagus, and on the surface of the aorta during hypothermia in man. British Journal of Surgery. 44:616-619. thermometry in a hot environment. International Journal of Sports Medicine. 29:713-718.

Costello, J.T., McInerney, C.D., Bleakley, C.M., Selfe, J., and Donnelly, A.E. (2012). The use of thermal imaging in assessing skin temperature following cryotherapy: a review. Journal of Thermal Biology. 37:103-110.

Cotter, J.D. (1998). The role of regional skin temperatures in thermoregulatory control during heat stress. Doctor of Philosophy, University of Wollongong, Australia.

Cotter, J.D., Patterson, M.J., and Taylor, N.A.S. (1995). Topography of eccrine sweating in humans during exercise. European Journal of Applied Physiology. 71:549-554.

Cotter, J.D., and Taylor, N.A.S. (2005). Distribution of cutaneous sudomotor and alliesthesial thermosensitivity in mildly heat-stressed humans: an open-loop approach. Journal of Physiology. 565:335-345.

Cotter, J.D., Webb, P., Wilsmore, B.R., and Taylor, N.A.S. (1996). Evaluating thermal inputs for the sweat of regulation in humans. Proceedings of the Australian Physiological and Pharmacological Society. 27:126P.

Coyne, M.D., Kesick, C.M., Doherty, T.J., Kolka, M.A., and Stephenson, L.A. (2000). Circadian rhythm changes in core temperature over the menstrual cycle: method for noninvasive monitoring. American Journal of Physiology. 279:R1316-R1320.

Craig, J.V., Lancaster, G.A., Taylor, S., Williamson, P.R., and Smyth, R.L. (2002). Infrared ear thermometry compared with rectal thermometry in children: a systematic review. Lancet. 360(9333):603-609.

Craig, J.V., Lancaster, G.A., Williamson, P.R., and Smyth, R.L. (2000). Temperature measured at the axilla compared with rectum in children and young people: systematic review. British Medical Journal. 320(7243):1174-1178.

Cranston, W.I., Gerbrandy, J., and Snell, E.S. (1954). Oral, rectal and oesophageal 
temperatures and some factors affecting them in man. Journal of Physiology. 126:347-358.

Currie, J. (1797). Medical reports on the effects of water, cold and warm, as a remedy in fever, and febrile diseases; whether applied to the surface of the body, or used as a drink: with observations on the nature of fever; and on the effects of opium, alcohol, and inanition. Cadell and Davies, London.

Currie, J., and Percival, T. (1792). An account of the remarkable effects of a shipwreck on the mariners; with experiments and observations on the influence of immersion in fresh and salt water, hot and cold, on the powers of the living body. Philosophical Transactions of the Royal Society of London. 82:199-224.

Daanen, H.A.M. (2006). Infrared tympanic temperature and ear canal morphology. Journal of Medical Engineering and Technology. 30:224-234. sublingual and axillary temperatures in elderly afebrile patients in a warm environment. Age and Ageing. 20:113-119.

\section{Davy, J. (1814). An account of some experiments on animal heat. Philosophical} Transactions of the Royal Society of London. 104:590-603.

Davey, M., Eglin, C., House, J., and Tipton, M. (2013). The contribution of blood flow to the skin temperature responses during a cold sensitivity test. European Journal of Applied Physiology. 113:2411-2417.

Deakin, C.D. (1998). Changes in core temperature compartment size on induction of general anaesthesia. British Journal of Anaesthesia. 81:861-864.

Dellinger, R.P., Levy, M.M., Rhodes, A., Annane, D., Gerlach, H., Opal, S.M., Sevransky, J.E., Sprung, C.L., Douglas, I.S., Jaeschke, R., Osborn, T.M., Nunnally, M.E., Townsend, S.R., Reinhart, K., Kleinpell, R.M., Angus, D.C., Deutschman, C.S., Machado, F.R., Rubenfeld, G.D., Webb, S., Beale, R.J., Vincent, J.L., and Moreno, R.; Surviving Sepsis Campaign Guidelines Committee including The Pediatric Subgroup. (2013). Surviving Sepsis Campaign: international guidelines for management of severe sepsis and septic shock, 2012. Intensive Care Medicine. 39:165-228.

Dollberg, S., Xi, Y., and Donnelly, M.M. (1993). A noninvasive transcutaneous alternative to rectal thermometry for continuous measurement of core temperature in the piglet. Pediatric Research. 34:512-517. 
Dreosti, A.O. (1935). The results of some investigations into the medical aspects of deep mining on the Witwatersrand. Journal of the Chemical, Metallurgical and Mining Society of South Africa. 6:102-129.

DuBois, E.F. (1941). The temperature of the human body in health and disease. In: American Institute of Physics. Temperature: Its measurement and control in science and industry. Reinhold Publishing Corporation, New York. Pp. 24-40.

DuBois E.F. (1951). The many different temperatures of the human body and its parts. Western Journal of Surgery, Obstetrics, and Gynecology. 59:476-490.

DuBois, D., and DuBois, E.F. (1915). Fifth paper. The measurement of the surface area of man. Archives of Internal Medicine. 15:868-881.

Ducharme, M.B., McLellan, T.M., Moroz, D., Buguet, A., and Radomski, M.W. (2001). A 36-hour comparison of core temperature at rest and during exercise using rectal probe and pill telemetry. Proceedings of the Australian Physiological and Pharmacological Society. 32(Supplement 1):28P.

Dugay, M.V., Sparrow, E.M., and Boetcher, S.K.S. (2009). Errors in skin temperature measurements. 2008 Proceedings of the ASME Summer Heat Transfer Conference, HT 2008. Volume 3, Pp. 341-346.

Durotoye, A.O., and Grayson, J. (1971). Heat production in the gastro-intestinal tract of the dog. Journal of Physiology. 214:417-426.

Easton, C., Fudge, B.W., and Pitsiladis, Y.P. (2007). Rectal, telemetry pill and tympanic membrane thermometry during exercise heat stress. Journal of Thermal Biology. 32:78-86.

Edwards, R.J., Belyavin, A.J., and Harrison, M.H. (1978). Core temperature measurement in man. Aviation, Space and Environmental Medicine. 49:1289-1294.

Edwards, R.H.T., Hill, D.K., and Jones, D.A. (1975). Heat production and chemical changes during isometric contractions of the human quadriceps muscle. Journal of Physiology. 251:303-315.

Edwards, B., Waterhouse, J., Reilly, T., and Atkinson, G. (2002). A comparison of the suitabilities of rectal, gut, and insulated axilla temperatures for measurement of the circadian rhythm of core temperature in field studies. Chronobiology International. 19:579-597.

Eglin, C.M., Coles, S., and Tipton, M.J. (2004). Physiological responses of fire-fighter instructors during training exercises. Ergonomics. 47:483-494. 
Eglin, C.M., Golden, F.StC., and Tipton, M.J. (2013). Cold sensitivity test for individuals with non-freezing cold injury: the effect of prior exercise. Extreme Physiology \& Medicine. 2:16.

Eichna, L.W. (1949). Thermal gradients in man; comparison of temperatures in the femoral artery and femoral vein with rectal temperatures. Archives of Physical Medicine and Rehabilitation. 30:584-593.

Eichna, L.W., Berger, A.R., Rader, B., and Becker, W.H. (1951). Comparison of intracardiac and intravascular temperatures with rectal temperatures in man. Journal of Clinical Investigation. 30:353-359.

Emmanuel, A.V., and Kamm, M.A. (1999). Laser Doppler measurement of rectal mucosal blood flow. Gut. 45:64-69.

Emmanuel, A.V., Kamm, M.A., and Beard, R.W. (2000). Reproducible assessment of vaginal and rectal mucosal and skin blood flow: laser doppler fluximetry of the pelvic microcirculation. Clinical Science. 98:201-207.

Erickson, R. (1980). Oral temperature differences in relation to thermometer and technique. Nursing Research. 29:157-164.

Erickson, R.S., and Woo, T.M. (1994). Accuracy of infrared ear thermometry and traditional temperature methods in young children. Heart \& Lung. 23:181-195.

Eriksson, H., Svärdsudd, K., Larsson, B., Welin, L., Ohlson, L.-O., and Wilhelmsen, L. (1985). Body temperature in general population samples. The study of men born in 1913 and 1923. Acta Medica Scandinavica. 217:347-352.

Ferguson, R.A., Ball, D., and Sargeant, A.J. (2002). Effect of muscle temperature on rate of oxygen uptake during exercise in humans at different contraction frequencies. Journal of Experimental Biology. 205:981-987.

Fogarty, A.L., Armstrong, K.A., Gordon, C.J., Groeller, H., Woods, B.F., Stocks, J.M., and Taylor, N.A.S. (2004). Cardiovascular and thermal consequences of protective clothing: a comparison of clothed and unclothed states. Ergonomics. 47:1073-1086.

Foundation for Research on Information Technologies in Society (2013). Database of tissue properties. Zurich, Switzerland. http://www.itis.ethz.ch/itis-for-health/tissue-properties/database/heat-capacity/ 
Accessed: June $8^{\text {th }}, 2014$.

Fourier, J.-B.-J. (1807). Théorie de la propagation de la chaleur dans les solides. Monograph submitted to the Institute de France, December 1807.

Fournet, D., Rossa, L., Voelcker, T., Redortier, B., and Havenith, G. (2013). Body mapping of thermoregulatory and perceptual responses of males and females running in the cold. Journal of Thermal Biology. 38:339-344.

Fox, R.H., Goldsmith, R., and Wolff, H.S. (1961). The use of a radio pill to measure body temperature. Journal of Physiology. 160:22P-23P.

Fox, R.H., and Solman, A.J. (1971). A new technique for monitoring the deep body temperature in man from the intact skin surface. Journal of Physiology. 212:8P$10 \mathrm{P}$.

Fox, R.H., Solman, A.J., Isaacs, R., Fry, A.J., and MacDonald, I.C. (1973a). A new method for monitoring deep body temperature from the skin surface. Clinical Science. 44:81-86.

Fox, R.H., Woodward, P.M., Exton-Smith, A.N., Green, M.F., Donnison, D.V., and Wicks, M.H. (1973b). Body temperatures in the elderly: a national study of physiological, social, and environmental conditions. British Medical Journal. 1(5847):200-206.

Fox, R.H., Woodward, P.M., Fry, A.J., Collins, J.C., and MacDonald, I.C. (1971). Diagnosis of accidental hypothermia of the elderly. Lancet. 1(7696):424-427.

Frim, J., Livingstone, S.D., Reed, L.D., Nolan, R.W., and Limmer, R.E. (1990). Body composition and skin temperature variation. Journal of Applied Physiology. 68:540-543.

Fulbrook, P. (1993). Core temperature measurement in adults: a literature review. Journal of Advance Nursing. 18:1451-1460.

Fusco, M.M. (1963). Temperature pattern throughout the hypothalamus in the resting dog. In: Hardy, J.D. (Editor). Temperature: Its measurement and control in science and industry. Volume 3, part 3. Reinhold Publishing Corporation, New York. Pp. 585587.

Gagge, A.P. (1936). The linearity criterion as applied to partitional calorimetry. American Journal of Physiology. 116:656-668.

Gagge, A.P., and Gonzalez, R.R. (1996). Mechanisms of heat exchange: biophysics and physiology. Comprehensive Physiology 2011, Supplement 14: Handbook of 
Physiology, Environmental Physiology: 45-84. First published in print 1996.

Gagge, A.P., and Hardy, J.D. (1967). Thermal radiation exchange of the human by partitional calorimetry. Journal of Applied Physiology. 23:248-258.

Gagge, A.P., Nishi, Y. (1977). Heat exchange between human skin surface and thermal environment. Comprehensive Physiology 2011, Supplement 26: Handbook of Physiology, Reactions to Environmental Agents: 69-92. First published in print 1977.

Ganio, M.S., Brown, C.M., Casa, D.J., Becker, S.M., Yeargin, S.W., McDermott, B.P., Boots, L.M., Boyd, P.W., Armstrong, L.E., and Maresh, C.M. (2009). Validity and reliability of devices that assess body temperature during indoor exercise in the heat. Journal of Athletic Training. 44:124-135.

Gant, N., Atkinson, G., and Williams, C. (2006). The validity and reliability of intestinal temperature during intermittent running. Medicine and Science in Sports and Exercise. 38:1926-1931.

Gass, G.C., Camp, E.M., Nadel, E.R., Gwinn, T.H., and Engel, P. (1988). Rectal and rectal vs. esophageal temperatures in paraplegic men during prolonged exercise. Journal of Applied Physiology. 64:2265-2271.

Gass, E.M., and Gass, G.C. (1998). Rectal and esophageal temperatures during upper- and lower-body exercise. European Journal of Applied Physiology. 78:38-42.

Gephart, F.C., and DuBois, E.F. (1915). Fourth paper. The determination of the basal metabolism of normal men and the effect of food. Archives of Internal Medicine. $15: 835-867$.

Gibbons, L.V. (1967). Body temperature monitoring in the external auditory meatus. Aerospace Medicine. 38:671-675.

Gibson, T.M., Redman, P.J., and Belyavin, A.J. (1981). Prediction of oesophageal temperatures from core temperatures measured at other sites in man. Clinical Physics and Physiological Measurement. 2:247-252.

Gillis, D.J., House, J.R., and Tipton, M.J. (2010). The influence of menthol on thermoregulation and perception during exercise in warm, humid conditions. European Journal of Applied Physiology. 110:609-618.

Gisolfi C, and Robinson, S. (1970). Venous blood distribution in the legs during intermittent treadmill work. Journal of Applied Physiology. 29:368-373.

Golden, F.St.C. (1979). Physiological changes in immersion hypothermia, with special 
reference to factors which may be responsible for death in the early re-warming phase. Doctoral Thesis, University of Leeds.

Golden, F.St.C., and Hervey, G.R. (1981). The 'after-drop' and death after rescue from immersion in cold water. In: Adam, J.M. (Editor). Hypothermia ashore and afloat. Aberdeen University Press. Pp. 37-56.

Gollan, F. (1959). Physiology of deep hypothermia by total body perfusion. Annals of the New York Academy of Science. 80:201-314.

González-Alonso, J. (2012). Human thermoregulation and the cardiovascular system. Experimental Physiology. 97:340-346.

González-Alonso, J., Quistorff, B., Krustrup, P., Bangsbo, J., and Saltin, B. (2000). Heat production in human skeletal muscle at the onset of intense dynamic exercise. Journal of Physiology. 524:603-615.

Goodman, D.A., Kenefick, R.W., Cadarette, B.S., and Cheuvront, S.N. (2009). Influence of sensor ingestion timing on consistency of temperature measures. Medicine and Science in Sports and Exercise. 41:597-602.

Graf, M. (1959). Patterns of human liver temperature. Acta Physiologica Scandinavica. 46(Supplement 160):5-135.

Graham, T.E., Viswanathan, M., Van Dijk, J.P., Bonen, A., and George, J.C. (1989). Thermal and metabolic responses to cold by men and by eumenorrheic and amenorrheic women. Journal of Applied Physiology. 67:282-290.

Granger, D.N., and Kvietys, P.R. (1981). The splanchnic circulation: intrinsic regulation. Annual Review of Physiology. 43:409-418.

Grayson, J. (1950). Observations on blood flow in human intestine. British Medical Journal. 2(4695):1465-1470.

Grayson, J. (1951). Observations on the temperature of the human rectum. British Medical Journal. 2(4744):1379-1382.

Greenleaf, J.E., and Castle, B.L. (1972). External auditory canal temperature as an estimate of core temperature. Journal of Applied Physiology. 32:194-198.

Grigg, G.C., Beard, L.A., and Augee, M.L. (2004). The evolution of endothermy and its diversity in mammals and birds. Physiological and Biochemical Zoology. 77:982997.

Guadagni, D.N., Kreith, F., Smyth, C.J., and Bartholomew, B.A. (1972). Contact probe for skin temperature measurements. Journal of Physics E: Scientific Instruments. 
5:869-876.

Guéritée, J. (2012). Thermal comfort during and following immersion. Doctor of Philosophy, University of Portsmouth, England.

Guidry, A.J., and McDowell, R.E. (1966). Tympanic membrane temperature for indicating rapid changes in body temperature. Journal of Diary Science. 49:74-77.

Gunga, H.-C., Sandsund, M., Reinertsen, R.E., Sattler, F., and Koch, J. (2008). A non-invasive device to continuously determine heat strain in humans. Journal of Thermal Biology. 33:297-307.

Haldane, J.S. (1905). The influence of high temperatures. Journal of Hygiene. 5:494-513. the estimation of exercise core temperature by infrared tympanic thermometry. Australian Journal of Science and Medicine in Sport. 26:26-31.

Hansen, J.T., and Netter, F.H. (2010). Netter's clinical anatomy. Second Edition. Saunders Elsevier, Philadelphia.

Hardy, J.D. (1934a). The radiation of heat from the human body: I. An instrument for measuring the radiation and surface temperature of the skin. Journal of Clinical Investigation. 13:593-604.

Hardy, J.D. (1934b). The radiation of heat from the human body: II. A comparison of some methods of measurement. Journal of Clinical Investigation. 13:605-614.

Hardy, J.D. (1934c). The radiation of heat from the human body: III. The human skin as a black-body radiator. Journal of Clinical Investigation. 13:615-620.

Hardy, J.D. (1954). Control of heat loss and heat production in physiologic temperature regulation. Harvey Lecture. 49:242-270.

Hardy, J.D., and DuBois, E.F. (1938). Basal metabolism, radiation, convection and vaporization at temperatures of 22 to $35^{\circ} \mathrm{C}$. Journal of Nutrition. 15:477-497.

Hardy, J.D., Hellon, R.F., and Sutherland, K. (1964). Temperature sensitive neurones in the dog's hypothalamus. Journal of Physiology. 175:242-253.

Hardy, J.D. and Muschenheim, C. (1934). The radiation of heat from the human body. IV. The emission, reflection, and transmission of infra-red radiation by the human skin. Journal of Clinical Investigation. 13:817-831.

Hardy, J.D., and Oppel, T.W. (1938). Studies in temperature sensation. IV The stimulation of cold sensation by radiation. Journal of Clinical Investigation. 17:771-778.

Hayward, J.N., and Baker, M.A. (1968). Role of cerebral arterial blood in the regulation 
of brain temperature in the monkey. American Journal of Physiology. 215:389-403.

Hayward, J.S., Eckerson, J.D., and Kemna, D. (1984). Thermal and cardiovascular changes during three methods of resuscitation from mild hypothermia. Resuscitation. 11:21-33.

Hayward, J.N., Smith, E., and Stuart, D.G. (1966). Temperature gradients between arterial blood and brain in the monkey. Proceedings of the Society for Experimental Biology and Medicine. 121:547-551.

Hellekant, G. (1976). The blood circulation of the tongue. Frontiers of Oral Physiology. $2: 130-145$.

He, Q., Zhu, L., and Weinbaum, S. (2003). Effect of blood flow on thermal equilibration and venous rewarming. Annals of Biomedical Engineering. 31:659-666.

Hertzman, A.B., Randall, W.C., Peiss, C.N., Ederstrom, H.E., and Seckendorf, R. (1952). A method of partitional calorimetry of individual skin areas. American Journal of Physical Medicine. 31:170-181.

Hissink Muller, P.C., van Berkel, L.H., and de Beaufort, A.J. (2008). Axillary and rectal temperature measurements poorly agree in newborn infants. Neonatology. 94:31-34.

Holmgren, A., Mossfeldt, F., Sjöstrand, T., and Ström, G. (1960). Effect of training on work capacity, total hemoglobin, blood volume, heart volume and pulse rate in recumbent and upright positions. Acta Physiologica Scandinavica. 50:72-83.

Horvath, S.M., Menduke, H., and Piersol, G.M. (1950a). Oral and rectal temperatures of man. Journal of the American Medical Association. 144:1562-1565.

Horvath, S.M., Rubin, A., and Foltz, E.L. (1950b). Thermal gradients in the vascular system. American Journal of Physiology. 161:316-322.

Houdas, Y., and Ring, E.F.J. (1982). Human body temperature. Its measurement and regulation. Plenum Press, New York.

Houmard, J.A., Costill, D.L., Davis, J.A., Mitchell, J.B., Pascoe, D.D., and Robergs, R.A. (1990). The influence of exercise intensity on heat acclimation in trained subjects. Medicine and Science in Sports and Exercise. 22:615-620.

Hunt, R.T. (1844). On the cause of death in fever. Provincial Medical and Surgical Journal. 8:71-74.

Ilsley, A.H., Rutten, A.J., and Runciman, W.B. (1983). An evaluation of body temperature measurement. Anaesthesia and Intensive Care. 11:31-39.

Ingram, D.L., and Smith, R.E. (1970). Brain temperature and cutaneous blood flow in the 
anesthetized pig. Journal of Applied Physiology. 29:698-704.

Inoue, Y., Nakao, M., Araki, T., and Ueda, H. (1992). Thermoregulatory responses of young and older men to cold exposure. European Journal of Applied Physiology. 65:492-498.

ISO 9886:2004. (2004). Ergonomics - evaluation of thermal strain by physiological measurements. Second International Standard Organisation, Geneva.

Ivanov, V., Konstantinov, N., Danilova, N., Sleptchuck, G., and Rumiantsev, G. (1986). Thermoreceptor distribution in different skin layers and its significance for thermoregulation. Journal of Thermal Biology. 11:25-29.

Ivy, A.C. (1944). What is normal or normality? Quarterly Bulletin of the Northwestern University Medical School. 18:22-32.

Jaeger, J.J., Deal, E.C., Roberts, D.E., Ingram, R.H., and McFadden, E.R. (1980). Cold air inhalation and esophageal temperature in exercising humans. Medicine and Science in Sports and Exercise. 12:365-369.

James, C.A., Richardson, A.J., Watt, P.W., and Maxwell, N.S. (2014). Reliability and validity of skin temperature measurement by telemetry thermistors and a thermal camera during exercise in the heat. Journal of Thermal Biology. 45:141-149.

Jay, O., DuCharme, M.B., Webb, P., Reardon, F.D., and Kenny, G.P. (2010). Estimating changes in volume-weighted mean body temperature using thermometry with an individualized correction factor. American Journal of Physiology. 299:R387-R394.

Jay, O., Gariépy, L.M., Reardon, F.D., Webb, P., Ducharme, M.B., Ramsay, T., and Kenny, G.P. (2007a). A three-compartment thermometry model for the improved estimation of changes in body heat content. American Journal of Physiology. 292:R167-R175.

Jay, O., Reardon, F.D., Webb, P., Ducharme, M.B., Ramsay, T., Nettlefold, L., and Kenny, G.P. (2007b). Estimating changes in mean body temperature for humans during exercise using core and skin temperatures is inaccurate even with a correction factor. Journal of Applied Physiology. 103:443-451.

Jessen, C. (1996). Interaction of body temperatures in control of thermoregulatory effector mechanisms. Comprehensive Physiology 2011, Supplement 14: Handbook of Physiology, Environmental Physiology: 127-138. First published in print 1996. Jirák, Z., Jokl, M., Stverák, J., Pechlát, R., and Coufalov, H. (1975). Correction factors in skin temperature measurement. Journal of Applied Physiology. 38:752-756. 
Johansen, L.B., Jensen, T.U., Pump, B., and Norsk, P. (1997). Contribution of abdomen and legs to central blood volume expansion in humans during immersion. Journal of Applied Physiology. 83:695-699.

Joule, J.P. (1850). On the mechanical equivalent of heat. Philosophical Transactions of the Royal Society of London. 140:61-82.

Karmani, S. (2006). The thermal properties of bone and the effects of surgical intervention. Current Orthopaedics. 20:52-58.

Keatinge, W.R., and Sloan, R.E. (1975). Deep body temperature from aural canal with servo-controlled heating to outer ear. Journal of Applied Physiology. 38:919-921.

Keeling, W.F., and Martin, B.J. (1987). Gastrointestinal transit during mild exercise. Journal of Applied Physiology. 63:978-981. Turgeon, W. (1985). Screening for hypothermia in the ambulatory elderly. The Maine experience. Journal of the American Medical Association. 254:1781-1784.

Kenny, G.P., Gagnon, D., Dorman, L.E., Hardcastle, S.G., and Jay, O. (2010). Heat balance and cumulative heat storage during exercise performed in the heat in physically active younger and middle-aged men. European Journal of Applied Physiology. 109:81-92.

Kenny, G.P., and Jay, O. (2007). Sex differences in postexercise esophageal and muscle tissue temperature response. American Journal of Physiology. 292:R1632-R1640.

Kenny, G.P., and Jay, O. (2013). Thermometry, calorimetry and mean body temperature during heat stress. Comprehensive Physiology. 3:1689-1719.

Kenny, G.P., Jay, O., Zaleski, W., Reardon, M.L., Sigal, R.J., Journeay, W.S., and Reardon, F.D. (2006). Postexercise hypotension causes a prolonged perturbation in esophageal and active muscle temperature recovery. American Journal of Physiology. 291:R580-R588.

Kenny, G.P., Reardon, F.D., Zaleski, W., Reardon, M.L., Haman, F., and Ducharme, M.B. (2003). Muscle temperature transients before, during, and after exercise measured using an intramuscular multisensor probe. Journal of Applied Physiology. 94:2350-2357.

Kenny, G.P., Webb, P., Ducharme, M.B., Reardon, F.D., and Jay, O. (2008). Calorimetric measurement of postexercise net heat loss and residual body heat storage. Medicine and Science in Sports and Exercise. 40:1629-1636. 
Kistemaker, J.A., Den Hartog, E.A., and Daanen, H.A.M. (2006). Reliability of an infrared forehead skin thermometer for core temperature measurements. Journal of Medical Engineering and Technology. 30:252-261.

Kitamura, K., Zhu, X., Chen, W., and Nemoto, T. (2010). Development of a new method for the noninvasive measurement of deep body temperature without a heater. Medical Engineering and Physics. 32:1-6.

Kiyatkin, E.A. (2007). Brain temperature fluctuations during physiological and pathological conditions. European Journal of Applied Physiology. 101:3-17.

Kobayashi, T., Nemoto, T., Kamiya, A., and Togawa, T. (1975). Improvement of deep body thermometer for man. Annals of Biomedical Engineering. 3:181-188.

Kolanowski, A., and Gunter, L. (1981). Hypothermia in the elderly. Geriatric Nursing. 2:362-365.

Kolka, M.A., Levine, L., and Stephenson, L.A. (1997). Use of an ingestible telemetry sensor to measure core temperature under chemical protective clothing. Journal of Thermal Biology. 22:343-349.

Kolka, M.A., Quigley, M.D., Blanchard, L.A., Toyota, D.A., and Stephenson, L.A. (1993). Validation of a temperature telemetry system during moderate and strenuous exercise. Journal of Thermal Biology. 18:203-210.

Korpelainen, J.T., Sotaniemi, K.A., and Myllylä, V.V. (1995). Asymmetrical skin temperature in ischemic stroke. Stroke. 26:1543-1547.

Ladell, W.S.S. (1951). Assessment of group acclimatization to heat and humidity. Journal of Physiology. 115:296-312.

Landolt, H.P., Moser, S., Wieser, H.G., Borbély, A.A., and Dijk, D.J. (1995). Intracranial temperature across 24-hour sleep-wake cycles in humans. NeuroReport. 6:913-917.

Langer, F., and Fietz, J. (2014). Ways to measure body temperature in the field. Journal of Thermal Biology. 42:46-51.

Lavery, L.A., Higgins, K.R., Lanctot, D.R., Constantinides, G.P., Zamorano, R.G., Armstrong, D.G., Athanasiou, K.A., and Agrawal, C.M. (2004). Home monitoring of foot skin temperatures to prevent ulceration. Diabetes Care. 27:2642-2647.

Lavoisier, A.L., and de Laplace, P.-S. (1780). Mémoire sur la Chaleur. Mémoires de l'Académie des Sciences. 355-408.

Lee, J.-Y., Nakao, K., Takahashi, N., Son, S.Y., Bakri, I., and Tochihara, Y. (2011) 
Validity of infrared tympanic temperature for the evaluation of heat strain while wearing impermeable protective clothing in hot environments. Industrial Health. 49:714-725.

Lee, J.-Y., Wakabayashi, H., Wijayanto, T., and Tochihara, Y. (2010). Differences in rectal temperatures measured at depths of 4-19 $\mathrm{cm}$ from the anal sphincter during exercise and rest. European Journal of Applied Physiology. 109:73-80.

Lee, S.M.C., Williams, W.J., Fortney Schneider, S.M. (2000). Core temperature measurement during supine exercise: esophageal, rectal, and intestinal temperatures. Aviation, Space and Environmental Medicine. 71:939-945.

Lees, D.E., Kim, Y.D., and Macnamara, T.E. (1980). Noninvasive determination of core temperature during anesthesia. Southern Medical Journal. 73:1322-1324.

Leslie, P.D., (1778). A philosophical inquiry into the cause of animal heat: with incidental observations on several phisiological and chymical questions, connected with the subject. Gordon, A., and Elliot, C., Edinburgh.

Lewit, E.M., Marshall,C.L., and Salzer, J.E. (1982). An evaluation of a plastic strip thermometer. Journal of the American Medical Association. 247:321-325.

Libert, J.P., Candas, V., Sagot, J.C., Meyer, J.P., Vogt, J.J., and Ogawa, T. (1984). Contribution of skin thermal sensitivities of large body areas to sweating response. Japanese Journal of Physiology. 34:75-88.

Libert, J.P., Candas, V., and Vogt, J.J. (1978). Sweating response in man during transient rises of air temperature. Journal of Applied Physiology. 44:284-290.

Liebermeister, C. (1875). Handbuch der pathologie und therapie des fiebers. F.C.W. Vogel, Leipzig.

Linder, F.E., and Carmichael, H.T. (1935). A biometric study of the relation between oral and rectal temperatures in normal and schizophrenic subjects. Human Biology. 7:24-46.

Lipkin, M., and Hardy, J.D. (1954). Measurement of some thermal properties of human tissues. Journal of Applied Physiology. 7:212-217.

Livingstone, S.D., Grayson, J., Frim, J., Allen, C.L., and Limmer, R.E. (1983). Effect of cold exposure on various sites of core temperature measurements. Journal of Applied Physiology. 54:1025-1031.

Livingstone, S.D., Nolan, R.W., Frim, J., Reed, L.D., and Limmer, R.E. (1987). A thermographic study of the effect of body composition and ambient temperature on 
the accuracy of mean skin temperature calculations. European Journal of Applied Physiology. 56:120-125.

Lotens, W.A., and Havenith, G. (1995). Effects of moisture absorption in clothing on the human heat balance. Ergonomics. 38:1092-1113.

Low, D.A., Vu, A., Brown, M., Davis, S.L., Keller, D.M., Levine, B.D., and Crandall, C.G. (2007). Temporal thermometry fails to track body core temperature during heat stress. Medicine and Science in Sports and Exercise. 39:1029-1035.

Machado-Moreira, C.A., Barry, R.J., Vosselman, M.J., Ruest, R.M., and Taylor, N.A.S. (2014). Temporal and thermal variations in site-specific thermoregulatory sudomotor thresholds: precursor versus discharged sweat production. Psychophysiology. Epub ahead of print. DOI: 10.1111/psyp.12292

Machino, R. (1959). Studies on the clinical thermometry. Journal of Japanese Balneo Climatological Association. 22:292-318.

Mackowiak, P.A., Wasserman, S.S., and Levine, M.M. (1992). A critical appraisal of 98.6 degrees $\mathrm{F}$, the upper limit of the normal body temperature, and other legacies of Carl Reinhold August Wunderlich. Journal of the American Medical Association. 268:1578-1580.

Magoun, H.W., Harrison, F., Brobeck, J.R., and Ranson, S.W. (1938). Activation of heat loss mechanisms by local heating of the brain. Journal of Neurophysiology. 1:101114.

Mahanty, S.D., and Roemer, R.B. (1979). The effect of pressure on skin temperature measurements for a disk sensor. Journal of Biomechanical Engineering. 101:261-266.

Mairiaux, P., Sagot, J.C., and Candas, V. (1983). Oral temperature as an index of core temperature during heat transients. European Journal of Applied Physiology. 50:331-341.

Maloney, S.K., Fuller, A., Mitchell, G., and Mitchell, D. (2001). Rectal temperature measurement results in artifactual evidence of selective brain cooling. American Journal of Physiology. 281:R108-R114.

33 Mariak, Z., Bondyra, Z., and Piekarska, M. (1993). The temperature within the circle of 
Willis versus tympanic temperature in resting normothermic humans. European Journal of Applied Physiology. 66:518-520.

Mariak, Z., Lewko, J., Luczaj, J., Połocki, B., and White, M.D. (1994). The relationship between directly measured human cerebral and tympanic temperatures during changes in brain temperatures. European Journal of Applied Physiology. 69:545-549.

Marino, F.E. (2002). Methods, advantages, and limitations of body cooling for exercise performance. British Journal of Sports Medicine. 36:89-94.

Marins, J.C.B., Fernandes, A.A., Cano, S.P., Moreira, D.G., da Silva, F.S., Costa, C.M.A., Fernandez-Cuevas, I., and Sillero-Quintana, M. (2014). Thermal body patterns for healthy Brazilian adults (male and female). Journal of Thermal Biology. 42:1-8.

Marion, G.S., McGann, K.P., and Camp, D.L. (1991). Core body temperature in the elderly and factors which influence its measurement. Gerontology. 37:225-232.

Martine, G. (1740). Essays medical and philosophical. A. Millar, London.

Mather, G.W., Nahas, G.G., and Hemingway, A. (1953). Temperature changes of pulmonary blood during exposure to cold. American Journal of Physiology. 173:390-392.

Maw, G.J., and Taylor, N.A.S. (1992). Dissociation of rectal and aural temperatures during lower body exercise. Physiologist. 35:175.

McCaffrey, T.V., McCook, R.D., and Wurster, R.D. (1975). Effect of head skin temperature on tympanic and oral temperature in man. Journal of Applied Physiology. 39:114-118.

McGann, K.P., Marion, G.S., Camp, L., and Spangler, J.G. (1993). The influence of gender and race on mean body temperature in a population of healthy older adults. Archives of Family Medicine. 2:1265-1267.

McGlone, B., and Bazett, H.C. (1927). The temperature of the air in contact with the skin. American Journal of Physiology. 82:452-461.

McKenzie, J.E., and Osgood, D.W. (2004). Validation of a new telemetric core temperature monitor. Journal of Thermal Biology. 29:605-611.

McLellan, T.M., Daanen, H.A.M., and Cheung, S.S. (2013). Encapsulated environment. Comprehensive Physiology. 3:1363-1391.

Mead, J., and Bonmarito, C.L. (1949). Reliability of rectal temperatures as an index of 
internal body temperature. Journal of Applied Physiology. 2:97-109.

Mekjavic, I.B., and Eiken, O. (2006). Contribution of thermal and nonthermal factors to the regulation of body temperature in humans. Journal of Applied Physiology. 100:2065-2072.

Mekjavic, I.B., and Rempel, M.E. (1990). Determination of esophageal probe insertion length based on standing and sitting height. Journal of Applied Physiology. 69:376-379.

Mellergård, P. (1994). Monitoring of rectal, epidural, and intraventricular temperature in neurosurgical patients. Acta Neurochirurgica. Supplementum. 60:485-487.

Minard, D., and Copman, L. (1963). Elevation of body temperature in health. In: Hardy, J.D. (Editor). Temperature: Its measurement and control in science and industry. Volume 3, part 3. Reinhold Publishing Corporation, New York. Pp. 527-543. effect of elevated body temperature and of stress on the motility of stomach and colon in man. Clinical Science. 34:149-159.

Mitchell, D., and Wyndham, C.H. (1969). Comparison of weighting formulas for calculating mean skin temperature. Journal of Applied Physiology. 26:616-622.

Mitchell, D., Wyndham, C.H., and Hodgson, T. (1967). Emissivity and transmittance of excised human skin in its thermal emission wave band. Journal of Applied Physiology. 23:390-394.

Mittleman, K.D., and Mekjavic I.B. (1988). Effect of occluded venous return on core temperature during cold water immersion. Journal of Applied Physiology. 65:2709-2713.

Molnar, G.W., and Read, R.C. (1974). Studies during open-heart surgery on the special characteristics of rectal temperature. Journal of Applied Physiology. 36:333-336.

Moran, D.S., and Mendal, L. (2002). Core temperature measurement: methods and current insights. Sports Medicine. 32:879-885.

Moore, J.W., and Newbower, R.S. (1978). Noncontact tympanic thermometer. Medical and Biological Engineering and Computing. 16:580-584.

Morgans, L.F., Nunneley, S.A., and Stribley, R.F. (1981). Influence of ambient and core temperatures on auditory canal temperature. Aviation, Space and Environmental Medicine. 52:291-293.

Nadel, E.R., Bullard, R.W., and Stolwijk, J.A.J. (1971). Importance of skin temperature 
in the regulation of sweating. Journal of Applied Physiology. 31:80-87.

Nadel, E.R., and Horvath, S.M. (1969). Peripheral involvement in thermoregulatory response to an imposed heat debt in man. Journal of Applied Physiology. 27:484488.

Nadel, E.R., and Horvath, S.M. (1970). Comparison of tympanic membrane and deep body temperatures in man. Life Sciences. 9:869-875.

Nadel, E.R., Mitchell, J.W., and Stolwijk, J.A.J. (1973). Differential thermal sensitivity in the human skin. Pflügers Archives. 340:71-76.

Nagano, C., Tsutsui, T., Monji, K., Sogabe, Y., Idota, N., and Horie, S. (2010). Technique for continuously monitoring core body temperatures to prevent heat stress disorders in workers engaged in physical labor. Journal of Occupational Health. 52:167-175.

Nakamura, K., Tanaka, M., Motohashi, Y., and Maeda, A. (1997). Oral temperatures of the elderly in nursing homes in summer and winter in relation to activities of daily living. International Journal of Biometeorology. 40:103-106.

Nakayama, T., Ohnuki, Y., and Kanosue, K. (1981). Fall in skin temperature during exercise observed by thermometry. Japanese Journal of Physiology. 31:757-762.

Nakayama, T., Ohnuki, Y., and Niwa, K. (1977). Fall in skin temperature during exercise. Japanese Journal of Physiology. 27:423-437.

Narasimhan, T.N. (1999). Fourier's heat conduction equation: history, influence, and connections. Reviews of Geophysics. 37:151-172.

Newton, I. (1700). Scala graduum caloris. Calorum descriptiones \& figna. Philosophical Transactions of the Royal Society of London. 22:824-829.

Nichols, G.A., and Kucha, D.H. (1972). Taking adult temperatures: oral measurements. American Journal of Nursing. 72:1091-1093.

Niedermann, R., Wyss, E., Annaheim, S., Psikuta, A., Davey, S., and Rossi, R.M. (2014). Prediction of human core body temperature using non-invasive measurement methods. International Journal of Biometeorology. 58:7-15.

Nielsen, B., and Nielsen, M. (1962). Body temperature during work at different environmental temperatures. Acta Physiologica Scandinavica. 56:120-129.

Nishiyasu, T., Shi, X., Gillen, C.M., Mack, G.W., and Nadel, E.R. (1992). Comparison of the forearm and calf blood flow response to thermal stress during dynamic exercise. Medicine and Science in Sports and Exercise. 24:213-217. 
Niu, H.H., Lui, P.W., Hu, J.S., Ting, C.K., Yin, Y.C., Lo, Y.L., Liu, L., and Lee, T.Y. (2001). Thermal symmetry of skin temperature: normative data of normal subjects in Taiwan. Zhonghua Yi Xue Za Zhi (Taipei). 64:459-468.

$\mathrm{Ng}$, E.Y.K., and Chong, C. (2006). ANN-based mapping of febrile subjects in mass thermogram screening: facts and myths. Journal of Medical Engineering and Technology. 30:330-337.

Nybo, L., Secher, N.H., and Nielsen, B. (2002). Inadequate heat release from the human brain during prolonged exercise with hyperthermia. Journal of Physiology. 545:697704.

Nybo, L., and White, M.D. (2008). Do humans have selective brain cooling? In: Taylor, N.A.S., and Groeller, H. (Editors). Physiological bases of human performance during work and exercise. Churchill Livingstone Elsevier, Edinburgh. Pp. 473-479.

O’Brien, C., Hoyt, R.W., Buller, M.J., Castellani, J.W., and Young, A.J. (1997). Telemetry pill measurement of core temperature during active heating and cooling. U.S. Army Research Institute of Environmental Medicine, Natick. Report T97-8.

Ogawa, T. (1997). Where should core temperature be measured in human experiments? Journal of the Human-Environment-System. 1:47-55.

Ogawa, T., Sugenoya, J., Ohnishi, N., Natsume, K., Imai, K., Kandori, Y., Ishizuka, A., and Osada, A. (1993). Effects of body and head positions on bilateral difference in tympanic temperatures. European Journal of Applied Physiology. 67:354-359.

Olesen, B.W. (1984). How many sites are necessary to estimate a mean skin temperature? In: Hales, J.R.S. (Editor). Thermal physiology. Raven Press, New York. Pp. 33-38. Olesen, B.W., and Fanger, P.O. (1973). The skin temperature distribution for resting man in comfort. Archives des Sciences Physiologiques. 27:A385-A393.

Otte, J.A., Oostveen, E., Geelkerken, R.H., Groeneveld, A.B., and Kolkman, J.J. (2001). Exercise induces gastric ischemia in healthy volunteers: a tonometry study. Journal of Applied Physiology. 91:866-871.

Pandolf, K.B., and Goldman, R.F. (1978). Convergence of skin and rectal temperatures as a criterion for heat tolerance. Aviation, Space and Environmental Medicine. 49:1095-1101.

Patterson, M.J., Stocks, J.M., and Taylor, N.A.S. (2004). Humid heat acclimation does not elicit a preferential sweat redistribution towards the limbs. American Journal of Physiology. 286:R512-R518. 
Pearson, J., Ganio, M.S., Seifert, T., Overgaard, M., Secher, N.H., and Crandall, C.G. (2012). Pulmonary artery and intestinal temperatures during heat stress and cooling. Medicine and Science in Sports and Exercise. 44:857-862.

Pembrey, M.S. (1898). Animal heat. In: Schäfer, E.A. (Editor). Text-book of Physiology. Young J. Pentland, Edinburgh. Pp. 785-867.

Pembrey, M.S., and Nicol, B.A. (1898). Observations upon the deep and surface temperature of the human body. Journal of Physiology. 23:386-406.

Pendergast, D.R. (1988). The effect of body cooling on oxygen transport during exercise. Medicine and Science in Sports and Exercise. 20(Supplement):S171-S176. human forearm. Journal of Applied Physiology. 1:93-122.

Pierau, F.-K. (1996). Peripheral thermosensors. Comprehensive Physiology 2011, Supplement 14: Handbook of Physiology, Environmental Physiology: 85-104. First published in print 1996.

Piironen, P. (1970). Sinudoidal signals in the analysis of heat transfer in the body. In: Hardy, J.D., Gagge A.P., and Stolwijk, J.A.J. (Editors). Physiological and behavioral temperature regulation. Thomas, Springfield, Ill. Pp. 358-366.

Psikuta, A., Niedermann, R., and Rossi, R.M. (2014). Effect of ambient temperature and attachment method on surface temperature measurements. International Journal of Biometeorology. 58:877-885.

Proppe, D.W., Brengelmann, G.L., and Rowell, L.B. (1976). Control of baboon limb blood flow and heart rate - role of skin vs. core temperature. American Journal of Physiology. 231:1457-1465.

Pušnika, I., and Miklaveca, A. (2009). Dilemmas in measurement of human body temperature. Instrumentation, Science \& Technology. 37:516-530.

Quinn, T.J. (1983). Temperature. Academic Press, London.

Ramanathan, N.L. (1964). A new weighting system for mean surface temperature of the human body. Journal of Applied Physiology. 19:531-533.

Rawson, R.O., and Quick, K.P. (1972). Localization of intra-abdominal thermoreceptors in the ewe. Journal of Physiology. 222:665-677.

Regan, J.M., Macfarlane, D.J., and Taylor, N.A.S. (1996). An evaluation of the role of skin temperature during heat adaptation. Acta Physiologica Scandinavica. 158:365375. 
Reilly, T., and Waterhouse, J. (2009). Circadian aspects of body temperature regulation in exercise. Journal of Thermal Biology. 34:161-170.

Richet, C.R., and Langlois, P. (1898). Chaleur. In: Dictionnaire de physiologie. Volume 3. Alcan, Paris. Pp.81-203.

Ring, E.F.J. (2006). The historical development of thermometry and thermal imaging in medicine. Journal of Medical Engineering and Technology. 30:192-198.

Ring, F.J. (2007). Pandemic? Thermography for fever screening of airport passengers. Thermology International. 17:67.

Roach, G.D., Sargent, C., Darwent, D., Kennaway, D.J., and Ferguson, S.A. (2010). Lost in transit: the journey of ingestible temperature sensors through the human digestive tract. Ergonomia. 32:49-61.

Ronneberg, K., Roberts, W.O., McBean, A.D., and Center, B.A. (2008). Temporal artery temperature measurements do not detect hyperthermic marathon runners. Medicine and Science in Sports and Exercise. 40:1373-1375.

Roth, R.N., Verdile, V.P., Grollman, L.J., and Stone, D.A. (1996). Agreement between rectal and tympanic membrane temperatures in marathon runners. Annals of Emergency Medicine. 28:414-417.

Rowell, L.B. (1977). Competition between skin and muscle for blood flow during exercise. In: Nadel, E.R. (Editor). Problems with temperature regulation during exercise. Academic Press, New York. Pp. 49-77.

Rowell, L.B. (1986). Human circulation. Regulation during physical stress. Oxford University Press, New York.

Rowell, L.B., Brengelmann, G.L., Blackmon, J.R., and Murray, J.A. (1970). Redistribution of blood flow during sustained high skin temperature in resting man. Journal of Applied Physiology. 28:415-420.

Rowell, L.B., Brengelmann, G.L., and Murray, J.A. (1969). Cardiovascular responses to sustained high skin temperature in resting man. Journal of Applied Physiology. 27:673-680.

Rowell, L.B., Kraning, K.K., Kennedy, J.W., and Evans, T.O. (1967). Central circulatory responses to work in dry heat before and after acclimatization. Journal of Applied Physiology. 22:509-518.

Rubenstein, B.B. (1937). The relation of cyclic changes in human vaginal smears to body temperatures and basal metabolic rates. American Journal of Physiology. 
119:635-641.

Rubin, A., Horvath, S.M., and Mellette, H.C. (1951). Effect of fecal bacteria activity on rectal temperature in man, Proceedings of the Society of Experimental Biology and Medicine. 76:410-411.

Saltin, B., Gagge, A.P., Bergh, U., and Stolwijk, J.A.J. (1972). Body temperatures and sweating during exhaustive exercise. Journal of Applied Physiology. 32:635-643.

Saltin, B., Gagge, A.P., and Stolwijk, J.A.J. (1970). Body temperatures and sweating during thermal transients caused by exercise. Journal of Applied Physiology. 28:318-327.

Saltin, B., and Hermansen, L. (1966). Esophageal, rectal and muscle temperature during exercise. Journal of Applied Physiology. 21:1757-1762.

Saltin, B., Rådegran, G., Koskolou, M.D., and Roach, R.C. (1998). Skeletal muscle blood flow in humans and its regulation during exercise. Acta Physiologica Scandinavica. 162:421-436.

Saunders, A.G., Dugas, J.P., Tucker, R., Lambert, M.I., and Noakes, T.D. (2005). The effects of different air velocities on heat storage and body temperature in humans cycling in a hot, humid environment. Acta Physiologica Scandinavica. 183:241-255.

Sasaki, N., and Kamada, A. (1952). A recording device for surface temperature measurements. Review of Scientific Instruments. 23:261-263.

Sato, K.T., Kane, N.L., Soos, G., Gisolfi, C.V., Kondo, N., and Sato, K. (1996). Reexamination of tympanic membrane temperature as a core temperature. Journal of Applied Physiology. 80:1233-1239.

Savard, G.K., Cooper, K.E., Veale, W.L., and Malkinson, T.J. (1985). Peripheral blood flow during rewarming from mild hypothermia in humans. Journal of Applied Physiology. 58:4-13.

Sawka, M.N., and Castellani, J.W. (2007). How hot is the human body? Journal of Applied Physiology. 103:419-420.

Sawka, M.N., Latzka, W.A., and Pandolf, K.B. (1989). Temperature regulation during upper body exercise: able-bodied and spinal cord injured. Medicine and Science in Sports and Exercise. 21(Supplement 5):S132-S140.

Sawka, M.N., and Wenger, C.B. (1988). Physiological responses to acute exercise-heat stress. In: Pandolf, K.B., Sawka, M.N., and Gonzalez, R.R. (Editors). Human performance physiology and environmental medicine at terrestrial extremes. 
Benchmark Press, Indianapolis. Pp. 97-151.

Scholander, P.F., and Schevill, W.E. (1955). Counter-current vascular heat exchange in the fins of whales. Journal of Applied Physiology. 8:279-282.

Selle, W.A. (1952). Body temperature: its changes with environment, disease and therapy. Charles C. Thomas, Springfield, Illinois.

Severinghaus, J.W. (1959). Temperature gradients during hypothermia. Annals of the New York Academy of Sciences. 80:515-521.

Sharkey, A., Elliott, P., Lipton, J.M., and Giesecke, A.H. (1987). The temperature of the air within the external auditory meatus compared with esophageal temperature

Sheard, C., Williams, M.M.D., and Horton, B.T. (1941). Skin temperatures of the extremities under various environmental and physiological conditions. In: American Institute of Physics. Temperature: Its measurement and control in science and industry. Reinhold Publishing Corporation, New York. Pp. 557-570.

Shibasaki, M., Kondo, N., Tominaga, H., Aoki, K., Hasegawa, E., Idota, Y., and Moriwaki, T. (1998). Continuous measurement of tympanic temperature with a new infrared method using an optical fiber. Journal of Applied Physiology. 85:921-926.

Shinozaki, T., Deane, R., and Perkins, F.M. (1988). Infrared tympanic thermometer: evaluation of a new clinical thermometer. Critical Care Medicine. 16:148-150.

Shiraki, K., Konda, N., Sagawa, S. (1986). Esophageal and tympanic temperature responses to core blood temperature changes during hyperthermia. Journal of Applied Physiology. 61:98-102.

Shiraki, K., Sagawa, S., Tajima, F., Yokota, A., Hashimoto, M., and Brengelmann, G.L. (1988). Independence of brain and tympanic temperatures in an unanesthetized human. Journal of Applied Physiology. 65:482-486.

Shvartz, E., Magazanik, A., and Glick, Z. (1974). Thermal responses during training in a temperate climate. Journal of Applied Physiology. 36:572-576.

Simpson, S., and Galbraith, J.J., (1905). An investigation into the diurnal variation of the body temperature of nocturnal and other birds, and a few mammals. Journal of Physiology. 33:225-238.

Simon, E. (1974). Temperature regulation: the spinal cord as a site of extrahypothalamic thermoregulatory functions. Reviews of Physiology, Biochemistry and Pharmacology. 71:1-76. 
Simon, E. (2007). Tympanic temperature is not suited to indicate selective brain cooling in humans: a re-evaluation of the thermophysiological basics. European Journal of Applied Physiology. 101:19-30.

Simon, E., Pierau, F.-K., and Taylor, D.C.M. (1986). Central and peripheral thermal control of effectors in homeothermic temperature regulation. Physiological Reviews. 66:235-300.

Singer, B., and Lipton, B. (1975). Monitoring of core temperature through the skin: a comparison with esophageal and tympanic temperatures. Bulletin of the New York Academy of Medicine. 51:947-952.

Sloan, R.E., and Keatinge, W.R. (1975). Depression of sublingual temperature by cold saliva. British Medical Journal. 1(5960):718-720.

Smith, N.T. (1962). Subcutaneous, muscle, and body temperatures in anesthetized man. Journal of Applied Physiology. 17:306-310.

Smith, R.E. (1969). Circadian variations in human thermoregulatory responses. Journal of Applied Physiology. 26:554-560.

Smith, P., Davies, G., and Christie, M.J. (1980). Continuous field monitoring of deep body temperature from the skin surface using subject-borne portable equipment: some preliminary observations. Ergonomics. 23:85-86.

Snellen, J.W. (1966). Mean body temperature and the control of thermal sweating. Acta Physiologica et Pharmacologica Neerlandica. 14:99-174.

Snellen, J.W. (1969). Body temperature during exercise. Medicine and Science in Sports. $1: 39-42$.

Snellen, J.W. (2000). An improved estimation of mean body temperature using combined direct calorimetry and thermometry. European Journal of Applied Physiology. 82:188-196.

Standring, S. (2008). Gray's anatomy: the anatomical basis of clinical practice. Fortieth Edition. Churchill Livingstone Elsevier, Edinburgh.

Starkie, R.L., Hargreaves, M., Lambert, D.L., Proietto, J., and Febbraio, M.A. (1999). Effect of temperature on muscle metabolism during submaximal exercise in humans. Experimental Physiology. 84:775-784.

Stoll, A.M., and Hardy, J.D. (1950). Study of thermocouples as skin thermometers. Journal of Applied Physiology. 2:531-543.

Stolwijk, J.A.J., and Hardy, J.D. (1966). Partitional calorimetric studies of responses of 
man to thermal transients. Journal of Applied Physiology. 21:967-977.

Strydom, N.B., Wyndham, C.H., Williams, C.G., Morrison, J.F., Bredell, G.A.G., and Joffe, A. (1965). Oral/rectal temperature differences during work and heat stress. Journal of Applied Physiology. 20:283-287.

Sund-Levander, M., Forsberg, C., and Wahren, L.K. (2002). Normal oral, rectal, tympanic and axillary body temperature in adult men and women: a systematic literature review. Scandinavian Journal of Caring Sciences. 16:122-128.

Tanabe, K., and Takaori, S. (1964). Effects of cooling and warming of the common carotid arteries on the brain and tympanic membrane temperatures in the rabbit. Japanese Journal of Pharmacology. 14:67-79.

Taylor, N.A.S. (2011). Is body temperature measurement an illusive concept? In: Kounalakis, S.N., and Koskolou, M. (Editors). Proceedings of the Fourteenth International Conference on Environmental Ergonomics. July $10^{\text {th }}-15^{\text {th }}$, Nafplio, Greece, 2011. Pp. 19-20.

Taylor, N.A.S. (2014). Human heat adaptation. Comprehensive Physiology. 4:325-365. Taylor, N.A.S., Allsopp, N.K., and Parkes, D.G. (1995). Preferred room temperature of young versus aged males: the influence of thermal sensation, thermal comfort and affect. Journals of Gerontology Series A: Biological Sciences and Medical Sciences. 50:M216-M221.

Taylor, N.A.S., Caldwell, J.N., van den Heuvel, A.M.J., and Patterson, M.J. (2008). To cool, but not too cool: that is the question: immersion cooling for hyperthermia. Medicine and Science in Sports and Exercise. 40:1962-1969.

Taylor, N.A.S., Cotter, J.D., and Griffiths, R.F. (1994). Epidemiology of hypothermia: fatalities and hospitalisations in New Zealand. Australian and New Zealand Journal of Medicine. 24:705-710.

Taylor, N.A.S., Fogarty, A.L., and Armstrong, K.A. (2001). Metabolic heat storage in thermal protective clothing: a comparison of firefighter personal protective ensembles. UOW-HPL-Report-002. Human Performance Laboratories, University of Wollongong, Australia.

Taylor, N.A.S., Machado-Moreira, C.A., van den Heuvel, A.M.J., and Caldwell, J.N. (2014). Hands and feet: physiological insulators, radiators and evaporators. European Journal of Applied Physiology. 114:2037-2060.

Taylor, N.A.S., Wilsmore, B.R., Amos, D., Takken, T., Komen, T. (1998). Insulated 
skin temperatures: indirect indices of human body-core temperature. Technical Report. DSTO-TR-0752, AR-010-690. Defence Science and Technology Organisation, Department of Defence, Melbourne, Australia.

Taylor, N.A.S., Wilsmore, B.R., Amos, D., Takken, T., Komen, T., Cotter, J.D., and Jenkins, A.B. (1999). Indirect measurement of core temperature during work: clothing and environmental influences. In: Hodgdon, J.A., Heaney, J.H., and Buono, M.J. (Editors) Environmental Ergonomics VIII. International Series on Environmental Ergonomics. Volume 1. Pp. 325-328.

Teichner, W.H. (1958). Assessment of mean body surface temperature. Journal of Applied Physiology. 12:169-176.

Teunissen, L.P.J, and Daanen, H.A.M. (2011). Infrared thermal imaging of the inner canthus of the eye as an estimator of body core temperature. Journal of Medical Engineering and Technology. 35:134-138.

Teunissen, L.P.J., de Haan, A., de Koning, J.J., Clairbois, H.E., and Daanen, H.A.M. (2011a). Limitations of temperature measurement in the aural canal with an ear mould integrated sensor. Physiological Measurement. 32:1403-1416.

Teunissen, L.P.J., de Haan, A., de Koning, J.J., and Daanen, H.A.M. (2012). Telemetry pill versus rectal and oesophageal temperature during extreme rates of exerciseinduced core temperature change. Physiological Measurement. 33:915-924.

Teunissen, L.P.J., Klewer, J., de Haan, A., de Koning, J.J., and Daanen, H.A.M. (2011b). Non-invasive continuous core temperature measurement by zero heat flux. Physiological Measurement. 32:559-570.

Terndrup, T.E., Allegra, J.R., and Kealy, J.A. (1989). A comparison of oral, rectal, and tympanic membrane-derived temperature changes after ingestion of liquids and smoking. American Journal of Emergency Medicine. 7:150-154.

Thatcher, R.M. (1983). 98.6 degrees F: what is normal? Journal of Gerontological Nursing. 9:22-27.

Tipton, M.J. (1989). The initial responses to cold-water immersion in man. Clinical Science. 77:581-588.

Tipton, M.J., and Golden, F.St.C. (2011) Decision-making guide for the search, rescue and resuscitation of submerged (head under) victims. Resuscitation. 82:819-824.

Tipton, M.J., Wakabayashi, H., Barwood, M.J., Eglin, C.M., Mekjavic, I.B., and Taylor, N.A.S. (2013). Habituation of the metabolic and ventilatory responses to cold-water 
immersion in humans. Journal of Thermal Biology. 38:24-31.

Todd, G., Gordon, C.J., Groeller, H., and Taylor, N.A.S. (2014). Does intramuscular thermal feedback modulate eccrine sweating in exercising humans? Acta Physiologica. 212:86-96.

Togawa, T. (1979). Non-invasive deep body temperature measurement. In: Rolfe, P. (Editor). Non-Invasive Physiological Measurements. Volume 1. Academic Press, London. Pp. 261-277.

Togawa, T. (1985). Body temperature measurement. Clinical Physics and Physiological Measurement. 6:83-108.

Togawa, T. (1989). Non-contact skin emissivity: measurement from reflectance using step change in ambient radiation temperature. Clinical Physics and Physiological Measurement. 10:39-48.

Togwa, T., Nemoto, T., Yamazaki, T., and Kobayashi, T. (1976). A modified internal temperature measurement device. Medical and Biological Engineering. 14:361-364.

Torii, M., Yamasaki, M., Sasaki, T., and Nakayama, T. (1992). Fall in skin temperature of exercising man. British Journal of Sports Medicine. 26:29-32.

Tschakovsky, M.E., and Pyke, K.E. (2008). Cardiovascular responses to exercise and limitations to human performance. In: Taylor, N.A.S., and Groeller, H. (Editors). Physiological bases of human performance during work and exercise. Churchill Livingstone Elsevier, Edinburgh. Pp. 5-27.

Tyler, C.J. (2011). The effect of skin thermistor fixation method on weighted mean skin temperature. Physiological Measurement. 32:1541-1547.

Vale, R.J. (1981). Monitoring of temperature during anesthesia. International Anesthesiology Clinics. 19:61-84.

Vallerand, A.L., Savourey, G., and Bittel, J.H.M. (1992a). Determination of heat debt in the cold: partitional calorimetry vs. conventional methods. Journal of Applied Physiology. 72:1380-1385.

Vallerand, A.L., Savourey, G., Hanniquet, A.-M., and Bittel, J.H.M. (1992b). How should body heat storage be determined in humans: by thermometry or calorimetry? European Journal of Applied Physiology. 65:286-294.

van Beaumont, W., and Bullard, R.W. (1963). Sweating: its rapid response to muscular work. Science. 141:643-646.

van Marken Lichtenbelt, W.D., Daanen, H.A., Wouters, L., Fronczek, R., Raymann, 
R.J., Severens, N.M., and Van Someren, E.J. (2006). Evaluation of wireless determination of skin temperature using iButtons. Physiology \& Behavior. 88:489-497.

Villanova, N., Azpiroz, F., and Malagelada, J.R. (1997). Perception and gut reflexes induced by stimulation of gastrointestinal thermoreceptors in humans. Journal of Physiology. 502:215-222.

Waites, G.M.H., and Moule, G.R. (1961). Relation of vascular heat exchange to temperature regulation in the testis of the ram. Journal of Reproduction and Fertility. 2:213-224.

Walker, J.E., Wells, R.E., and Merrill, E.W. (1961). Heat and water exchange in the respiratory tract. American Journal of Medicine. 30:259-267.

Wartzek, T., Mühlsteff, J., and Imhoff, M. (2011). Temperature measurement. Biomedizinische Technik. Biomedical Engineering. 56:241-257.

Watmough, D.J., and Oliver, R. (1968). Emissivity of human skin in vivo between $2.0 \mu$ and 5.4 $\mu$ measured at normal incidence. Nature. 218(5144):885-886.

Webb, P. (1985). Human Calorimeters. Praeger Publishers Division, Greenwood Press Incorporated, New York.

Webb, P. (1986). Afterdrop of body temperature during rewarming: an alternative explanation. Journal of Applied Physiology. 60:385-390.

Webb, P. (1992). Temperatures of skin, subcutaneous tissue, muscle and core in resting men in cold, comfortable and hot conditions. European Journal of Applied Physiology. 64:471-476.

Weingart, S., Mayer, S., and Polderman, K. (2009). Rectal probe temperature lag during rapid saline induction of hypothermia after resuscitation from cardiac arrest. Resuscitation. 80:837-838.

Weinstein, S.A., Weinstein, G., Weinstein, E.L., and Gelb, M. (1991). Facial thermography, basis, protocol, and clinical value. Cranio. 9:201-211.

Werner, J. (1994). Beneficial and detrimental effects of thermal adaptation. In: Zeisberger, E., Schönbaum, E., and Lomax, P. (Editors). Thermal balance in health and disease. Birkhäuser Verlag, Basel. Pp. 141-154.

Werner, J. (2010). System properties, feedback control and effector coordination of human temperature regulation. European Journal of Applied Physiology. 109:13-25.

Werner, J. (2014). Measurement of temperatures of the human body. In: Brahme, A. 
(Editor). Comprehensive biomedical physics. Volume 5. Elsevier, Amsterdam. Pp. 107-126.

Werner, J., Mekjavic, I.B., and Taylor, N.A.S. (2008). Concepts in physiological regulation: a thermoregulatory perspective. In: Taylor, N.A.S., and Groeller, H. (Editors). Physiological bases of human performance during work and exercise. Churchill Livingstone Elsevier, Edinburgh. Pp. 325-340.

Werner, J., and Reents, T. (1980). A contribution to the topography of temperature regulation in man. European Journal of Applied Physiology. 45:87-94.

Whitby, J.D., and Dunkin, L.J. (1968). Temperature differences in the oesophagus. Preliminary study. British Journal of Anaesthesia. 40:991-995.

Whitby, J.D., and Dunkin, L.J. (1969). Temperature differences in the oesophagus. The effects of intubation and ventilation. British Journal of Anaesthesia. 41:615-618.

Whitby, J.D., and Dunkin, L.J. (1971). Cerebral, oesophageal and nasopharyngeal temperatures. British Journal of Anaesthesia. 43:673-676.

Whiting, M.H. (1915). On the association of temperature, pulse and respiration with physique and intelligence in criminals: a study in criminal anthropometry Biometrika. 11:1-37.

Wilkinson, D.M., Carter, J.M., Richmond, V.L., Blacker, S.D., and Rayson, M.P. (2008). The effect of cool water ingestion on gastrointestinal pill temperature. Medicine and Science in Sports and Exercise. 40:523-528.

Williams, R.J., and Thompson, R.C. (1948). A device for obtaining a continuous record of body temperature from the external auditory canal. Science. 108:90-91.

Wilsmore, B.R. (1996). Human heat storage and sweating: a reassessment of determining factors. Bachelor of Science (Honours) Dissertation. University of Wollongong, Australia.

Wilsmore, B.R. (2008). Thermoregulation in people with spinal-cord injury. Doctor of Philosophy, University of Wollongong, Australia.

Winslow, C.-E.A., Herrington, L.P., Gagge, A.P. (1936). A new of partitional calorimetry. American Journal of Physiology. 116:641-655.

33 Woodman, E.A., Parry, S.McC., and Simms, L. (1967). Sources of unreliability in oral 
temperatures. Nursing Research. 16:276-279.

Worthing, A.G. (1941). Is temperature a basic concept? In: American Institute of Physics. Temperature: Its measurement and control in science and industry. Reinhold Publishing Corporation, New York. Pp. 41-44.

Wunderlich, C.A. (1869). The course of the temperature in diseases: a guide to clinical thermometry. American Journal of the Medical Sciences. 144:425-447.

Wunderlich, C.A., and Seguin, E. (1871). Medical thermometry and human temperature. William Wood \& Company, New York.

Xu, X., Karis, A.J., Buller, M.J., and Santee, W.R. (2013). Relationship between core temperature, skin temperature, and heat flux during exercise in heat. European Journal of Applied Physiology. 113:2381-2389.

Yamakage, M., Iwasaki, S., and Namiki, A. (2002). Evaluation of a newly developed monitor of deep body temperature. Journal of Anesthesia. 16:354-357.

Yamakage, M., and Namiki, A. (2003). Deep temperature monitoring using a zero-heat-flow method. Journal of Anesthesia. 17:108-115.

Zaproudina, N., Varmavuo, V., Airaksinen, O., and Närhi, M. (2008). Reproducibility of infrared thermography measurements in healthy individuals. Physiological Measurement. 29:515-524.

Zeyl, A., Stocks, J.M., Taylor, N.A.S., and Jenkins, A.B. (2004). Interactions between temperature and human leptin physiology in vivo and in vitro. European Journal of Applied Physiology. 92:571-578.

Zhang, H., Huizenga, C., Arens, E., and Wang, D. (2004). Thermal sensation and comfort in transient non-uniform thermal environments. European Journal of Applied Physiology. 92:728-733.

Zotterman, Y. (1959). Thermal sensations. In: Field, J. (Editor). Handbook of Physiology. Volume 1. Neurophysiology. American Physiological Society, Washington, DC. Pp. 431-458. 


\section{FIGURE CAPTIONS:}

$3 \quad$ Figure 1: Newton's Cooling Law (Newton, 1700) and the heat conduction equation

4 (Fourier, 1807). The rate of temperature change of an object $\left({ }^{\circ} \mathrm{C} . \mathrm{s}^{-1}\right)$ is dependent upon the size of the difference between its initial and final steady-state temperatures $\left({ }^{\circ} \mathrm{C}\right)$. Figure 1A: Temperatures were recorded from the centre of a steel sphere (mass $6.98 \mathrm{~kg}$, radius 0.061 $\mathrm{m})$. Following thermal equilibration to each of three steady-states (stirred water baths: $15^{\circ}$, $25^{\circ}$ and $\left.35^{\circ} \mathrm{C}\right)$, the sphere was transferred to a second regulated water bath $\left(38.5^{\circ} \mathrm{C}\right.$ stirred). Warming curves are shown for each of these three trials, with warming rates indicated for the period 80-150 s (shaded). Thermal equilibration was achieved at about $450 \mathrm{~s}$ in each trial. Figure 1B: To better illustrate the heat-transfer law and the impact of the heat conduction equation, these instantaneous temperatures were expressed as non-dimensional changes: temperature change $=\left(\mathrm{T}_{\mathrm{i}}-\mathrm{T}_{\mathrm{f}}\right) /\left(\mathrm{T}_{\mathrm{o}}-\mathrm{T}_{\mathrm{f}}\right)$; where: $\mathrm{T}_{\mathrm{i}}=$ instantaneous temperature, $\mathrm{T}_{\mathrm{o}}$ $=$ initial temperature, $\mathrm{T}_{\mathrm{f}}=$ final temperature. Figure 1C: It is sometimes easier to visualise these concepts in terms of thermal gradients and change rates. The thermal gradient of the $25^{\circ} \mathrm{C}$ trial was 3.96 times that of the $35^{\circ} \mathrm{C}$ trial (left bars and ordinate), while the gradient for $15^{\circ} \mathrm{C}$ was 1.77 times larger than the $25^{\circ} \mathrm{C}$ condition. Accordingly, when the rates of temperature change at each 5-s interval were averaged over the entire warming phase (80-450 s: right bars and ordinate), identical between-trial ratios were observed for

Figure 2: A steel sphere (mass $6.98 \mathrm{~kg}$, radius $0.061 \mathrm{~m}$ ) containing well-insulated thermistors embedded at its centre, and at 33\% (shallow: $0.0203 \mathrm{~m}$ ) and 66\% (deep: $0.0407 \mathrm{~m}$ ) of the distance from the centre to its surface, was heated to a steady state of $38.5^{\circ} \mathrm{C}$ (stirred water bath). Once a thermal equilibrium was established at all sites, the sphere was transferred to a second, but cooler stirred water bath $\left(15^{\circ} \mathrm{C}\right.$ : time zero $)$ until the temperature of the sensor at the centre of the sphere first started to decrease (position A: 35 $\mathrm{s})$. At this point, the sphere was moved back into the first water bath $\left(38.5^{\circ} \mathrm{C}\right)$, and the temperature profile of each sensor was recorded (5-s intervals) until local temperatures had all risen to $35^{\circ} \mathrm{C}$. Positions $\mathrm{B}, \mathrm{C}$ and $\mathrm{D}$ identify points where heat loses changed to heat gains, whilst $\mathrm{E}$ and $\mathrm{F}$ coincide with temperature trace cross-overs. This simulation was 
Figure 3: Whole-body calorimetry data illustrating total heat production rate (metabolic minus external work rates) and total (nett) heat loss rate (dry and evaporative) during seated rest, cycling at an external work rate of $70 \mathrm{~W}(0-60 \mathrm{~min})$ and a 60-min seated, resting recovery (Figure 3A: air temperature $30^{\circ} \mathrm{C}$, water vapour pressure $5.4 \mathrm{kPa}$ ). The difference between these heat production and heat loss rates (grey shaded zone) dictates whole-body heat storage (Figure 3B). Data are means with standard errors of the means $(N=8)$. Modified from Kenny et al. (2008) and used with permission.

Figure 4: Oesophageal, auditory-canal (insulated), rectal and intramuscular (vastus lateralis) temperatures plotted with mean local sweat rate (five sites [sweat capsules]: forehead, chest, ventral forearm, bilateral anterior thighs) during three consecutive, sinusoidal work-rate waveforms (cycling: 8-min periods; $60 \mathrm{rev} \cdot \mathrm{min}^{-1} ; 25.2^{\circ} \mathrm{C}, 1.15 \mathrm{kPa}$ ), increasing from $30 \mathrm{~W}$ to $60 \%$ of each subject's peak power (mean: $206 \mathrm{~W}$ ). This forcing function followed 20 min cycling at $35 \%$ of peak power (mean: $118 \mathrm{~W}$ ) to establish thermal and thermoeffector steady-states. Data are average curves (sampled at 5-s intervals, $N=8$ ) extracted from Todd et al. (2014) and used with permission.

Figure 5: Tympanic membrane, rectal, oesophageal and zero-gradient auditory-canal temperatures during steady-state cycling at $40 \%$ peak power in hot, moderately humid conditions $\left(36.6^{\circ} \mathrm{C}\right.$, water vapour pressure $\left.2.62 \mathrm{kPa}\right)$. Data are average curves with means and standard errors of the means at approximately 5-min intervals $(N=6)$. Local sweat rates (sweat capsules) for the forehead (upper) and dorsal foot surfaces are also shown (grey dotted curves). Modified from Cotter et al. (1995) and used with permission.

Figure 6: Variations in resting, deep-body temperature among twelve measurement sites (ascending order). Data were extracted from the reports listed below, with means and $95 \%$ confidence intervals for each total sample. Numbers above the confidence intervals are the total number of subjects, whilst those below indicate the number of contributing investigations.

Sources: Axilla: Ilsley et al. (1983), Darowski et al. (1991), Childs et al. (1999). Sublingual: Linder and Carmichael (1935), Ivy (1944), Barcroft and Edholm (1946), Consolazio et al. (1963), Fox et al. (1971), Fox et al. (1973b), Collins et al. (1977), Edwards et al. (1978) Erickson (1980), Kolanowski and Gunter (1981), 
Ilsley et al. (1983), Mairiaux et al. (1983), Thatcher (1983), Baker et al. (1984), Eriksson et al. (1985), Keilson et al. (1985), Terndrup et al. (1989), Darowski et al. (1991), Marion et al. (1991), Mackowiak et al. (1992), Maw and Taylor (1992), Castle et al. (1993), McGann et al. (1993), Nakamura et al. (1997). Auditory canal: Edwards et al. (1978), Terndrup et al. (1989), Darowski et al. (1991), Chamberlain et al. (1995), Shibasaki et al. (1998), Childs et al. (1999), Easton et al. (2007), Jay et al. (2007b), Nagano et al. (2010), Lee et al. (2011), Taylor (2012: unpublished observations). Liver: Graf (1959). Stomach: Graf (1959). Tympanic membrane: Brinnel and Cabanac (1989), Mariak et al. (1993), Cotter et al. (1995), Shibasaki et al. (1998). Oesophagus: Saltin and Hermansen (1966), Keatinge and Sloan (1975), Edwards et al. (1978), Mairiaux et al. (1983), Brinnel and Cabanac (1989), Maw and Taylor (1992), Cotter et al. (1995), Kolka et al. (1997), Shibasaki et al. (1998), Lee et al., (2000), Booth et al. (2004), Jay et al. (2007b), Nagano et al. (2010), Taylor (2012: unpublished observations), Wilsmore (2008). Zero-gradient auditory canal: Keatinge and Sloan (1975), Maw and Taylor (1992), Cotter et al. (1995), Wilsmore (2008). Urine: Marion et al. (1991). Rectum: Linder and Carmichel (1935), DuBois (1941), Bazett et al. (1948), Pennes (1948), Eichna (1949), Horvath et al. (1950a), Graf (1959), Consolazio et al. (1963), Saltin and Hermansen (1966), Fox et al. (1971), Edwards et al. (1978), Kolanowski and Gunter (1981), Ilsley et al. (1983), Mairiaux et al. (1983), Terndrup et al. (1989), Maw and Taylor (1992), Chamberlain et al. (1995), Cotter et al. (1995), Lee et al., (2000), McKenzie and Osgood (2004), Easton et al. (2007), Jay et al. (2007b), Nagano et al. (2010), Lee et al. (2010, 2011), Taylor (2012: unpublished observations), Wilsmore (2008). Gastriointestinal tract: Kolka et al. (1997), Lee et al., (2000), McKenzie and Osgood (2004), Gant et al. (2006), Easton et al. (2007), Pearson et al. (2012), Taylor (2012: unpublished observations). Bladder: Ilsley et al. (1983).

Figure 7: Rectal (A) and sublingual (B) temperature distributions in humans with means from Figure 6 shown as dotted vertical lines. Data for Figure 7A were extracted from DuBois (1941) for afebrile men and women under supine, basal conditions ( $N=252$ [digitised from original]). The solid vertical line shows the derived sample mean $\left(36.99^{\circ} \mathrm{C}\right)$ based on the digitised counts. Modified and used with permission. Figure 7B was extracted 
from Eriksson et al. (1985) for afebrile, seated men (57-75 years; $N=760)$. The mean was provided by the original author (solid vertical line: $36.70^{\circ} \mathrm{C}$ ). Modified and used with permission. Ivy (1944) also provided a sublingual temperature distribution: seated medical students $\left(N=276\right.$; mean: $\left.36.73^{\circ} \mathrm{C}\right)$, although the methods of Eriksson et al. (1985) were considered to be superior.

Figure 8: Temperatures and thermal gradients within the arteries and veins of normothermic humans, arranged to illustrate heat flow direction. Data are means obtained from the literature (below), with $95 \%$ confidence intervals. Data for all but three sites were taken from single experiments, and those sites are indicated by dataset numbers to the left of each mean. Numbers to the right are site-specific sample sizes.

Sources: Bazett et al. (1948: brachial artery), Eichna (1949: femoral artery and vein), Pennes (1948: brachial artery), Eichna et al. (1951: all sites except brachial artery), Ilsley et al. (1983: pulmonary artery), Mariak et al. (1993: carotid artery), Pearson et al. (2012: pulmonary artery).

Figure 9: Deep-body temperatures during a sequential cooling and heating trial. Following preparatory thermal equilibration (phase $1: 20^{\circ} \mathrm{C}$; swimming costume only), the subject (an author) was positioned above an immersion tank (phase 2: $12.5^{\circ} \mathrm{C}$ ) and lowered into the water (12 min), remaining there until the oesophageal temperature reached $35^{\circ} \mathrm{C}$ (phase 3 ). At this time (44.5 min), he was removed from the water (phase 4), dried and immediately transferred into a pre-heated climate chamber $\left(40^{\circ} \mathrm{C}\right)$, sitting at rest for $12 \mathrm{~min}$ (phase 5). Note the afterdrop at each site, but most pronounced for rectal and gastrointestinal temperatures. The rectal probe was partially and transiently dislodged during phase 5 (data omitted). Finally, steady-state cycling commenced (100 W: phase 6), and continued until oesophageal temperature rose to $39^{\circ} \mathrm{C}$. Data were sampled at 5-s intervals except for gastrointestinal temperature (1-min intervals). This trial was performed on four individuals, all of whom showed qualitatively similar responses, but the timing varied, as this was set by the oesophageal temperature targets. The aberration in gastrointestinal temperature (82$85 \mathrm{~min}$ ) was possibly physiological in nature, and occurred in two participants.

Figure 10: Variations in gastrointestinal-tract temperature in one individual (an author) during the complete transit of seven radio pills (Jonah 500-0100-02, Respironics 
1 Deutschland, Herrsching, Germany) over a 37.35-h period. Each pill was equilibrated in

2 water at $37^{\circ} \mathrm{C}$ and consumed with that water, with ingestion sequence corresponding to the

3 sensor numbers. Figure 10A: The complete transit data for seven sensors are shown

4 following removal of ingestion- and exercise-induced artefacts as well as random errors, so

5 that these data reflected sedentary activities. Times are referenced to ingestion time $(0 \mathrm{~h})$.

6 Data logging commenced on day 1 at 18:27 h (sensor 1) and 21:36 h (sensor 2), and on day

$7 \quad 2$ at 05:07 h (sensor 3), 09:40 h (sensor 4), 13:25 h (sensor 5), 17:53 h (sensor 6) and

$8 \quad 21: 58 \mathrm{~h}$ (sensor 7). Data were smoothed (5-point averages) and reported at 15-min

9 intervals. In Figure 10B, data from two sensors consumed immediately before retiring on

10 each night are shown (sensors 2 and 7). Time zero signifies retiring. Sleep commenced

11 within $30 \mathrm{~min}$, with arousal occurring $6.1 \mathrm{~h}$ (sensor 2) and $7.2 \mathrm{~h}$ (sensor 7) after retiring.

12 Data were smoothed (5-point averages) and reported at 15-min intervals. Figure 10C:

13 Endurance running (shaded area) and recovery. Data were collected at 1-min intervals and

14 were not smoothed. Legend times show the time from ingestion to the first data point on the 15 graph. The time axis is referenced to the start of data-collection (Figure 10A). Figure 10D:

16 Resistance exercise (shaded area) and recovery. Data were collected at 1-min intervals and

17 not smoothed. Legend times show the time from ingestion to the first data point on the

18 graph. Time is referenced to the start of data-collection (Figure 10A).

Figure 11: Intramuscular temperatures from three body segments recorded during cycling at an external work rate of $70 \mathrm{~W}(0-60 \mathrm{~min})$ and during a 60-min seated, resting recovery (air temperature $30^{\circ} \mathrm{C}$, water vapour pressure $5.4 \mathrm{kPa}$ )). Data are means with standard errors of the means $(N=8)$. Modified from Kenny et al. (2008) and used with permission.

Figure 12: Variations in regional skin temperatures (infrared thermography) obtained from resting (standing), normothermic males $(N=16)$. Data are means with $95 \%$ confidence intervals taken from Zaproudina et al. (2008), and used with permission of IOP Publishing ( ${ }^{\circ}$ Institute of Physics and Engineering in Medicine. All rights reserved). 

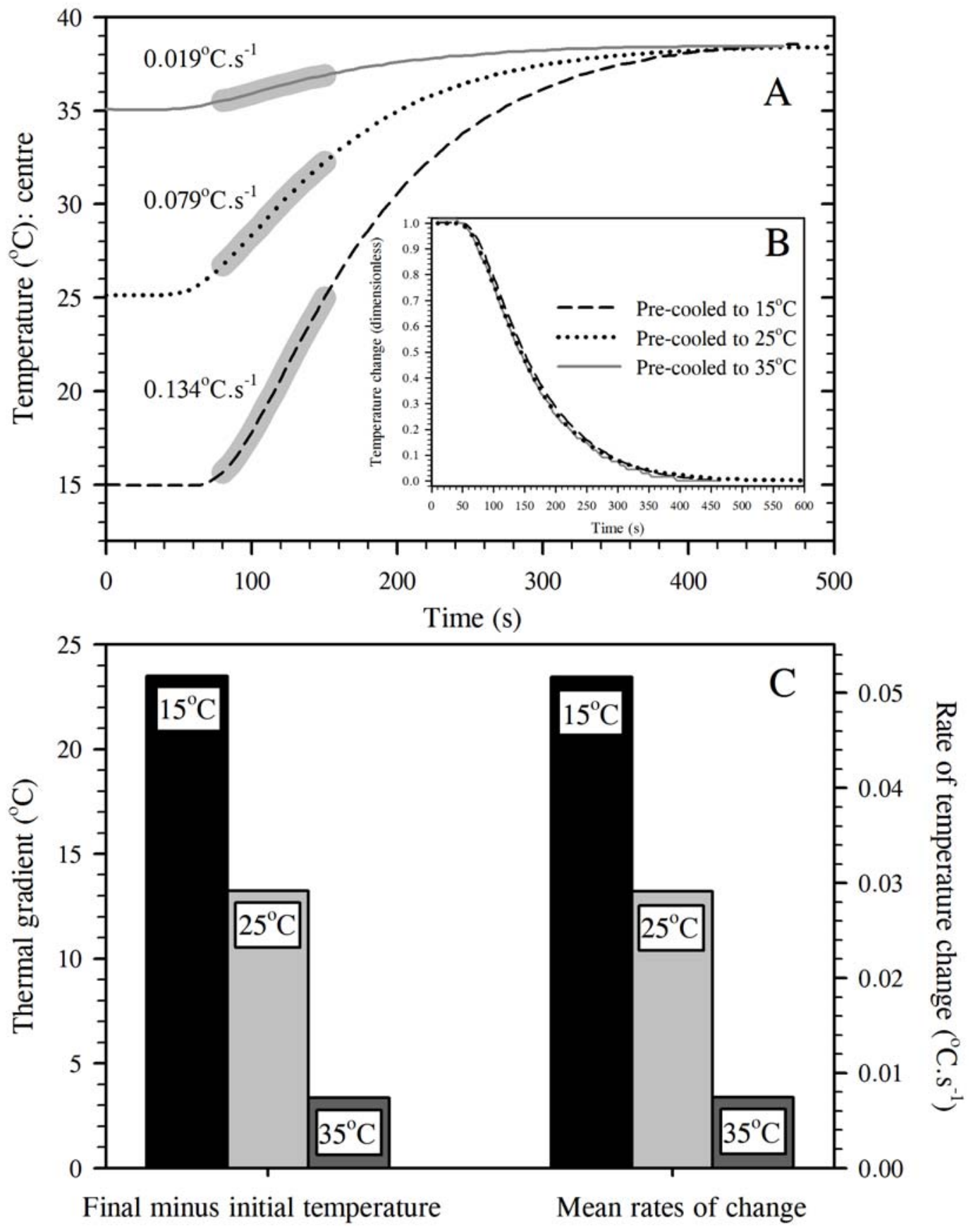
Figure 2:

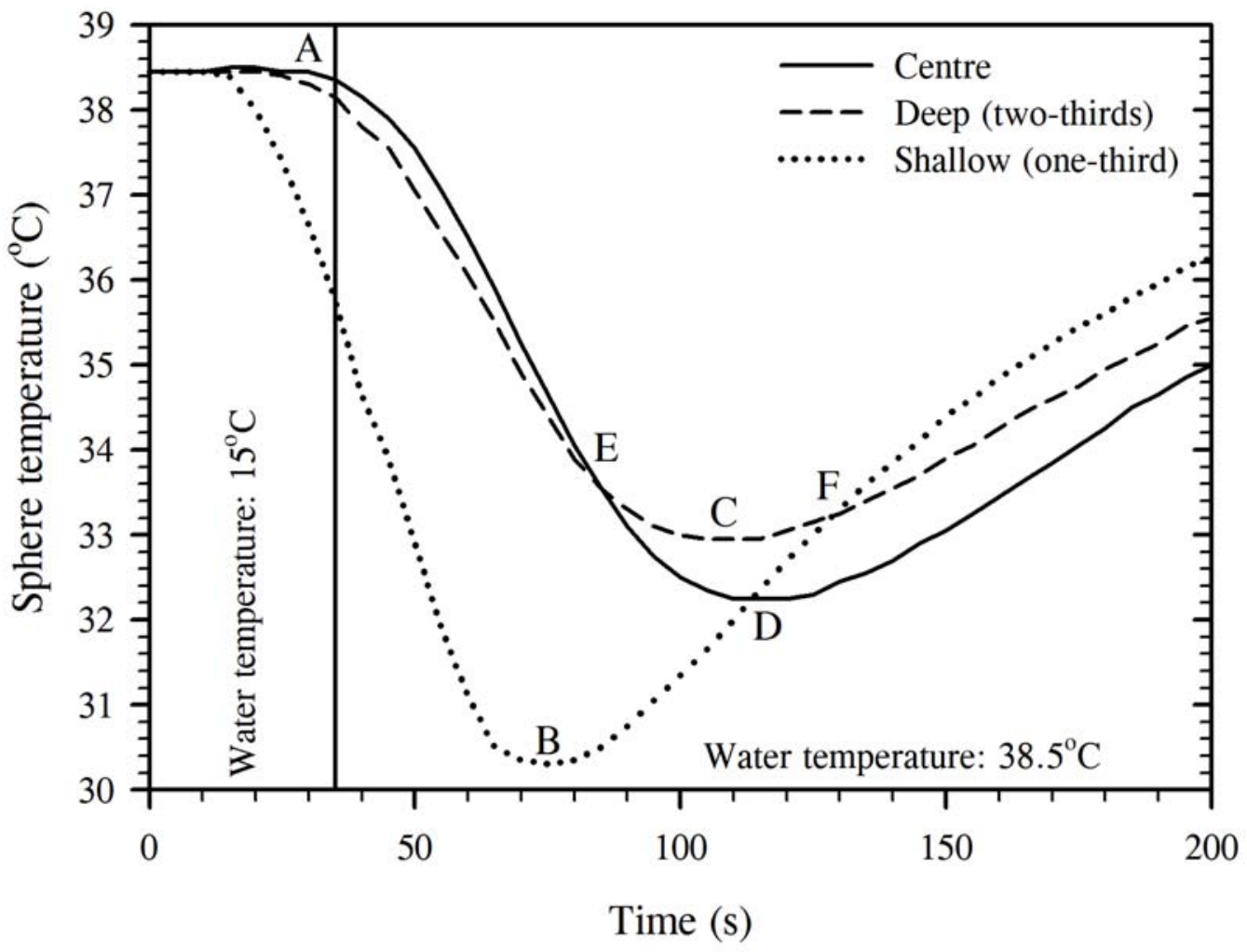


Figure 3:
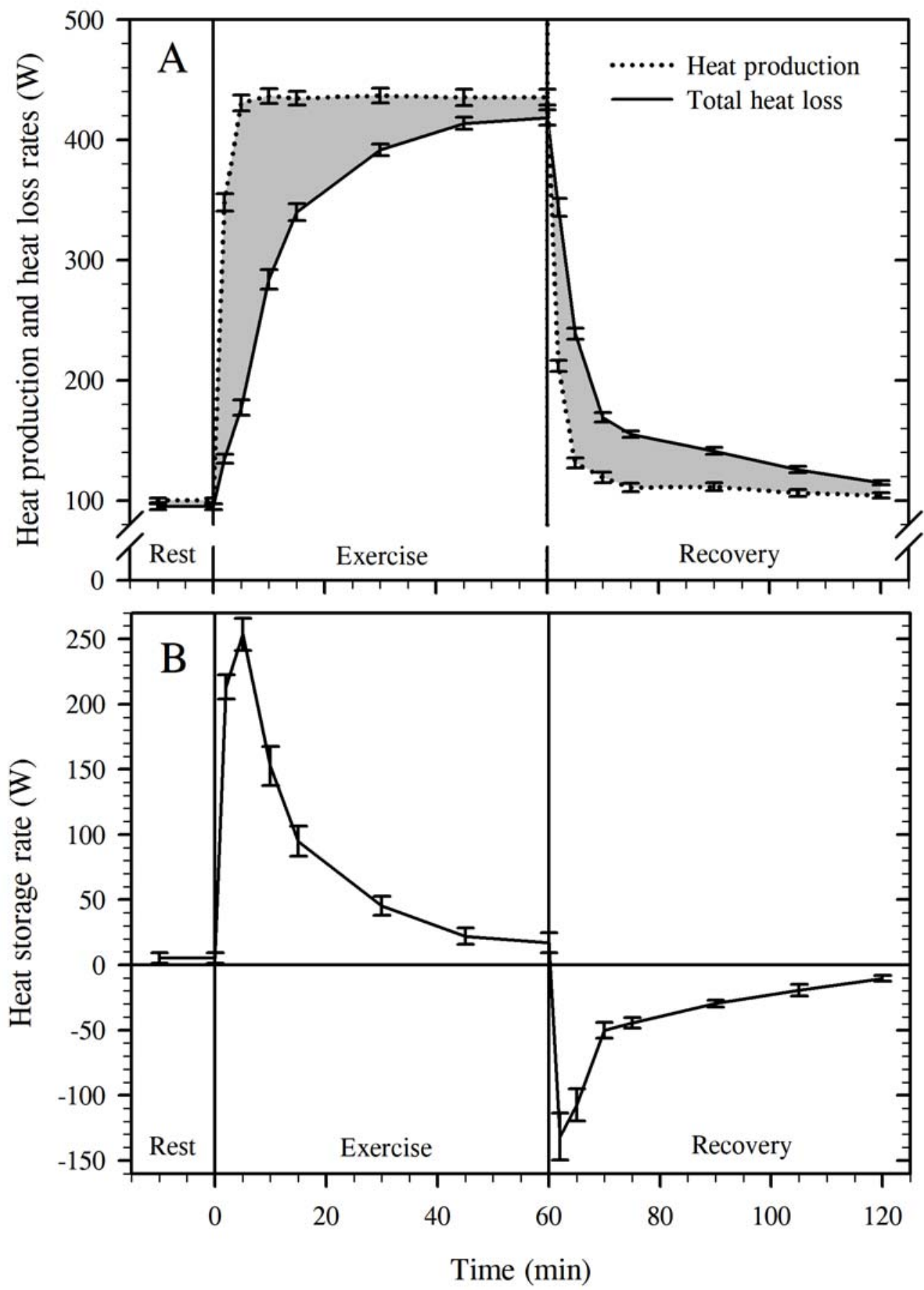
Figure 4:

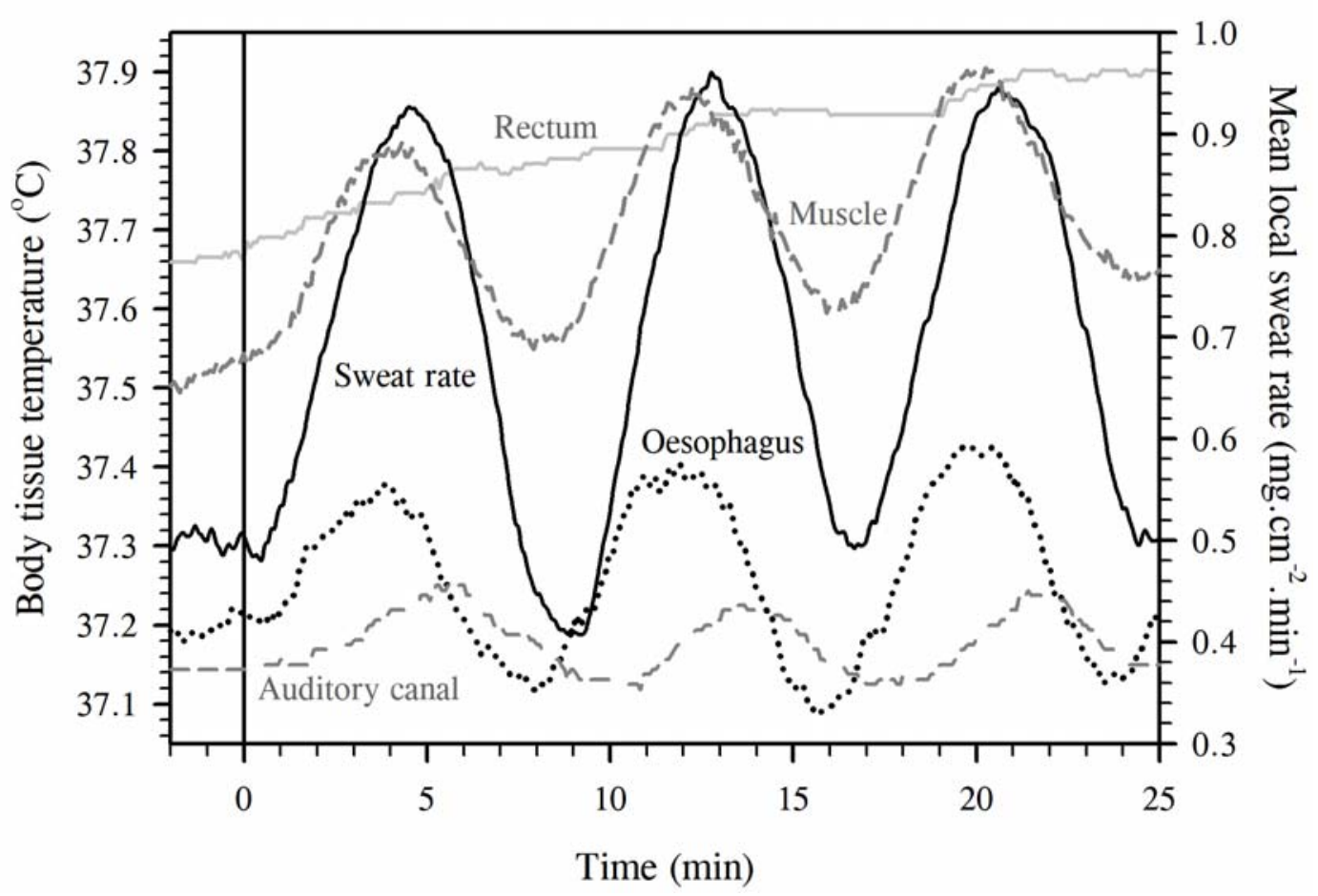


Figure 5:

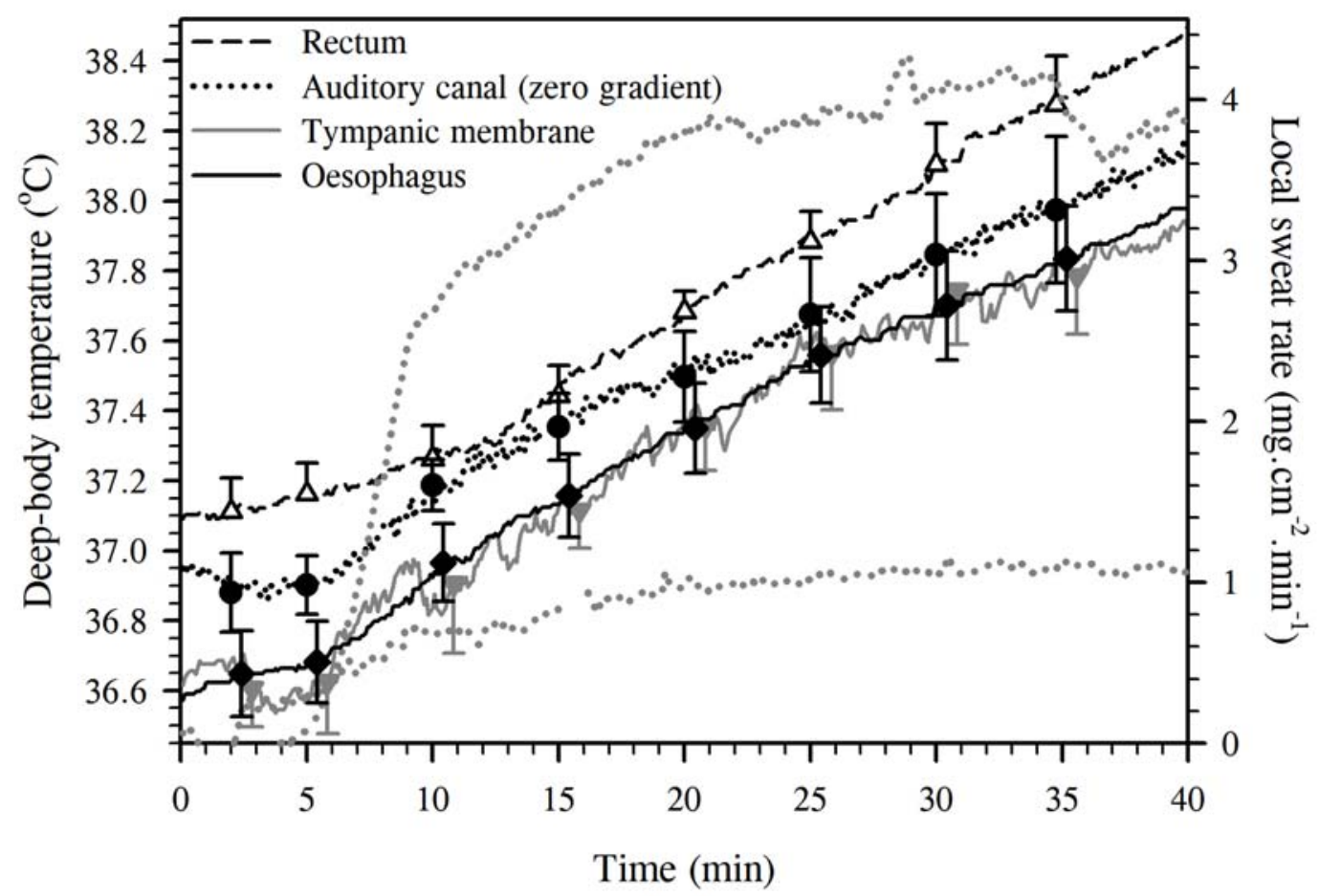


Figure 6:

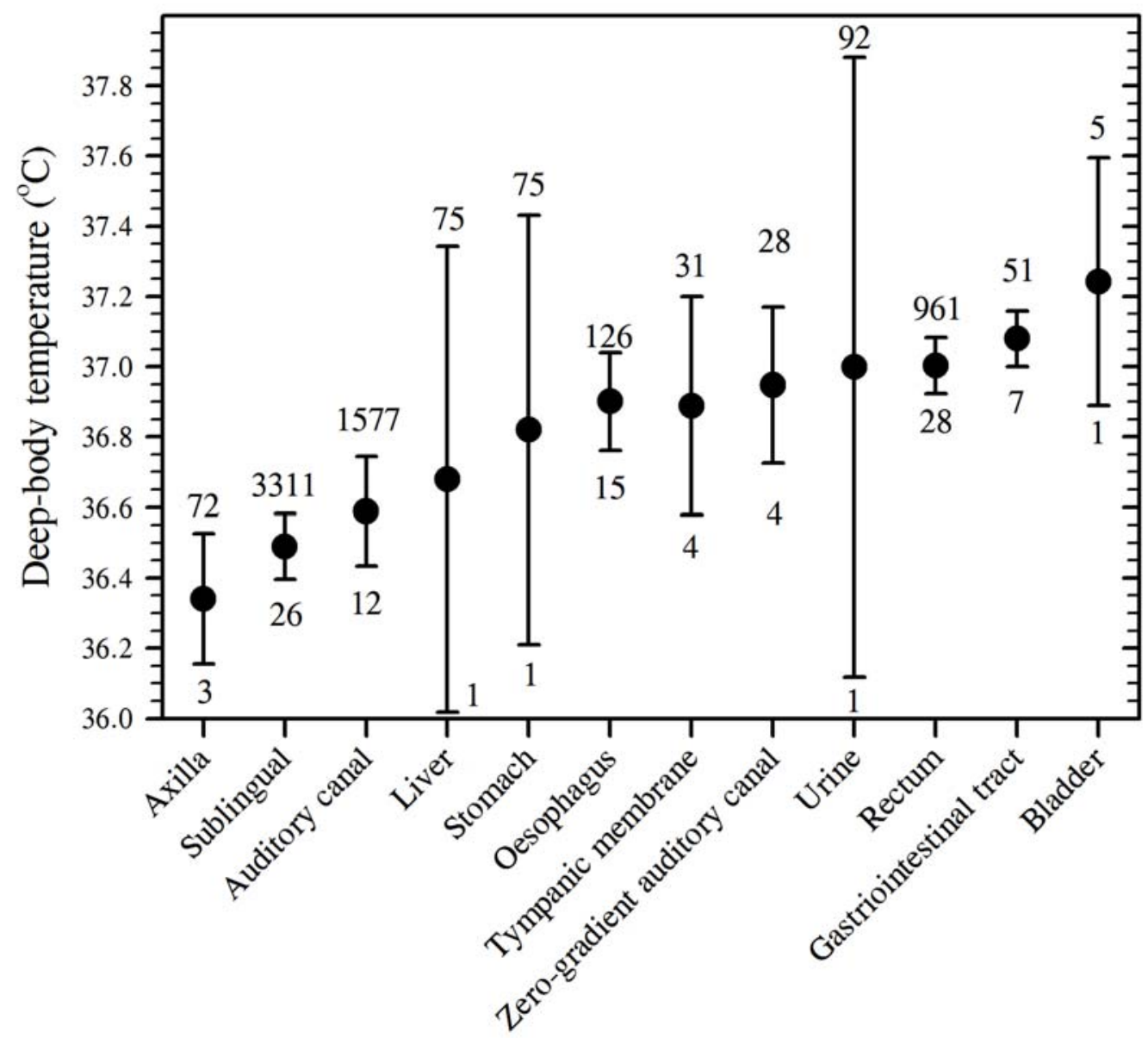


Figure 7:

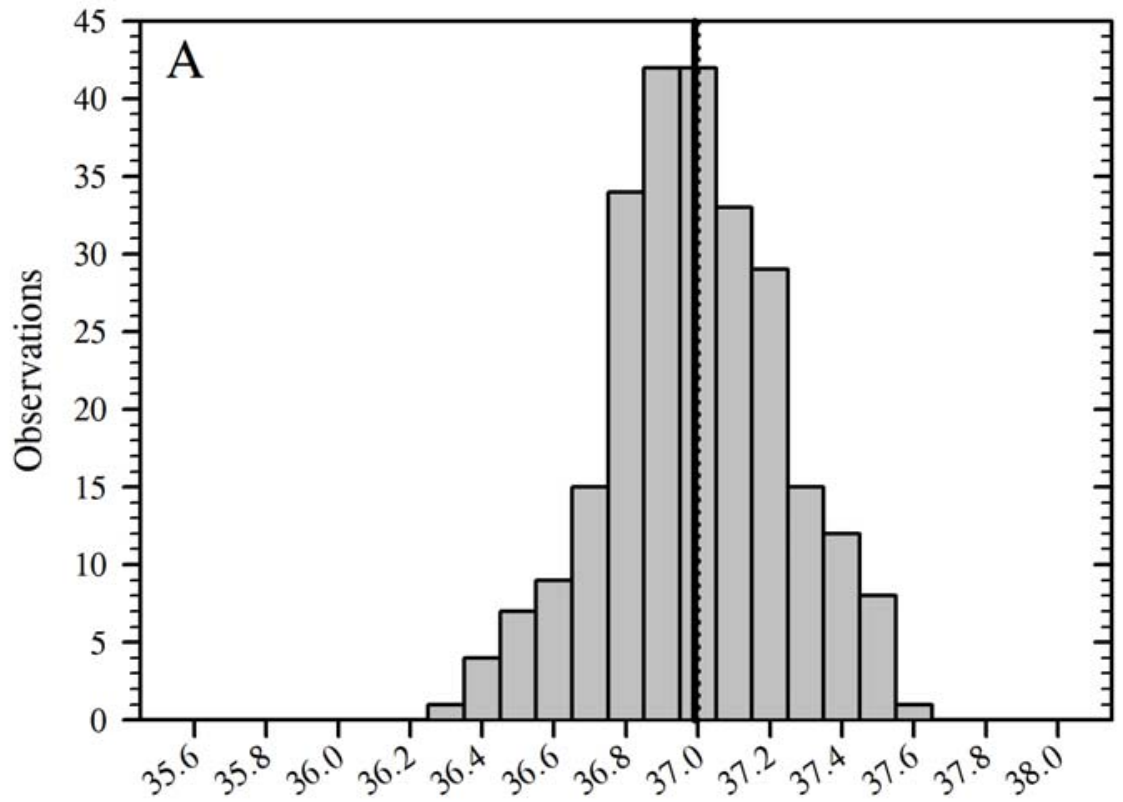

Rectal temperature $\left({ }^{\circ} \mathrm{C}\right)$

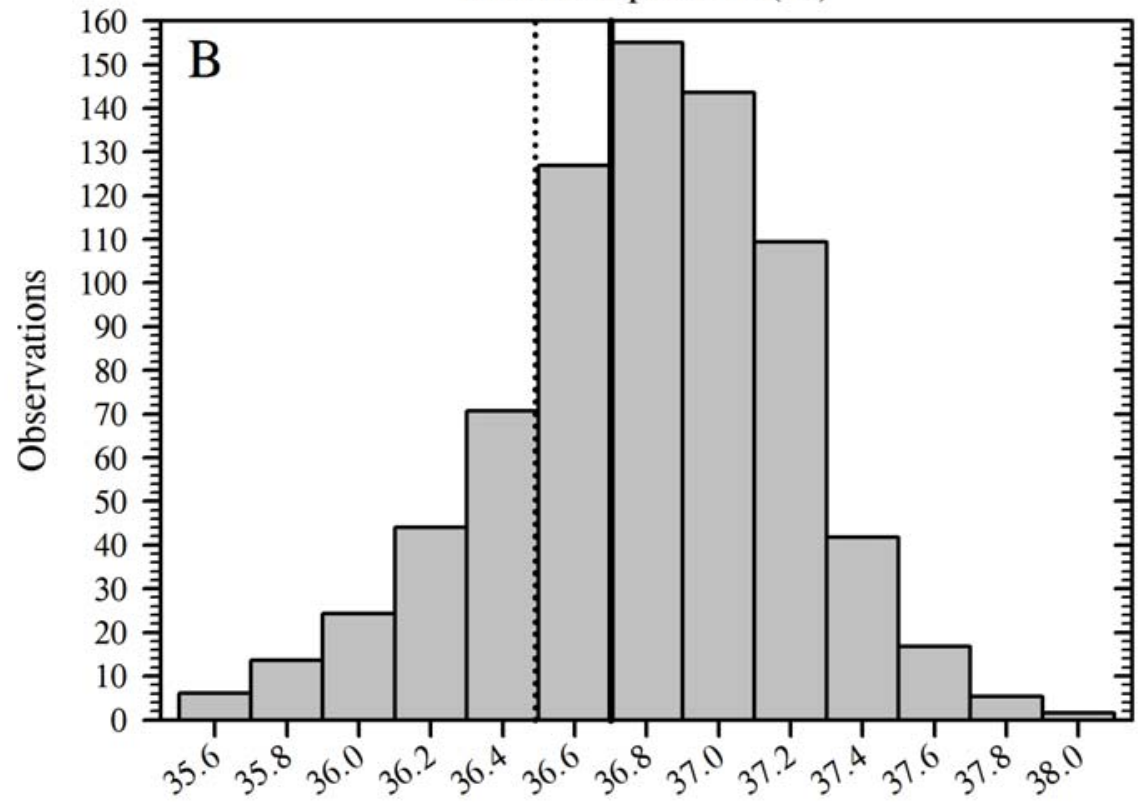

Sublingual temperature $\left({ }^{\circ} \mathrm{C}\right)$ 
Figure 8:

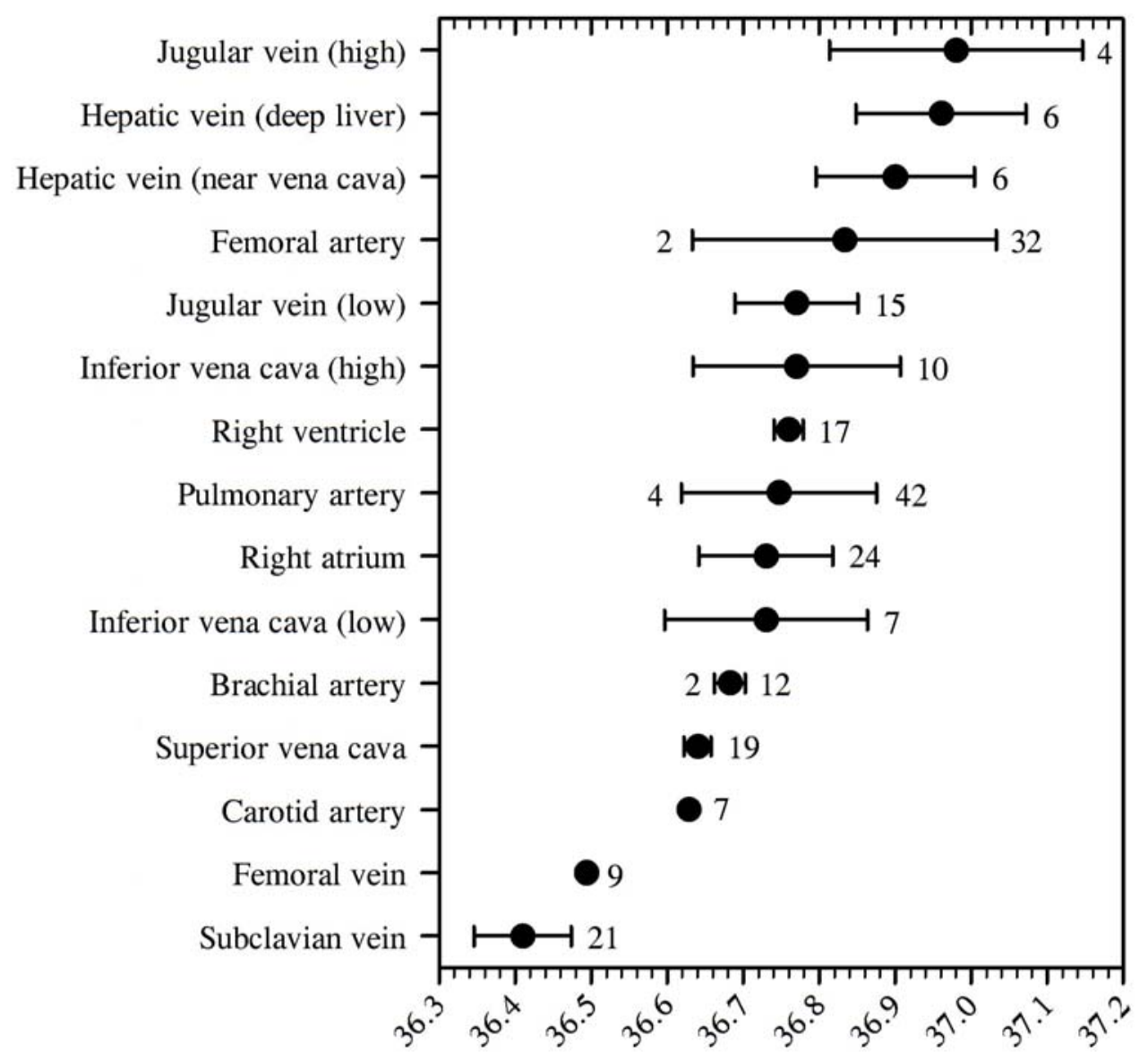

Blood temperature $\left({ }^{\circ} \mathrm{C}\right)$ 
Figure 9:

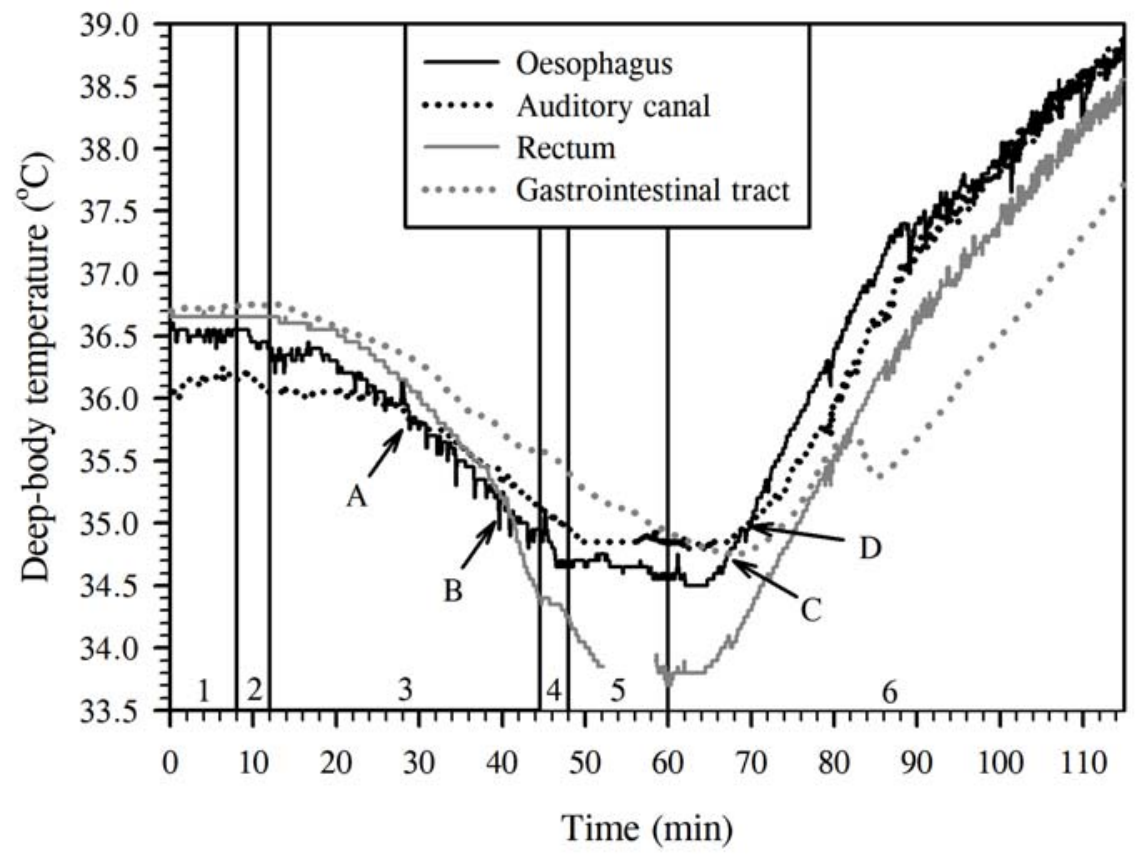


Figure 10:
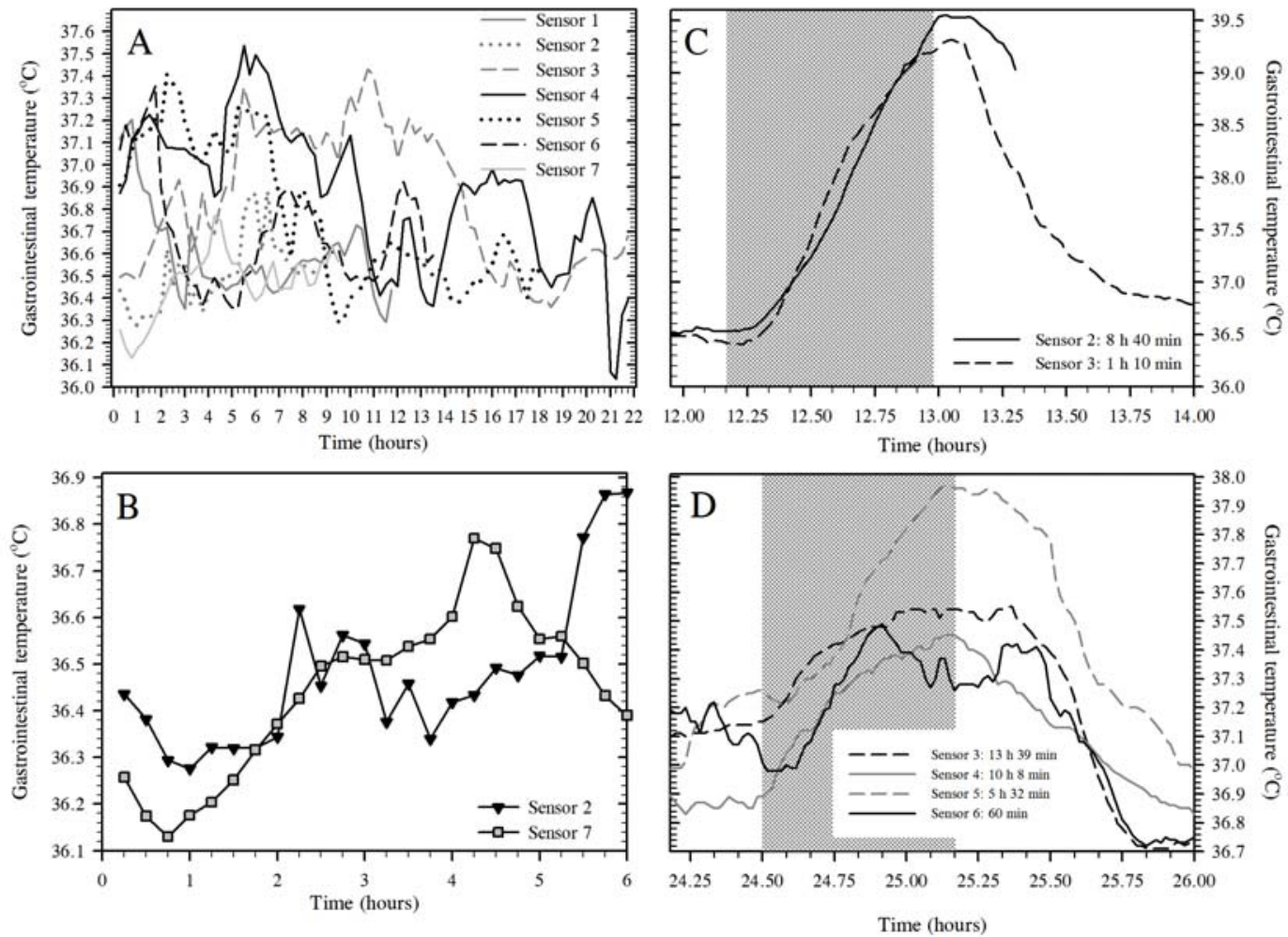
Figure 11:

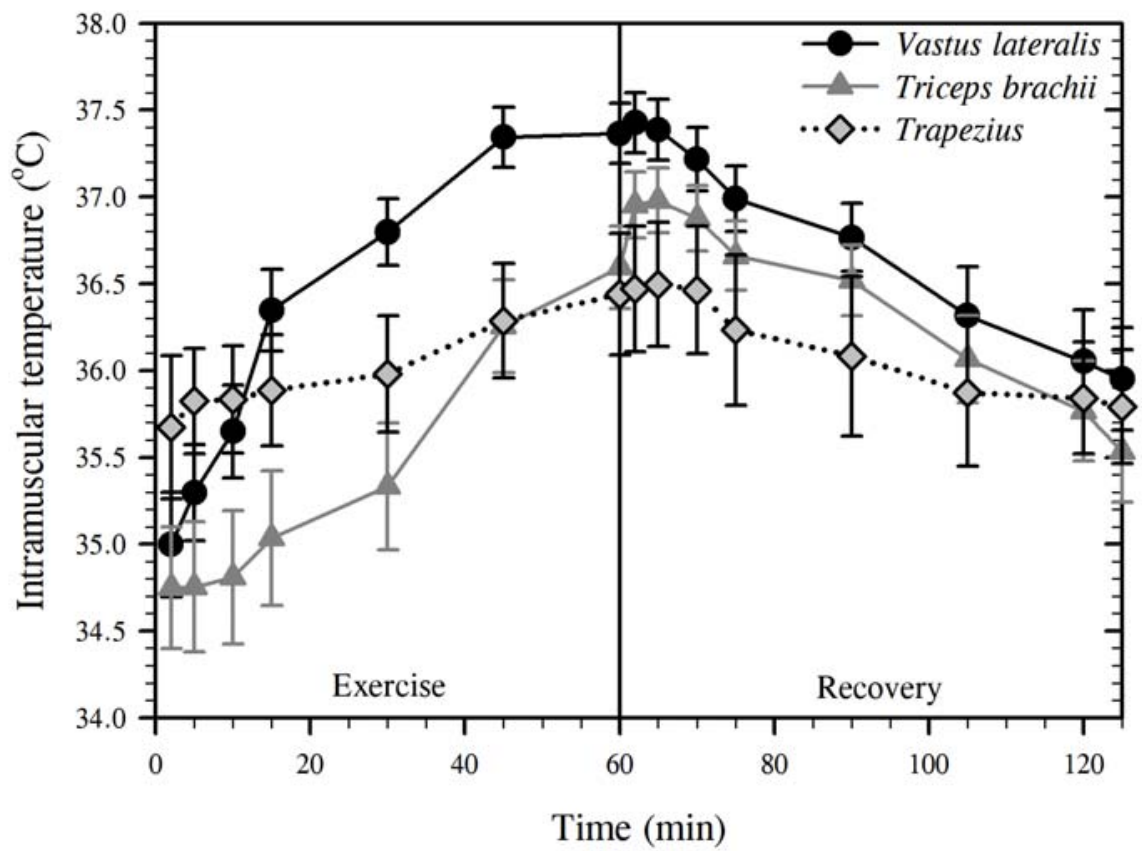


Figure 12:

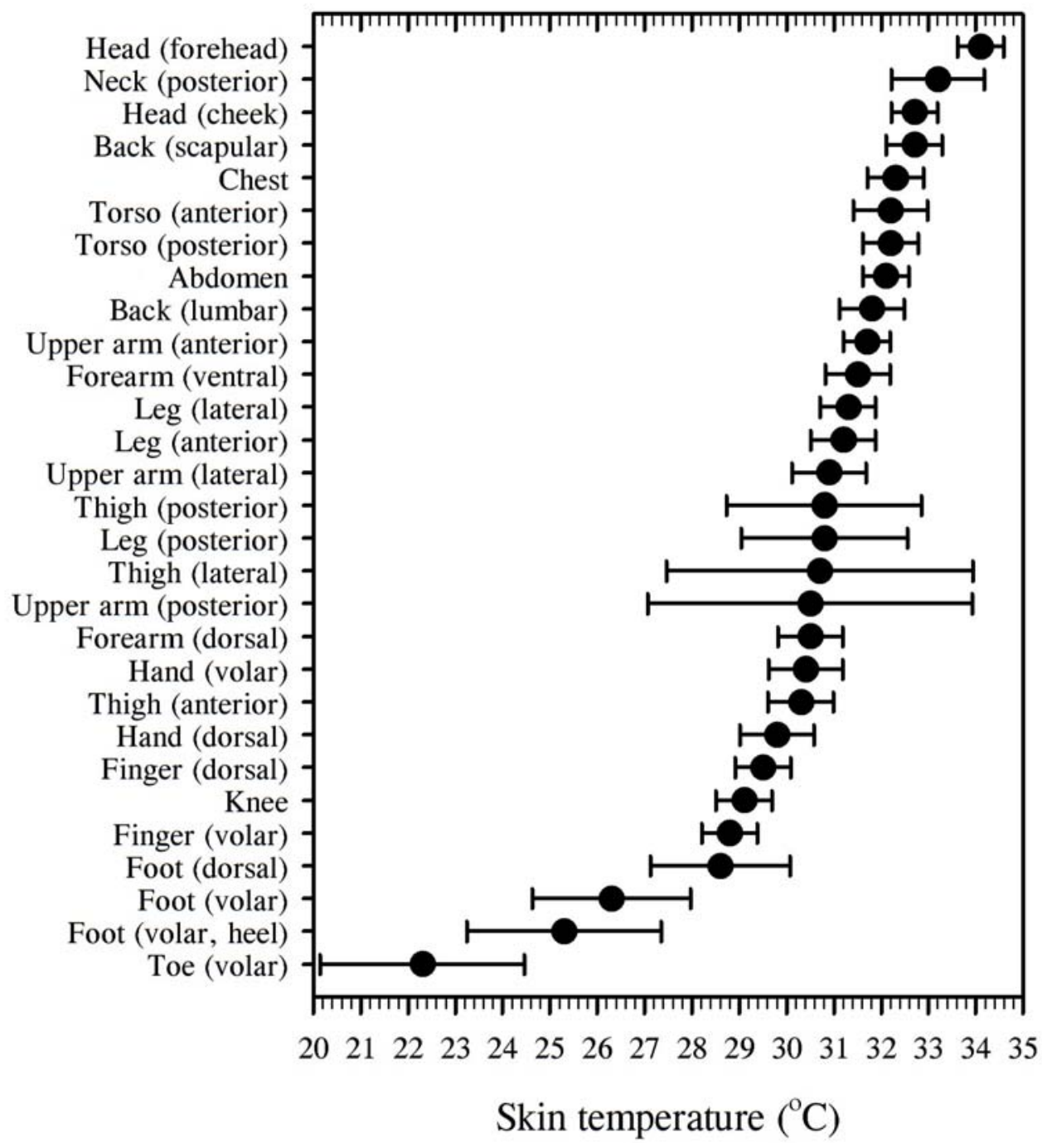

